$$
\text { DOE/PC/91292-T19 }
$$

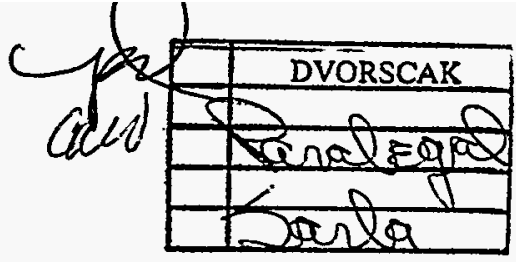

\title{
RHEOLOGICAL PROPERTIES ESSENTIAL FOR THE ATOMIZATION OF COAL WATER SLURRIES (CWS).
}

\author{
FINAL REPORT \\ Period of Performance; August, 1991-July 31, 1995 \\ FRANK OHENE \\ Department of Chemistry \\ Grambling State University \\ Grambling, LA 71245 \\ Technical Project Officer \\ U. S. Department of Energy \\ Pittsburgh Technology Energy Center \\ P. O. Box 10940 \\ Pittsburgh, PA 15236
}

Work Performed for the Department of Energy Under

Contract \#DE-FG22-91PC91292

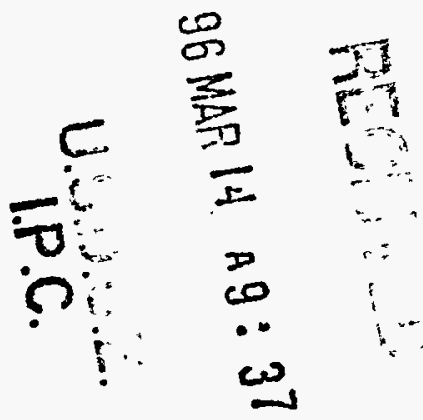




\title{
RHEOLOGICAL PROPERTIES ESSENTIAL FOR THE ATOMIZATION OF COAL WATER SLURRIES (CWS).
}

\author{
Final Report \\ September 1, 1991-July 31, 1995 \\ FRANK OHENE \\ Department of Chemistry \\ Grambling State University \\ Grambling, LA 71245 \\ Technical Project Officer \\ U. S. Department of Energy \\ Pittsburgh Technology Energy Center \\ P. O. Box 10940 \\ Pittsburgh, PA 15236 \\ Work Performed for the Department of Energy Under \\ Contract \#DE-FG22-91PC91292
}

\section{DISCLAMMER}

"This report was prepared as an account of work sponsored by an agency of the United States Government. Neither the United States Government nor any agency thereof, nor any of their employees, makes any warranty, express of implied, or assumes any legal liability or responsibility for the accuracy, completeness, or usefulness of any information, apparatus, product, or process disclosed, or represents that its use would not infringe privately owned rights. Reference therein to any specific commercial product, process or service by tradename, trademark, manufacturer, or otherwise, does not necessarily constitute or imply its endorsement, recommendation, or favoring by the United States Government or any agency thereof. The views and opinions of the author expressed herein do not necessary state or reflect those of the United States or Government or any agency thereof." 


\section{ACKNOWLEDGMENTS}

The Principal Investigator would like to express his sincere appreciation to Mr. Perry Brobbey of Dow Chemicals, Plaquimine, Louisiana. Dr. John Dooher and John Truden of Adelphi University for their assistance in conducting the atomization studies. He would also like to thank the following students: Yolanda Rhone, Urelaine Simon, Terrance Bratton, Gregory Ford, Catherine Attong and Darrel Luther, who assisted the PI during the course of this work.

Finally, he would like to thank Ms. Jo Ann Brown for her secretarial services. 


\section{TABLE OF CONTENTS}

\section{Page}

List of Tables

iii

List of Figures

$\mathbf{v}$

Executive Summary

viii

1. Introduction

2. CAPTER 2.

2-1 Coal Selection 5

2-2 Characterization of Coal Surface Properties 9

2-3 ESCA Analyses 10

2-4 FTIR Analyses 11

2-5 Zeta Potential measurements 14

3. CHAPTER 3

$\begin{array}{lll}3-1 & \text { Rheology } & 19\end{array}$

3-2 Newtonian vs. Non-Newtonian 19

3-3 Time Dependency 23

3-4 Effect of Particle Interactions

3-5 Importance of Coal Properties 23

3-6 Rheology of Suspensions 24

3-7 Effect of Packing on CWS Viscosity 26

$\begin{array}{lll}3-8 & \text { Viscoelasticity } & 28\end{array}$

3-9 Dynamic Flow 
3-10 Non-Newtonian Flow in a Capillary Tube

3-11 Bingham's Fluid Flow 29

3-12 Extensional Viscosity $\quad 30$

3-13 Rheometry 31

3-14 Surface Tension $\quad 52$

3-15 Viscoelastic Behavior of CWS 56

3-16 Results of High Shear Rheological measurements 56

4. CHAPTER 4

4-1 Summary of Atomization Experimental Set-up 70

4-2 Flow pattern Exiting the Nozzle 70

$\begin{array}{lll}\text { 4-3 Atomization Unit } & 77\end{array}$

4-4 Procedure for Malvern Instruments $\quad 83$

4-5 Phenomenological model $\quad 83$

5. CHAPTER 5

5-1 Atomization Results $\quad 86$

5-2 Newtonian Fluid Spray Data $\quad 87$

5-3 Simulated non-Newtonian Fluid Spray Data 103

$\begin{array}{ll}\text { 5-4 CWS Spray Data } & 109\end{array}$

6. CHAPTER 6

Conclusions and Recommendations For Future Work 117

$\begin{array}{lr}\text { References } & 119\end{array}$

$\begin{array}{ll}\text { A. Appendix } & 124\end{array}$ 


\section{LIST OF TABLES}

Page

Table 2-1 Proximate and Ultimate analyses of Coal Samples.............................6

Table 2-2 Particle size Distribution of Coal Samples............................................7

Table 2-3 Coal-Water Slurry Properties............................................................ 8

Table 2-4 ESCA Data For As Received Coal Samples........................................10

Table 2-5 ESCA Data For Coal Samples After One Year Storage.......................11

Table 3-1 Weight Fractions and Packin Concentrations.......................................32

Table 3-2 Rheological Properties of CWS (PSOC-1475)....................................45

Table 3-3 Rheological Properties of CWS (PSOC-1527)...................................45

Table 3-4 Rheological Properties of CWS (PSOC-1472).....................................46

Table 3-5 Physical Data For Corn Syrup Solution.................................................53

Table 4-1 Flow Rate of $61 \%$ CWS Through $0.8 \mathrm{~mm}$ Capillary Tube.....................75

Table 4-2 Flow Rate of 61\% CWS Through $1.5 \mathrm{~mm}$ Capillary Tube...................75

Table 4-3 Flow Rate of 61\% CWS Through $3.0 \mathrm{~mm}$ Capillary Tube...................76

Table 4-4 Flow Rate of 35\% CWS Through $0.8 \mathrm{~mm}$ Capillary Tube...................76

Table 4-5 Flow Rate of 15\% CWS Through $0.8 \mathrm{~mm}$ Capillary Tube...................77

Table 5-1 Atomization Data-Glycerol-Water Solution...........................................88

Table 5-2 Atomization Data-Clycerol Xantham Gum Solution.............................91

Table 5-3 Atomization Data-Clycerol Xantham Gum Solution.............................91

Table 5-4 Atomization Data-Clycerol Xantham Gum Solution............................92

Table 5-5 Atomization Data-CWS (PSOC-1527)..................................................92

Table 5-6 Atomization Data-CWS (PSOC-1472)................................................93 
Table 5-7 Atomization Data-CWS (PSOC-1475; Ash =3.2\%)..........................93

Table 5-8 Atomization Data-CWS (PSOC-1475; Ash =2.5\%)............................94

Table 5-9 Atomization Data-CWS (PSOC-1475; Ash=2.1\%).............................94 


\section{LIST OF OF FIGURES}

Figure 2-1. $\quad$ FTIR Spectrum of As Received PSOC-1527.............................12

Figure 2-2 FTIR Spectrum of As Received PSOC-1475.............................13

Figure 2-3 FTIR Spectrum of PSOC-1475 (After One Year)...........................15

Figure 2-4 Interparticle Interaction.........................................................

Figure 2-5 Zeta Potential of Coal-Water Slurries As a Function of pH.............18

Figure 3-1 Shear Stress As A Function of Shear Rate...................................21

Figure 3-2 Shear Stress As A Function of Shear Rate..................................22

Figure 3-3 Flow Behavior of 57\% CWS (PSOC-1472)................................33

Figure $3-4$ Flow Behavior of 64\% CWS (PSOC-1472)...............................34

Figure 3-5 Flow Behavior of 63\% CWS (PSOC-1472)...................................35

Figure 3-6 Flow Behavior of 55\% CWS (PSOC-1527)................................36

Figure 3-7 Flow Behavior of 58\% CWS (PSOC-1527).................................37

Figure 3-8 Flow Behavior of 62\% CWS (PSOC-1527).................................38

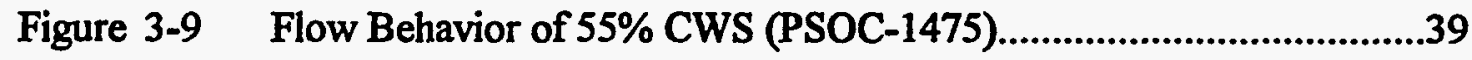

Figure 3-10 Flow Behavior of 56\% CWS (PSOC-1475).............................40

Figure 3-11 Flow Behavior of 63\% CWS (PSOC-1475)................................41

Figure 3-12 Flow Behavior of 64\% CWS (PSOC-1475)...............................42

Figure 3-13 Flow Behavior of 65\% CWS (PSOC-1475................................43

Figure 3-14 Flow Behavior of 66\% CWS (PSOC-1475)..................................44

Figure 3-15 Flow Behavior of Corn Syrup Solution..........................................48

Figure 3-16 Flow Behavior of Corn Syrup -10\% (0.1\%) Polymer Solution.........49 
Figure 3-17 Flow Behavior of Com Syrup -20\% (0.1\%) Polymer Solution..........50

Figure 3-18 Flow Behavior of Corn Syrup -50\% (0.1\%) Polymer Solution.........51

Figure 3-20 Viscoelastic Behavior of CWS (PSOC-1472, 1475 \& 1527).............54

Figure 3-19 Viscoelastic Behavior of CWS with Different Ash Content................55

Figure 3-21 Mechanics of the HVA-6 Capillary Viscometer..................................57

Figure 3-22 High Shear Flow Behavior of Glycerol.............................................58

Figure 3-23 High Shear Flow Behavior of 0.1\% Xantham-Gum Solution............59

Figure 3-24 Viscosity of Glycerol As a Function of Shear Rate ..........................60

Figure 3-25 Viscosity of $0.1 \%$ Xantham Gum Solution vs. Shear Rate................61

Figure 3-26 High Shear Flow Behavior of 63 \% CWS (PSOC-1475)..................62

Figure 3-27 High Shear Flow Behavior of $63 \%$ CWS-0.3\% Polymer Solution....63

Figure 3-28 Viscosity As A Function of Shear Rate (63\% CWS PSOC-1475)..64

Figure 3-29 Viscosity As A Function of Shear Rate (63\% CWS PSOC) and

$0.3 \%$ Xantham Gum Solution

Figure 3-30 High Shear Flow Behavior of 63\% CWS (PSOC-1475)

Using 1.5mm Capillary Tube Diameter...........................................66

Figure 3-31 Analysis of Slippage in A Capillary Flow.......................................68

Figure 3-32 Comparison of High Shear Flow Behavior of CWS With

Different Ash Content...................................................................69

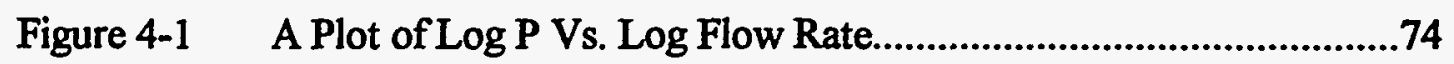

Figure 4-2 Calibration Curve For Fluid Flow..................................................78

Figure 4-3. Calibration Curve For Air Flow Rate...................................................80 
Figure 4-4 Airo Solid Cone Atomizing Nozzle....................................................81

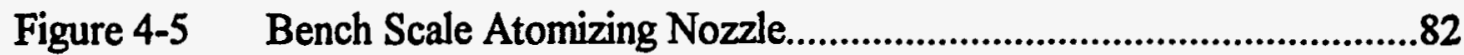

Figure 4-6 Particle Size Distributions of Corn Syrup Solutions..............................84

Figure 5-1 A Plot of SMD vs. Air/Fuel (AFR) For Glycerol Solutions................95

Figure 5-2 A Plot of SMD vs. Air/Fuel (AFR) For Xantham-Gum Solutions....96

Figure 5-3 A Plot of SMD vs. Viscosity At High Air/Fuel (AFR) ......................97

Figure 5-4 A Plot of SMD vs. Air/Fuel (AFR) For CWS (PSOC-1527) .............98

Figure 5-5 A Plot of SMD vs. Air/Fuel (AFR) For CWS (PSOC-1472) ............99

Figure 5-6 A Plot of SMD vs. Air/Fuel (AFR) For CWS (PSOC-1475) ...........100

Figure 5-7 A Plot of SMD vs. Air/Fuel (AFR) For CWS (PSOC-1475) ...........101

Figure 5-8 A Plot of SMD vs. Air/Fuel (AFR) For CWS (PSOC-1475) ...........102

Figure 5-9 A Plot of SMD vs. (1+ Air/Fuel ) For Glycerol Solution ...................104

Figure 5-10 A Plot of SMD vs. (1+ Air/Fuel ) For Glycerol Solution ..................105

Figure 5-11 A Plot of SMD vs. (1+Air/Fuel) For PSOC-1475 ..............................106

Figure 5-12 A Plot of SMD vs. (1+Air/Fuel) For PSOC 1472 and 1527.............107

Figure 5-13 A Plot of Calculated SMD vs. Measured SMD (Glycerol-Polymer)..110

Figure 5-14 A plot of Calculated SMD vs. Measured SMD (PSOC1475.............111

Figure 5-15 A Plot of Calculated SMD vs. Measured SMD (PSOC 1527)..........112

Figure 5-16 A Plot of Calculated SMD vs. Measured SMD (PSOC 1472)..........113

Figure 5-17 A Plot of Calculated SMD vs. Measured SMD (PSOC 1475...........114 


\section{EXECUTIVE SUMMARY}

Coal-Water Slurries (CWS) have the potential to be an immediate substitute for premium liquid and gaseous fossil fuels in newly designed boilers and retrofit installations.

Efficient utilization of CWS requires the production of fine sprays during the atomization process, since carbon conversion efficiencies of CWS have been directly related to the droplet size distribution. Thus, to examine the factors that govern fine spray production during atomization of CWS, an experimental study of the effect of rheological properties on atomization of CWS was proposed.

The objective of this study was to understand the effect of low shear, high shear rheology, viscoelastic, and extensional properties on the atomization of CWS. In the atomization studies, the mean drop size of the CWS sprays were determined at various air-to-CWS ratios using a Malvern 2600 particle size analyzer and a Delavan Solid Cone Atomizing Nozzle.

Solids-loadings, coal particle size distributions, and chemical additives were varied in order to determine the significant properties that influence CWS atomization. A correlation of the mass mean droplet size with high shear, viscoelastic and extensional behaviors were made in order to determine the influence of these parameters on CWS atomization.

The objectives of this project were:

* Perform rheological analysis of the CWS over a considerable shear rate and temperature range.

* Measure the Rheological Properties of the CWS.

* Measure the Rheological Properties of Simulated Fluids 
* Explore the atomization characteristics of the CWS (1-5 gph flow range) in order to determine the atomization quality.

* Develop a Phenomenological model to relate Drop size to Air/Fuel and Rheological Properties.

* Perform a statistical analysis of the spray droplets in order to develop a linkage between ratio of mass of CWS/air and SMD.

* Investigate the Effect of the Rheological Properties on Atomization.

These objectives were accomplished by:

Identifying coal slurry fuel elements and properties such as :

particle size distribution of the coal particles

Additive type

Viscosity of fuel

Fuel density and Gas-fuel interfacial tension

which influence the CWS rheology, and also, performing a literature search to further understand the atomization characteristics of the coal-water slurries. This was followed by:

Selection and grinding of coal samples

Establishing baseline properties for the coal-water slurries

Performing rheological properties on the coal-water slurries and simulated fluids

Performing atomization studies on coal-water slurry samples and simulated fluids as a

function of air/fuel

Developing a phenomenological model to test the experimental results

Identifying the elements which influence atomization characteristics such as: 
particle size distribution of spray droplets, atomization air pressure, orifice diameter, nozzle velocity of air, and exit velocity of liquid

Testing the phenomenological model with experimental results

Examining the flow characteristics of the coal-water slurry samples and relating the flow characteristics to the quality of atomization.

Ascertain the statistical influence on coal slurry atomization

Application of air-assist atomization to coal-water slurries requires an analysis of the effects of slurry rheological properties which is greatly influenced by additives, particle size distribution, type of coal and dynamic surface tension. The effect of these properties on the spray formation process were investigated and the results were used to fit the phenomenological model developed in this work. Newtonian liquids, derived from solutions of glycerol- water mixture, corn syrup-water mixture and glycerol-water-xantham gum mixture were sprayed and the Sauter mean diameter (SMD) measurements were obtained at various nozzle pressures and Air to Fuel Ratio (AFR), values. This provided information on the effect of flow consistency index on the spraying characteristics. Also, spray data for three coal water slurry mixtures with varying formulations were collected, again at varying nozzle pressures and AFR values. This provided information on the relationship between drop size and AFR.

The experimental data obtained were then analyzed to explain the physical processes responsible for spray formation. The analysis began by considering an energy balance across a control volume that extended from the nozzle exit plane to the line of spray measurement. The inlet conditions were calculated using two-phase flow techniques and the outlet conditions were 
calculated by using conservation of momentum and assuming that the loss of kinetic energy of the fuel and the air was used in breaking up the fuel into droplets.

The results showed that air-assist nozzles effectively atomized CWS, as well as Newtonian and non-Newtonian fluids and that, the storage modulus of the slurries correlated very well with the sauter mean diameter. It was however, not possible to eliminate clogging and erosion problems. In addition, it was determined that viscoelastic properties of the CWS influences the drop sizes produced in the air assist atomization and that, the extensional properties had minimal effect on the atomization. 


\section{CHAPTER 1}

\section{INTRODUCTION}

Coal-Water Slurries (CWS) have the potential to be an immediate substitute for premium liquid and gaseous fossil fuels, in newly designed boilers and retrofit installations [1,2]. Optimization of the fundamental aspects of such fuels include (1) preparation and handling CWS fuels, (2) combustion of these fuels, (3) the hardware which must be designed to accommodate fuel atomization requirements and different flame patterns necessary to insure complete combustion.

The combustion intensity and the burning velocity of fuels in general can be increased by increasing the surface to fuel ratio of the fuel. this process helps to increase the vaporization, ignition and burnout of the CWS samples. The quality of the atomization is characterized by factors which influence the evaporation and subsequent combustion. The size of the spray droplets governs the ignition and burnout rates of the CWS samples. The characteristic slurry properties:- solid/liquid interaction, fluid mechanics of atomizing influences the global flame geometry.

Coal-water slurry is a highly viscous, non-Newtonian, two-phase fluid that sometimes contains polymers in order to maintain suspension of the coal particles. The rheological properties and polymers make slurries hard to atomize, and coal particles make it abrasive and prone to clogging orifices [3]. The difficulty in atomizing CWS magnifies the problem of efficiently burning the fuel can be increased by exposing more surface area of the fuel to the hot 
combustion gases, but it is necessary to produce small drop sizes in order to accomplish that goal.

The majority of atomizers are incapable of efficiently atomizing CWS since they are sensitive to slurry rheological properties. In order to overcome rheological effects, some atomizers require that the injection velocity be increased. This is often accomplished by raising injection pressure and decreasing orifice diameter [4]. Increasing exit velocity is however, detrimental to nozzle operation since the abrasive effect of CWS increases. In addition, the probability of clogging increases with decreasing nozzle diameter. Increasing AFR is undesirable due to the increase in cost associated with pumping large volumes of air at high pressure.

Several studies have been directed towards relating rheological properties of CWS to atomization quality $[5,6,7]$. The trend towards this work is due to the fact that low shear viscosity data had correlated well with droplets of Newtonian liquids. Coal water slurries are however, non-Newtonian. Thus, attempts to correlate low shear viscosity data with CWS atomization were unsuccessful. This is due to the fact that for such fluids, the effective viscosity is shear rate dependent, and this dependence can take two distinct forms; shear thinning (pseudoplastic) and shear thickening (dilatant). The behavior of CWS is complicated by their changing from one type of behavior to the other as the shear rate is varied. Much effort has therefore been directed towards correlating high shear viscosity data of coal-water slurries with atomization [8].

The significance of shear viscosity in CWS atomization is manifested in the formation of ripples on the fuel surface [9]. The rate of growth of the ripples is dependent on the Weber number, $\left(W_{e}=\frac{\rho_{A} U_{R} D_{0}}{\sigma_{L}}\right)$, where $\rho_{A}$ is the density of surrounding air, $U_{R}$ is the relative velocity between liquid jet and surrounding air, $D_{o}$ is the diameter of liquid jet, and $\sigma_{L}$ is the surface tension of the liquid [10]. 
Previous investigations on CWS atomization covered the details of sprays and simplification of computational work necessary to simulate the physical history of the droplets in a multiphase [11 ]. Owing to the complexity of the various physical phenomena involved in pressure atomization, studies on CWS atomization has been pursued principally by empirical methods, yielding correlations for the mean drop size of the form [12]:

$S M D=C \rho_{a}^{0.06} \mu_{f}^{0.385} \rho_{f}^{0.352} \sigma_{f}^{0.737} \Delta P_{f}^{-0.54}$ $1-1$ where $S M D$ is the Sauter Mean Diameter, $C$ is a constant, $\rho_{A}$ is the density of air, $\rho_{f}$ is the density of fuel, $\Delta P_{f}$ is the injection pressure differential, $\mu_{f}$ is the dynamic viscosity of the fuel and, $\sigma_{f}$ is the surface tension of the fuel.

CWS show non-Newtonian fluid behavior. Thus, the shear rate needs to be known for determining the viscosity of CWS during atomization. The actual shear rate during atomization varies with the position of the CWS jet within the atomizer because of changes in the liquid thickness and relative velocity between atomizing air and CWS [13]. Studies of CWS rheology in $100,00 / \mathrm{s}$ shear rate regime has been shown to correlate very well with the sauter mean diameter of the atomized droplets. Thus, it was deemed necessary to investigate the effect of high shear rheology on the size of the atomized droplets.

Dooher and Wildman [14] have indicated that viscoelastic properties may be important predictors of atomization data. They have also reported extensional viscosities data of slurries determined via the filament technique of Gupta [15]. Rakitsky et. al [16] measured extensional viscosities of slurries having identical shear viscosities but different formulations. They found out that the slurry with the higher extensional viscosity sprayed poorly, when compared to the slurry with a lower extensional viscosity, despite having identical shear viscosities. Their work suggests that extensional viscosity measurements are important in correlating with atomization data. Extensional viscosities are important in predicting pressure losses of non-Newtonian liquids that 
contain polymer additives. The presence of polymeric additives used to stabilize CWS, may give CWS a great extensional viscosity component.

It was therefore deemed necessary to examine rheological properties such as:

viscoelastic behavior, extensional behavior, low and high shear behavior of CWS and relate the data to the atomization quality of CWS. 


\section{CHAPTER 2}

\section{Preparation and Characterization of Coal- Water Slurries.}

\section{2-1 Cosl Selection}

Three Coal samples were selected for this study. These coal samples were obtained from Pennsylvania State University coal data bank. The proximate and ultimate analysis of these samples are as shown in Table 2-1. The samples were ground to a distribution as shown in Table

2-2. Coal-water slurries used in this study were prepared from a blended distribution of the samples.

The prepared CWS samples utilized in this work had the following general specifications:

$55-64 \%$ by coal weight depending on the coal type

99\% through 80 mesh and 100\% less than 50 mesh sieve size.

Less than $3 \%$ increase in solids content measured at the bottom of settling column after 24 hours

Power Law index of less than 1.3

$0.3 \%$ concentration of additive A-23 obtained from Henkel Corporation $\mathrm{pH}$ of between 8-9.5

Zeta potential of less than $-25 \mathrm{mV}$ at a pH of 8 .

Table 2-3 lists the summary of the CWS characteristics utilized in this work. 
Table 2-1

Proximate and Ultimate Analyses of The Coal Samples.

PSOC-1475

PSOC-1527

PSOC-1472

Proximate Analyses

Moisture

3.37

0.46

2.54

Ash

3.22

27.52

11.4

Volatile

36.03

23.14

30.98

Fixed Carbon

57.38

46.10

55.08

Ultimate Analyses

Ash

3.22

27.52

11.4

Carbon

78.38

60.66

75.87

Hydrogen

5.20

3.59

4.56

Nitrogen

1.44

1.11

1.51

Total Sulfur

0.95

0.83

.38

Oxygen

7.45

4.97

3.31 
Table 2-2

Particle Size Distributions of Coal Samples.

$\begin{array}{lll}\text { PSOC-1475 } & \text { PSOC-1527 } & \text { PSOC-1472 }\end{array}$

Size (Microns)

564

261.6

160.1

112.8

84.8

64.6

50.2

39.0

30.3

23.7

18.5

14.5

11.4

9.1

7.2

5.8

Packing Concentration
100

99.9

88.6

81.0

74.5

68.2

61.3

55.1

49.6

45.0

41.1

31.3

22.6

18.6

15.2

10.1

78.5
100

87.1

65.7

65.7

65.7

49.4

46.6

43.8

36.3

32.5

31.0

29.1

24.7

19.0

16.4

9.2

82.6
100

97

71.4

57.4

51.4

48.2

42.7

38.0

34.6

31.4

28.3

23.8

18.1

14.2

10.8

6.5

80.1 
Table 2-3

\section{Coal Water Properties}

Coal Content

Additives (A-23, MCG23ALS, A-23S)

Fuel Viscosity at $100 / \mathrm{s}$

Zeta Potential

Top size

Settling

$\mathrm{pH}$

pH change/week

Slip Effect

Flow behavior

Stabilizer

Packing
$55-65 \%$

0.3-5\% Coal Weight

180-250 mPas.s baseline

-22 to $-40 \mathrm{mV}$ (Anionic Additive)

$99 \%$ minus 60 mesh

No significant settling in 14 days

9.5

very slight

very slight

Pseudoplastic

xantham Gum

$>76 \%$ 


\section{2-2 Characterization of Coal Surface Properties}

There is a need to improve the stability and flow characteristics of the CWS in order to understand the rheological properties. The coal particle surface, grinding media and the presence of additives utilized in the CWS formulation, can influence subsequent utilization of the CWS $[17,18]$. The chemistry of the coal surface plays a significant role in the stability of the coal-water slurries [19]. Three main effects which contribute to the coal surface properties are:

The number and type of polar groups (carboxylic and phenolic),

The ash content, and

The hydrocarbon skeleton.

The mineral matter of coal which constitutes the inorganic matter in coal is generally associated with the ash content in coal. Also, the C/O of the coal surface is decreased by the process of aging or oxidation during which polar functional groups such as $-\mathrm{COOH},-\mathrm{CO}$, and phenolic, $-\mathrm{OH}$ groups are formed. The formation of these groups influence the quality, stability and flow characteristics of the slurries.

There are two basic mechanisms that contribute to the surface charge of the coal particles in aqueous media. The first is the dissociation of ionogenic groups on the coal surface, such as those having carboxylic, phenolic, and hydroxylic functionality. The surface charge is governed by the ionization of the acid groups

$-\mathrm{COOH} \Longrightarrow \mathrm{COO}^{-}+\mathrm{H}^{+}$

Phenolic-OH $\Longrightarrow$ Phenolic- $\mathrm{O}^{-}+\mathrm{H}^{+}$

and for the surface containing hydroxyl groups which may be considered to be amphoteric, such as those that exist on the surface of inorganic oxides on the surface of coal, the charging process may be represented by:

$\mathrm{M}-\mathrm{OH} \Longrightarrow \mathrm{M}-\mathrm{O}^{-}+\mathrm{H}^{+}$ 
It therefore seemed desirable to study the surface characteristics of the coal samples including their oxidation and relate these characteristics to the rheological behavior and, subsequent atomization.

The experiments conducted were Fourier Transform Infrared Diffuse Reflectance Spectroscopy, FTIR(DRT), Fourier Transform Infrared Reflectance Spectroscopy, FTIR (RAS), Electron Spectroscopy for Chemical Analysis, ESCA, and Zeta Potential measurements.

\section{ESCA Analyses}

Tables 2-4 and 2-5 list data from ESCA analysis of these samples taken a year apart. The values were obtained by curve fitting analysis of the 1 s region with the four peaks due to different carbon containing groups: Those containing $\mathrm{C}-\mathrm{C}$ single bonds, carbon containing $\mathrm{C}=\mathrm{C}$ double bonds, carbon containing $\mathrm{C}=0$ bonds and carbon containing $\mathrm{C}-\mathrm{O}$ bonds. The values do show that the total C-O bonds at the surface of the coal, decrease in the order of PSOC 1472>PSOC 1527> PSOC 1475. Comparison of the data in Tables $2-4$ and 2-5, indicate that oxidation of the coal samples occurred during the one year storage period, since there was an increase in the percentage amounts of $\mathrm{C}-\mathrm{O}$ and $\mathrm{C}(=0)-0$ groups and a decrease in the $\mathrm{C}-\mathrm{C}$ and $\mathrm{C}=\mathrm{C}$ groups.

\section{Table 2-4}

\section{Percentage of Different Functional Groups at the Surface of the Coal Samples:}

As Received Coal Samples $\quad \% \mathrm{C}=\mathrm{C}, \mathrm{C}-\mathrm{C} \quad \% \mathrm{C}-\mathrm{O} \quad \% \mathrm{C}=\mathrm{O} \quad \%(\mathrm{C}=\mathrm{0})-\mathrm{O}$

PSOC-1475

PSOC-1527

PSOC-1472
88.5

83.3

77.0
8.0

14.0

18.2
1.4

1.2

2.7
2.1

1.5

2.1 
Table 2-5

Percentage of Different Functional Groups at the Surface of The Coal Samples After One Year Storage.

$\begin{array}{lrrrr}\text { As Received Coal Samples } & \% \mathrm{C}=\mathrm{C}, \mathrm{C}-\mathrm{C} & \% \mathrm{C}-\mathrm{O} & \% \mathrm{C}=0 & \%(\mathrm{C}=0)-0 \\ \text { PSOC-1475 } & 80.1 & 16.0 & 2.4 & 1.3 \\ \text { PSOC-1527 } & 78.2 & 18.0 & 2.5 & 1.2 \\ \text { PSOC-1472 } & 74.2 & 19.1 & 1.4 & 5.3\end{array}$

\section{FTIR Analyses}

All the samples were dried in a nitrogen atmosphere for a period of 24 hours after grinding, and the FTIR transmittance spectrum of each sample was taken, using $\mathrm{KBr}$ as a diluent.

A transmission spectra of as received coal (PSOC-1475 and 1527) are as shown in Figures 2-1 and 2-2. Based on previous infrared spectral studies of coals [20 ], the following assignments were made.

1. The peak at 3770 wavenumbers are due to the presence of hydroxyl groups $(\mathrm{O}-\mathrm{H})$ structural components of illitic and kaolinitic clay minerals inherent within the coal.

2. A broad composite band, arising from the $\mathrm{O}-\mathrm{H}$ groups within the organic matrix of the coals (alcoholic, phenolic, acidic, etc.) spans the region from 3600 to 2500 wavenumbers.

3. A band at $\mathbf{3 0 5 6}$ wavenumber is due to the presence of aromatic hydrocarbons (Ar-H).

This is a band present in all aromatic hydrocarbons. The peaks at 2960 and 2852 wavenumbers are to the presence of terminal vibrational modes of methyl $\left(\mathrm{CH}_{3}\right)$ groups and the methylene $-\mathrm{CH}_{2}$ - and methene $\mathrm{CH}=$ groups appended to the polynuclear matrix 


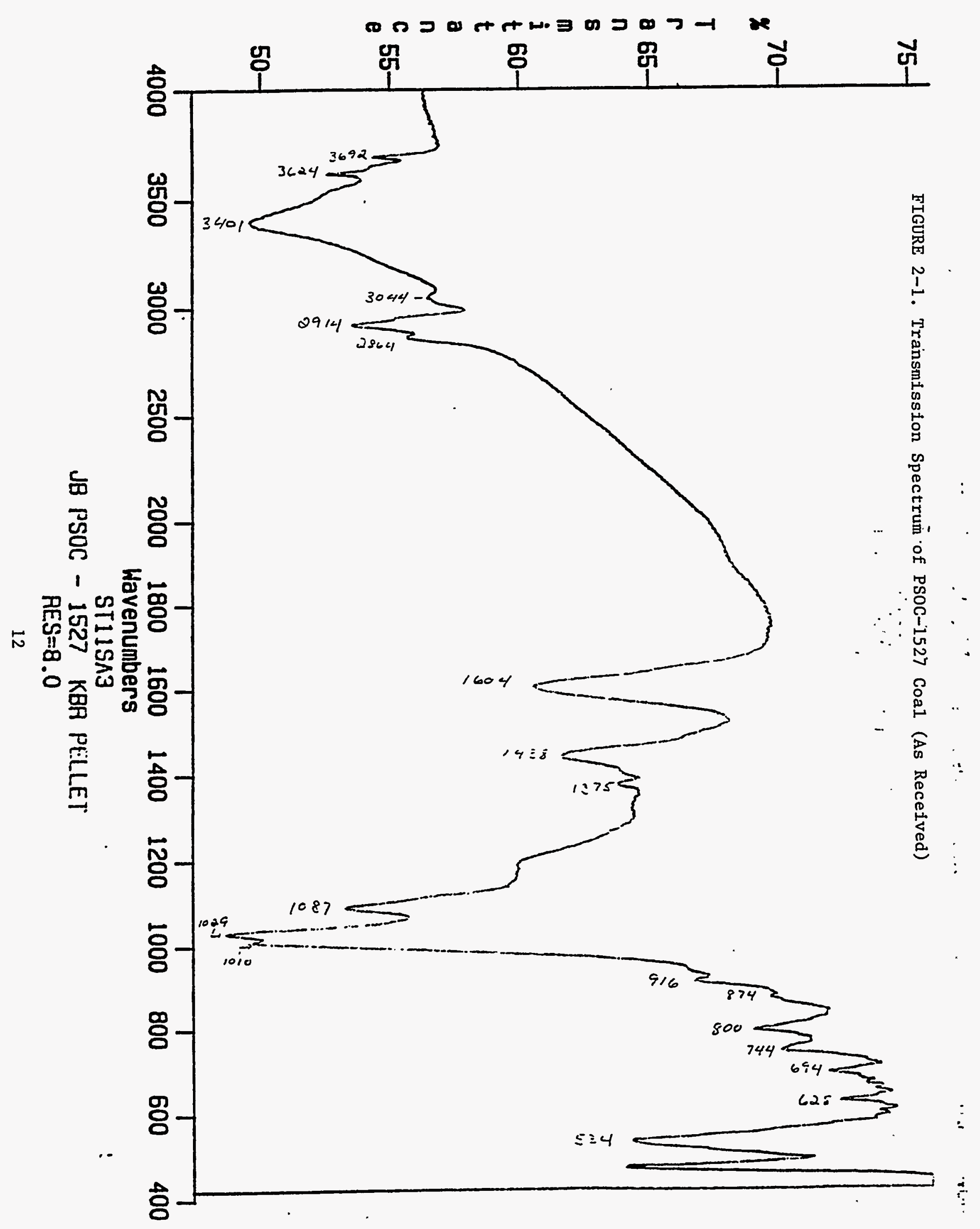




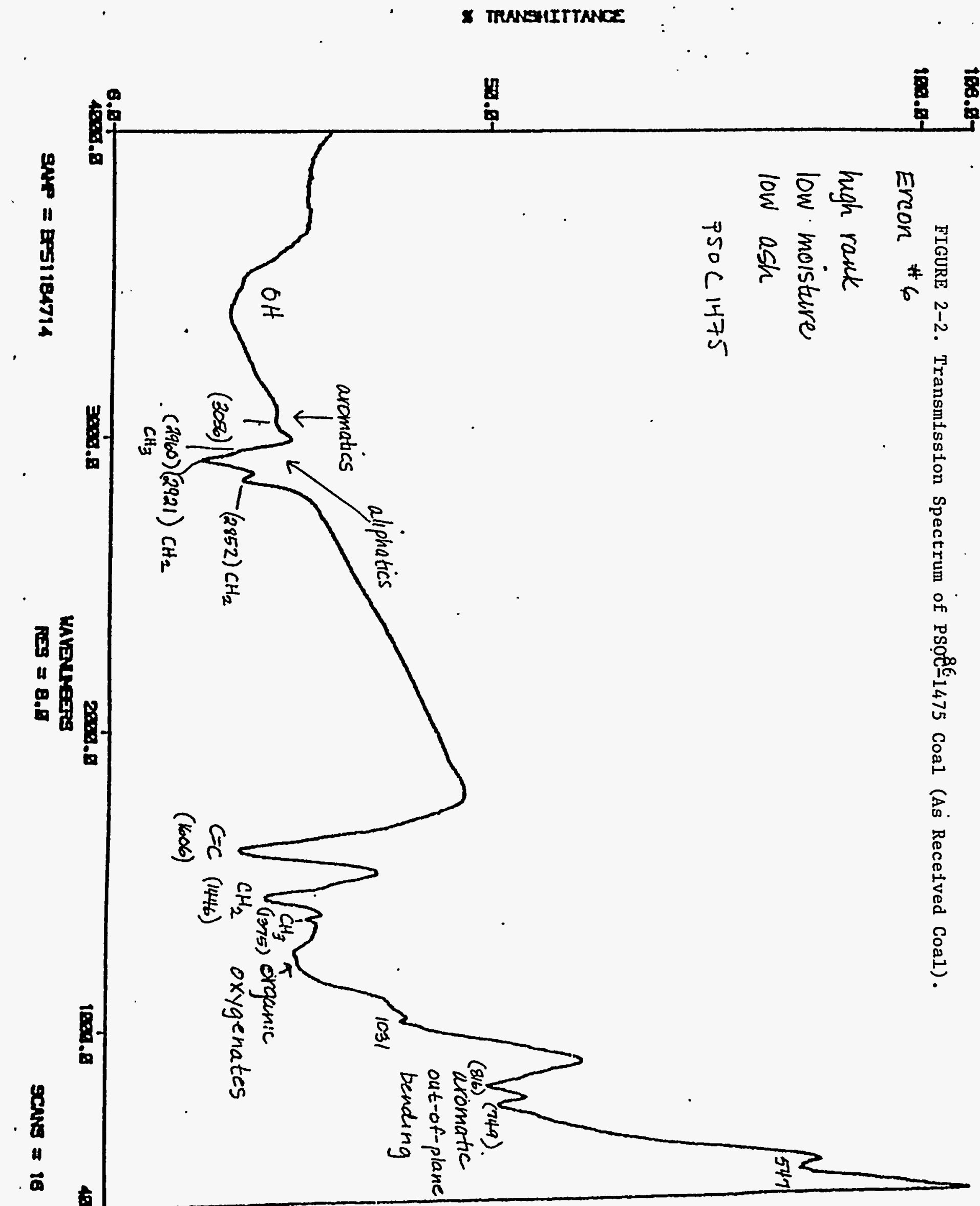


4. The bands at 1606,1446 , and 1375 wavenumbers are due to $-\mathrm{C}=\mathrm{C}-, \mathrm{CH}_{2}, \mathrm{CH}_{3}$ and organic oxygenates, $\mathrm{C}-\mathrm{O}-\mathrm{C}, \mathrm{C}-\mathrm{O}-\mathrm{H}, \mathrm{C}-\mathrm{C}-\mathrm{O}$. Clay minerals also exhibit lattice mode of vibration in this region.

5. The band at 1031 is due lattice mode of vibration of clay and silicates.

6. The bands at 855,816 and 749 wavenumbers are due to out of plane bending modes of Ar- $\mathrm{H}$ and presence of silicates.

Figure 2-3 is spectrum of the coal sample PSOC-1475 after one year storage period. The bands associated with the $\mathrm{O}-\mathrm{H}$ are much larger compared to the bands in Figure 2-1. Also, the bands at 2852 in Figure 2-1 are absent in Figure 2-3. This shows that the storage process has altered the distribution of Hydrogens in the polynuclear matrix. The $\mathrm{C}-\mathrm{H}$ aliphatic mode stretching region is the region most sensitive to oxidation [20]. The absence of this bands in Figure 2-3 indicate that, oxidation of the coal matrix did take place during storage. A comparison of the data in Tables 2-4 and 2-5 indicate that there is a decrease in the percent amount of $C-C, C=C$ and an increase in the percent amounts of $\mathrm{C}-\mathrm{O}$ and $(\mathrm{C}-\mathrm{O})=0$ during this storage period.

\section{Zeta potential}

The theory of the electrical double layer associated with a charged particle in aqueous electrolyte solution has been well documented [21]. The charge is assumed to be smeared out uniformly over the particle surface, and this is balanced by ions, regarded as point charges, which are of opposite sign and distributed in the medium around the particle.

The dissociation constant expressions in equations $2-1$ and 2-2, can be represented by:

$$
K_{\text {acld }}=\frac{\left[\mathrm{COO}-\left[\mid\left[H_{H}^{+(s)}\right]\right.\right.}{[-\mathrm{COOH}]}
$$

$K_{\text {Phenolic }}=\frac{\left[O^{-} \mid\left[a_{H}^{+(S)}\right]\right.}{[-O H]}$ 


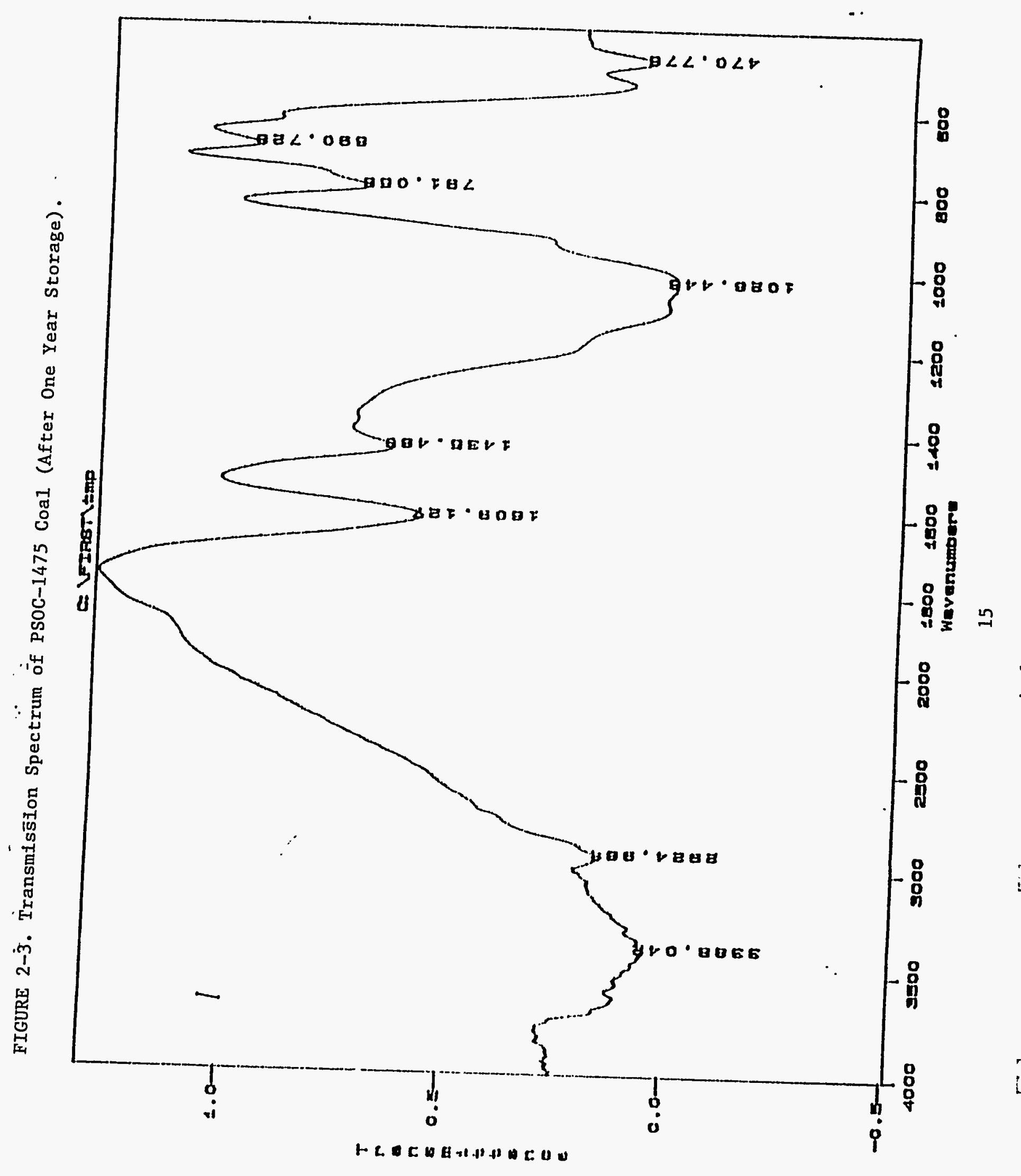


where $a_{H}^{+(s)}$ is the activity of the hydrogen ions at the surface of the coal, and it is related to the acidity in the bulk, i.e., $\mathrm{pH}$ by the relation:

$a_{H}^{+(s)}=a_{H}^{+(s)} e^{-\frac{\sigma \psi_{0}}{k T}} \quad 2-8$

where $\psi_{0}$ is the potential at the solid-liquid interface, $e$ is the electronic charge, $k$ is the Boltzmann constant and $\mathrm{T}$ is the absolute temperature.

The surface has an electrostatic potential, $\psi_{0}$, and on moving away from the surface, the potential decays exponentially to zero in the bulk liquid. The shear plane, which corresponds to the boundary of the layer of bound solvent, is the location of the zeta potential (Figure 2-4).

\section{Zeta Potential Measurements:}

The zeta potential was determined using a Micromeretics Zeta Potential Analyzer (model 1200). Operation allows the effective particle surface charge in a liquid/solid sample to be measured by the application of a constant electric current applied across a maximum of $50 \%$ by weight solids suspension. by determining the rate at which the particles migrate into a cell, electropheretic mobility and zeta potential can be determined. All measurements were made in a constant ionic medium of $0.001 \mathrm{M} \mathrm{KNO}_{3}$ in order to help eliminate any anomalies, due to changes in ionic strength of the aqueous phase as a result of leaching of ions from the coal into the aqueous phase. The zeta potential measurements as a function of $\mathrm{pH}$ are as shown in Figure $2-5$. 


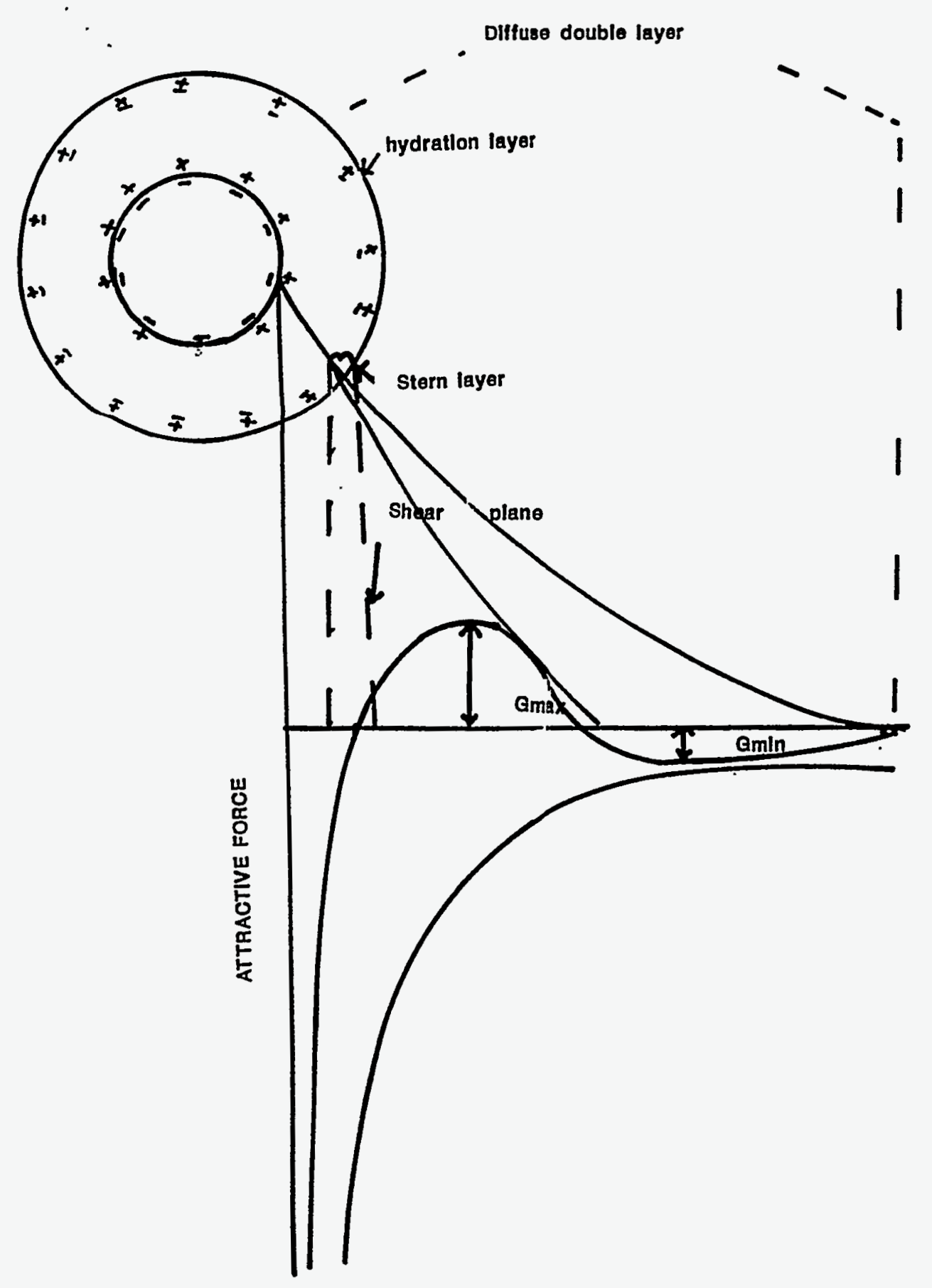

FIGURE 2-4. Interparticle Attraction 


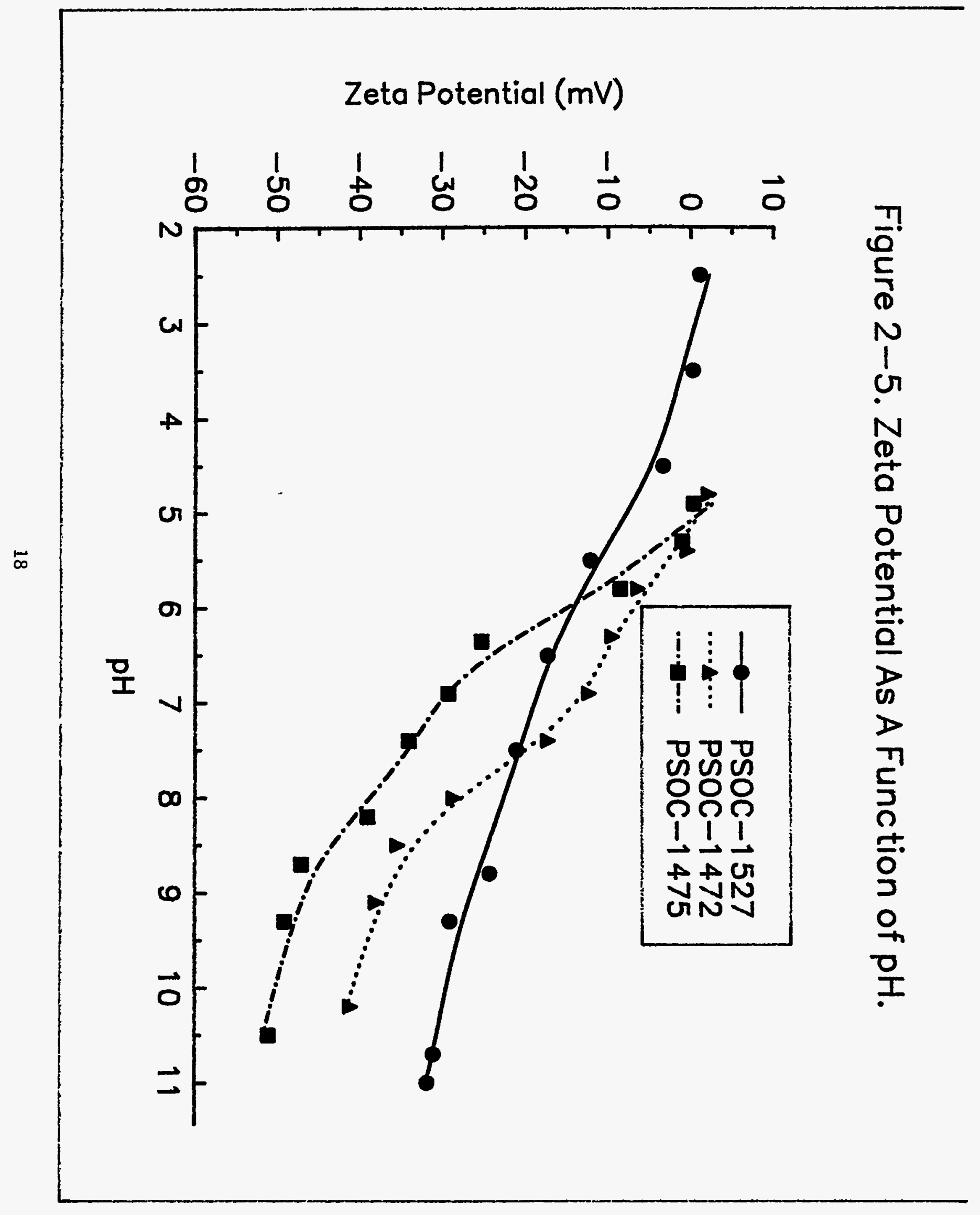




\section{CHAPTER 3.}

\section{Rheology of Coal Slurries.}

Conventional rheological evaluation of Coal-Water Slurries by steady shear flow measurements and specifications of plastic viscosity and yield stress, have provided a strong technical base for preparing and controlling the stability of CWS $[22,23,24]$. These specifications however, fail to provide complete insight into the CWS properties that control the flow properties and those necessary for their subsequent atomization $[25,26]$. This is because steady flow measurements reveal only the viscous, energy dissipative effects in the CWS flow for very long shearing time and with constantly increasing deformation.

\section{3-1 Rheology}

Many of the problems encountered in the utilization of coal-water slurries (CWS) are as a result of their flow properties. Rheology is the branch of mechanics dealing with the deformation and flow of materials in response to a mechanical force, or conversely, the prediction of the force system necessary to cause a given deformation or flow. From the study of the rheology of a system, one can gain insight into the factors that affect the structure of the system and to what extent. The behavior of a fluid under shear forces can be examined, such as the investigation of flow properties through pumps, pipes, and nozzles. The atomization of a fuel is also a function of its rheology. Rheological studies can be used in a predictive manner, for example, to determine the effects of varying one parameter of a system or how flow behavior will change from one configuration to another.

\section{3-2 Newtonian vs. Non-Newtonian Rheology}

For a Newtonian fluid, the shear stress, $\tau$ is directly proportional to the shear rate, $\gamma$; the constant of proportionality is the viscosity, $\mu$. $\tau=\mu \gamma \cdot$ 
Viscosity is measured in Pascal-seconds (Pa-s) in Sl units; shear stress in Pascals (Pa) and shear in reciprocal seconds $(1 / \mathrm{s})$.

For pipe flow, the average shear rate is shown by equation 3-2:

$\gamma=\frac{8 \times \text { bulk Velocity }}{\text { pipediameter }}$

The shear stress for pipe flow is the force/area at the wall resisting the flow. It is directly related to the pressure required to pump a fluid. However, many types of fluids, including CWS, are non-Newtonian, i.e. their viscosity is not constant but dependent on the shear rate to which the fluid is subjected. The non-Newtonian viscosity is denoted by $\eta(\gamma)$. If the shear stress is divided by the shear rate at a particular point, the apparent Newtonian viscosity is obtained.

In a viscometer or in a pipe, the shear stress can be measured as a function of shear rate. When this is done, a flow curve is generated. Figure 3-1 shows flow curves for some types of Newtonian and non-Newtonian fluids. Curve 1 represents a Bingham plastic. For these liquids, a certain shear stress, the yield point, must be applied before they start to flow. Shear thinning (pseudoplastic) behavior is seen in curve 2. In this type of liquid, the apparent viscosity decreases with increasing shear rate. Dilatant behavior, curve 3 , is present in some concentrated suspensions. The apparent viscosity increases as the shear rate increase. Curve 4 shows a shear thinning fluid which also has a yield point. This flow is also seen in some concentrated suspensions.

In order to mathematically describe the relationship between shear stress and shear rate, equations have been developed to fit the flow curves obtained in a viscometer or pipeline. Curves 2 and 4 are generally developed using a power law model: $\tau=k \gamma^{n}$

The constants $\mathrm{k}$ and $\mathrm{n}$ can be evaluated from the raw data from either a viscometer pipeline. 
FIGURE 3-1. Shear Stress As A Function of Shear Rate.

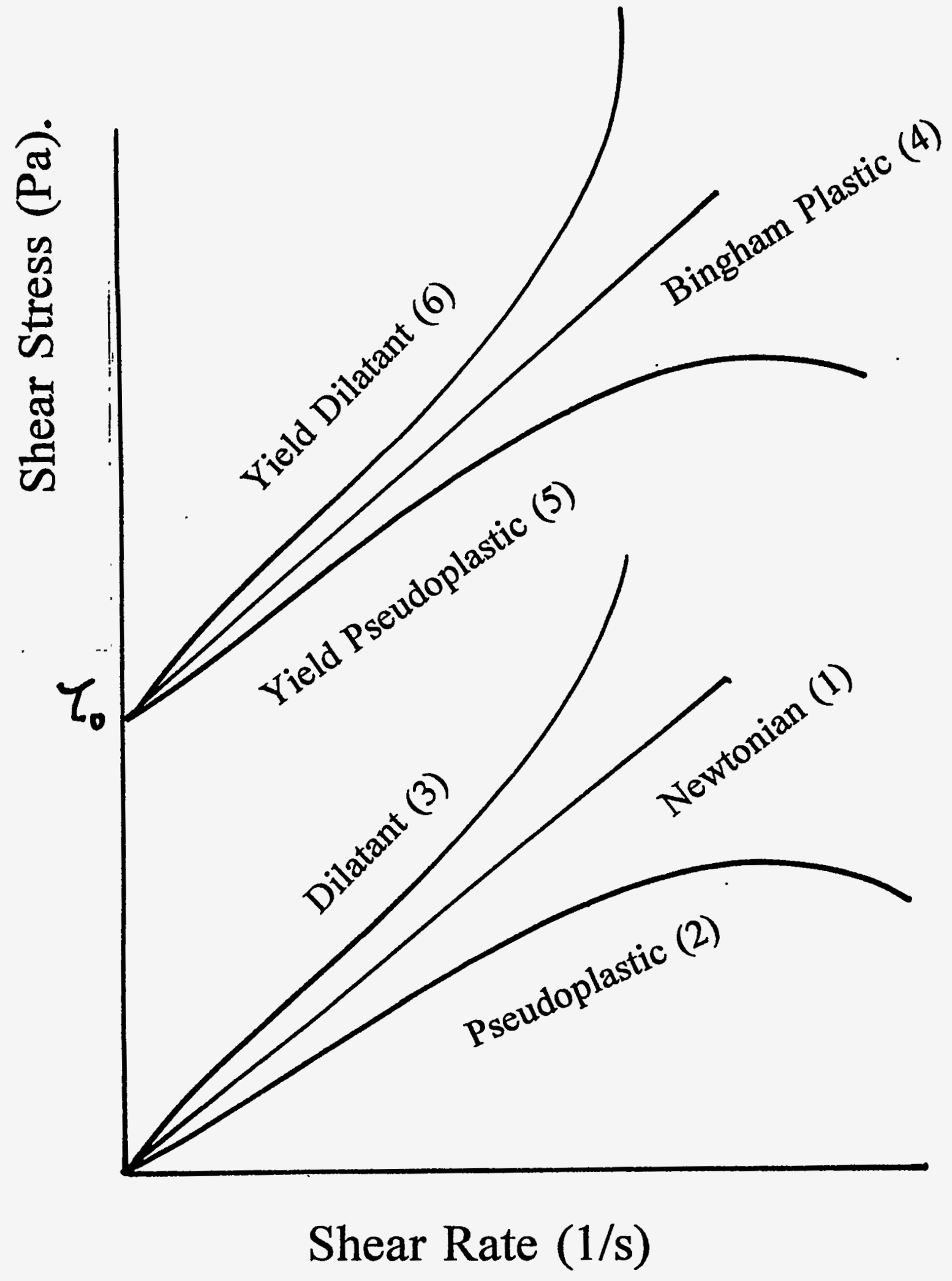


FIGURE 3-2. Shear Stress As A Function of Shear Rate.

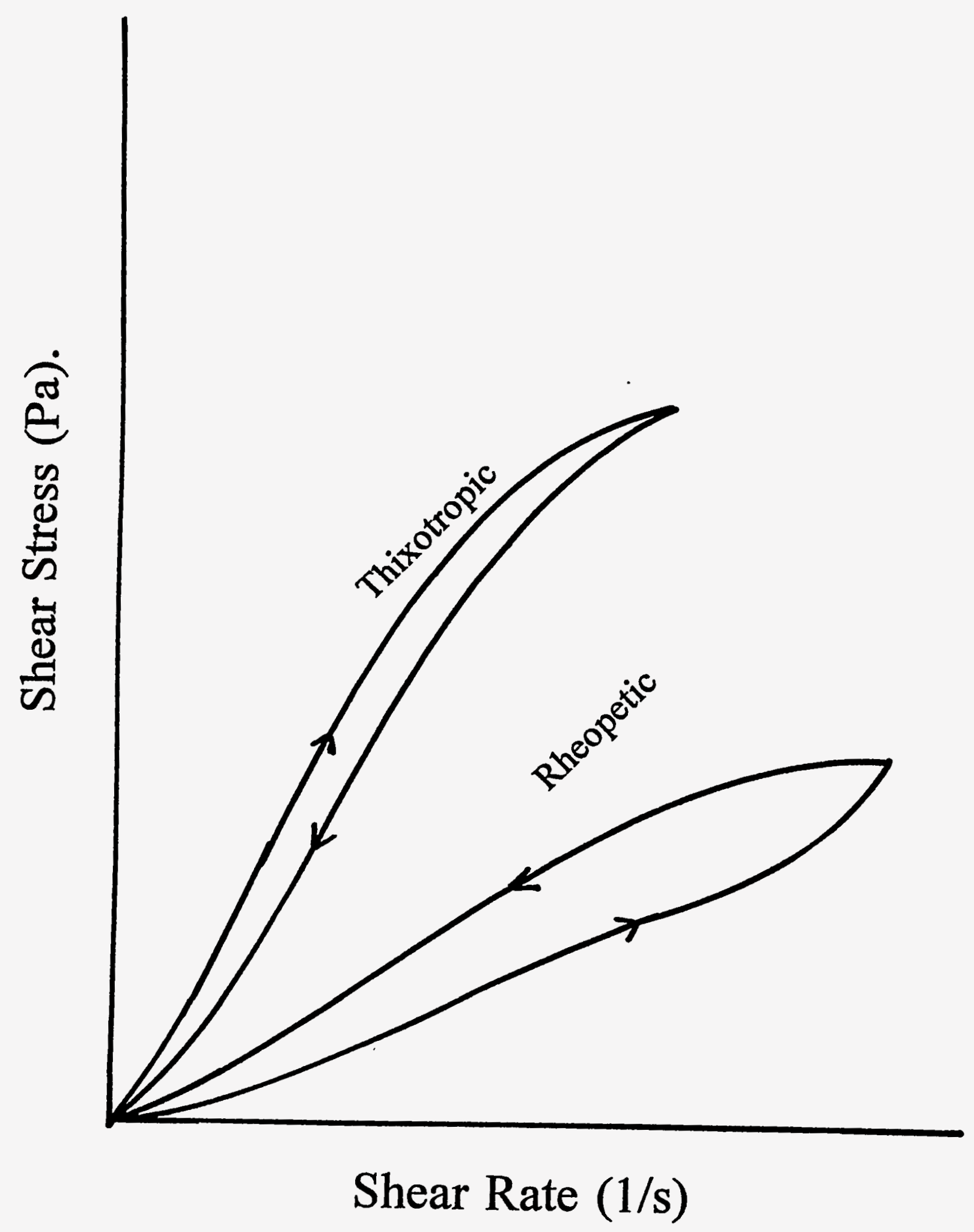


If $n=1$, the fluid is Newtonian and $k=\mu$; if $n>1$, the fluid is dilatant; if $n<1$, the fluid is shear thinning. Curve 1, a Bingham plastic is described by:

$\tau=\tau_{0}+\eta(\gamma \cdot)_{p l}$

where $\tau_{0}$ is the yield point, and $\eta_{p l}$ is the plastic viscosity.

A yield pseudoplastic fluid, curve 4, can be described by:

$\tau=\tau_{0}+k \gamma^{n}$

where $k$, and $n$ are as described above.

\section{3-3 Time Dependency}

The equations described above deal only with the effect of shear rate on viscosity; the effect of duration of shear is not included. When a constant or variable shear is applied to a fluid, the rheology can change with time as the structure of the fluid is altered. Figure 3-2 shows the effect of slowly increasing the shear rate to a maximum, and then slowly decreasing it. For a thixotropic fluid, the decreasing shear curve is lower than the increasing shear curve; the viscosity of the sample decreases with time. The opposite behavior is seen with rheopectic fluids. The samples of CWS that were studied previously at Grambling State University, exhibited both of these properties [27].

\section{3-4 Effect of Particle Interactions}

In suspensions, there are interactions between the particles, and between the particles and the continuous phase. These interactions may give rise to agglomerates, which can trap some of the continuous phase. At low shear rates, there is random orientation of these agglomerates and the shear force is not sufficient to affect either the size or the alignment of the agglomerates. As the shear is increased, the structure of the agglomerates is broken down, the trapped fluid is released, and the particles and smaller agglomerates are oriented in the direction of the flow. These effects give rise to a decrease in viscosity. When the maximum degree of de-agglomeration 
and orientation has occurred, the viscosity of the fluid again become constant, but at a much lower value than the original apparent viscosity.

\section{3-5 Importance of Coal Properties}

The CWS utilized in this program are suspensions of coal which had previously been studied at Grambling State University. The rheology of these slurries were found to be dependent upon the following factors [27]:

Hydrodynamical interactions between coal particles and suspending medium (water);

Surface specific interactions between coal particles and suspending medium:

Interparticle interactions.

These factors were dependent upon the properties of the coal used for the slurry formulation. A relationship between coal properties and resulting rheology of a CWS developed in the previous program, was a vital step in establishing the acceptable range of coal types to be used for the current study.

\section{3-6 Rheology of Suspensions}

The rheological properties of suspensions are predictable from basic principles in only a few cases for extremely dilute suspensions. One can, however, investigate the degree of structural formation in a suspension by studying the variables which affect the system through rheological measurements, thus obtaining a qualitative picture of the behavior of the system. Rheological analysis is also the best quantitative method to obtain information on the properties of a concentrated suspension as it settles. Besides examining the viscosity of the suspension at low shear rates for information on the structure of the system, the high shear rate behavior is important for practical use considerations. 
The introduction of solid particles into a Newtonian fluid medium disturbs the flow pattern and increases the amount of energy dissipation. The viscosity of a suspension is independent of shear rate, i.e. Newtonian, when only the hydrodynamic interactions are taken into account. Agglomeration of the particles, needed to explain shear thinning and other non-Newtonian properties, must involve non-hydrodynamic forces of attraction, such as the London-van der Waals force. These forces will depend on the physics and chemistry of the coal particle surfaces. At high shear rates, when the structure is broken down, hydrodynamic effects become more important.

The non-hydrodynamic forces acting on particles in a suspension include thermal forces, electrical forces, London-van der Waals, and the chemical and surface interactions between the particles.The London-van der Waals force between the particles in a suspension influences the formation of agglomerates. The depth of the secondary minimum in the potential energy-distance curve between particles determines the net attraction (Figure 2-4). The viscosity of the system is proportional to the depth of the secondary minimum..

If there is a surface charge on the particles in a suspension, an ion cloud is formed around each particle. This electric double layer stores energy like a capacitor and tends to resist deformation by flow, and also screens the charge on the particles, reducing the repulsive forces. Ionic dispersants bond to the particle surfaces effecting changes in the surface charges and therefore the ionic double layer. A change in the potential energy of interparticle interaction results. Dispersants can thereby be used to modify the viscosity of CWS by reducing the net attractive forces between coal particles. A reduction in agglomerate formation improves the rheological properties. 


\section{3-7 Effect of Particle Packing on CWS Viscosity.}

Previous studies indicate that coal particle packing exert considerable influence on the CWS behavior. In previous work at Grambling State University, a computer program that had been developed at Adelphi University which allows for the calculation of the maximum packing based on coal particle distribution, was used to select the PSD in order to obtain a high efficiency packing. This program was also used to select the PSD for this study [27]. The optimum particle size distribution selected for the formulation of the coal-water slurries is shown in Table 2-2.

\section{3-8 Viscoelastic Behavior}

Dense suspensions will exhibit viscoelastic behavior depending on the type of strain or stress applied to the material. Viscoelastic properties of material relate directly to its internal structure. If a dense suspension is subjected to a varying external force of frequency, $\omega$, then the dense suspension will behave as an ordinary viscous liquid if $\omega T<1$ where $T$ is the time during which the stresses are damped, and if $\omega T>1$, the internal stresses will not be damped and the suspension will behave as an amorphous solid. When dense suspensions are elastically deformed during short intervals of time, shear stresses remain, which are damped after sufficiently long time, $\mathrm{T}$.

The response of viscoelastic material which has been subjected to a small-amplitude oscillatory shear is given by [28]:

$\gamma(t)=\gamma_{o} \exp (i \omega t)$

where $\omega$, is the frequency and $\gamma_{0}$ is the strain amplitude.

In oscillatory shear, a complex modulus, $\mathrm{G}^{*}$, can be defined as:

$\sigma(t)=G^{*}(\omega) \gamma(t)$

$\mathrm{G}^{*}$ can also be expressed as: 
where $G^{\prime}$ and $G^{\prime \prime}$ are the storage modulus and loss modulus respectively.

Dense suspensions such as coal-water slurries, can be treated as a continuum model where their response to applied stresses and strains can be examined.

For ideally elastic substances based on a model following Hooke's Law, the following relationship applies:

$\tau(t)=G . \gamma(t)$ with controlled strain.

$\gamma(t)=\frac{1}{G} \cdot \tau(t)$ with controlled stress.

For ideally viscous substances, the relationship

$\tau(t)=\eta \cdot \gamma \cdot(t)$ with controlled strain or shear rate

$\gamma(t)=\frac{1}{\eta} \cdot \tau(t)$ with controlled stress

The angular frequency $\omega$, is related to both the strain and the stress sinusoidally thus:

$\gamma(t)=\gamma_{0}$. Sin $\omega t$ (controlled strain)

$\tau(t)=\tau_{o} . \operatorname{Sin} \omega t$

3-14

The delay of $\tau(t)$ curve against $\gamma(t)$ curve has the phase displacement angle $0^{\circ}>\delta>90^{\circ}$.

The storage modulus, $G^{\prime}$, which is the strain energy reversibly stored in the sample and recoverable is defined as:

$G^{\prime}=\frac{\tau_{0}}{\gamma_{0}} \cdot \operatorname{Cos} \delta$

alternatively,

$G^{\prime}(\omega)=G_{1} \frac{\omega^{2} t_{R}^{2}}{\left(1+\omega^{2} t_{R}^{2}\right)}$ (Maxwell's Model)

This chracterizes the elastic behavior of the sample. The $G^{\prime}$ value represents the quantity of the strain energy reversibly stored in the substance and recoverable.

The loss modulus is given by:

$G^{\prime \prime}=\frac{\tau_{0}}{\gamma_{0}} \cdot \operatorname{Sin} \delta$

alternatively

$G^{\prime}(\omega)=G_{1} \frac{\omega t_{R}}{\left(1+\omega^{2} t_{R}^{2}\right)}$ (Maxwell's Model)

This quantity represents the energy which is irreversibly given off by the substance to its 
environment and thus lost. It characterizes the viscous behavior of the substance. The loss factor, $\tan \delta$, which is a ratio of the dissipated and the stored energy is given by: $\tan \delta=\frac{G^{\prime \prime}}{G^{\prime}}$

The study of the oscillatory behavior allows the systematic characterization of the CWS suspensions so that their flow properties could be described by mechanical parameters which represent the system in the region of interest. The oscillation test provide more detailed information about the elasticity of the sample. The creep and relaxation test are made with a given constant load (shear stress, $\tau$ or shear rate, $\gamma$ ) and permit the determination of the ratio between the viscous and the elastic portions, the retardation time, and the shear modulus. These values depend on the constant presetting and results are obtained only under these constant conditions. Oscillation test can be made under varying loads with controlled shear stress, $\tau$ or controlled shear strain, $\gamma$. especially, the characterization of the relative importance of elastic to viscous effects. Stress and strain relaxation as well as viscometric measurements are essential in relating elastic to viscous effects. Other parameters such as: yield points, shear moduli, storage moduli, and moduli of rigidity can be related to interparticle forces. These parameters form good basis for characterizing the flow properties.

\section{3-9 Dynamic Flow}

In a capillary, the material's law can be determined from the pressure, $\mathbf{P}$ and the flow rate, $Q$, if the tube flow fulfills the following criteria:

(a) The flow is laminar, i.e. all volume elements of the sample within the tube with the same distance, $r$, from the tube axis, move at the same velocity in the direction of the tube axis.

(b) The flow is steady- At any point within the tube, the flow velocity has the same value at consecutive time intervals, therefore, is independent of time.

(c) The flow is isothermal- It is assumed that the temperature of the sample remains constant. When flowing through the capillary, the sample can, however, be warmed up by shearing. 
(d) The sample is incompressible and its viscosity is independent of pressure

(e) The sample adheres on the tube wall-No wall shearing.

The basic equation of capillary viscometry for any material's law is [29]

$\tau(r)=\frac{P . r .}{2 l}$

Where $\tau(r)$ is the shear stress dependent on the distance, $r$, from the tube axis,

$P$ is the pressure drop along length, 1 , within the tube,

and $\quad l$ is the length of the tube

The shear rate can be expressed as a function of the distance, $r$, from the tube axis thus:

$\gamma^{\bullet}(r)=\frac{d u(r)}{d r}=f(\tau(r))$

The flow rate, $Q$, can be obtained by integrating the velocity distribution, $v(r)$, across the tube cross section.

$Q=\int_{0}^{r=R} v(r) .2 \pi r d r$

\section{3-10 Newtonian Flow in a capillary Tube}

Newtonian fluid flow in a capillary tube can be evaluated from the relationship:

$\tau(r)=\frac{P, r}{2 l}=\tau_{w}$ (shear stress at the wall)

Substituting these expressions in equation (3-22), results in the flow velocity, $v(r)$ expression:

$v(r)=\frac{P\left(R^{2}-r^{2}\right)}{4 \eta l}$

and the flow rate, $Q$, is given by:

$Q=\frac{\pi R^{4} p}{8 \eta l}$

where $R$ is the inside radius of the tube.

For such Newtonian fluids, the shear rate at the wall, $\gamma_{w}^{*}=\gamma^{\bullet}(R)=\frac{4 Q}{R^{3} \pi}=D$

\section{3-11 Bingham's Fluid Flow:}

Bingham's material's flow law is given by the relation:

$\tau=\tau_{f}: \tau=\tau_{f}+\eta_{B} \cdot \gamma$ 
For distance of $r$ smaller than $r_{f}=\frac{2 \tau, 1}{P}, \gamma$ becomes zero in the range $\tau(r)<\tau_{f}$, and no shearing is exercised on the sample.

The flow rate for a plug -shaped flow results is given by:

$Q=\frac{x R^{4} P}{8 \eta_{B} l}\left(1-\frac{3}{4} \cdot \frac{r_{f}}{R}+\frac{1}{3}\left(\frac{r_{f}}{R}\right)^{4}\right)$

and the shear rate is given by:

$D=\frac{4 Q}{R^{3} \pi}=\frac{1}{\eta_{B}}\left(\tau_{w}-\frac{3}{4} \tau_{f}+\frac{1}{3}\left(\frac{\psi}{\tau w}\right)^{4} \cdot \tau_{w}\right)$

\section{3-12 Extensional Viscosity}

The definition of extensional viscosity can be visualized in the simple case of the uniform extension of a cylinder of an incompressible Newtonian fluid along its axis. In a cylindrical coordinate system where $\mathrm{z}$ is oriented along the cylinder axis and the radial dimension, $\mathrm{r}$, the following can be written for the case of symmetry about the $\phi$ direction [30 ]:

$\sigma_{r r}=-P+2 \mu \frac{\partial V_{r}}{\partial r}$

$\sigma_{\phi \phi}=-P+2 \mu \frac{V_{r}}{r}$

$\sigma_{Z Z}=-P+2 \mu \frac{\partial V_{z}}{\partial z}$

For the stress equation where $P$ is the hydrostatic pressure, and $\sigma_{r}, \sigma_{\psi}$, and $\sigma_{z z}$ are the extra stresses normal to planes perpendicular to the $r, \phi, z$ axis, respectively. The equation of continuity for an incompressible fluid is given by:

$\frac{V_{r}}{r}+\frac{\partial V_{r}}{\partial r}+\frac{\partial V_{Z}}{\partial Z}=0$

Combining equations, we have

$\sigma_{r r}+\sigma_{\phi}=-2 P+2 \mu\left(\frac{V_{r}}{r}+\frac{\partial V_{r}}{\partial r}\right)=-2 p-2 \mu \frac{\partial V_{x}}{\partial z}$

In an equilibrium situation:

$\sigma_{r r}=\sigma_{\phi}=0$

It follows that

$P=-\mu \frac{\partial V_{2}}{\partial z}$

Combining equations (3-31) and (3-35) yields:

$\sigma_{z z}=3 \mu \frac{\partial V_{x}}{\partial z}=n_{e} \frac{\partial V_{z}}{\partial z}$

where $\mathrm{n}_{e}$ is defined as the extensional viscosity, which is $3 \mu$ for a newtonian fluid. 


\section{3-13 Rheometry}

The flow behavior of the CWS prepared were characterized by various rheological methods in order to gain insight into their flow properties and internal structure. Low shear, High shear and viscoelastic effects were examined using a Haake RV20-CV20 with oscillatory capabilities, RV20-M5 concentric cylinder viscometer, and Parr HVA-6 Capillary viscometer. Results of Rheological Measurements.

Low shear viscosity as a function of shear rate were determined using the Haake RV20-M5 with MVIII, MVII, MV1, MVIIP and MVIP sensors. The sample is sheared in an annular gap between a rotating bob and stationary cup. The torque necessary to rotate the bob at a given speed is measured by a torsion spring. The drive unit consists of a driving motor, a tachometer-generator and a reduction gear. The stator is surrounded by a tempering vessel connected with a constant temperature bath. The temperature bath can be controlled to $0.1 \mathrm{C}$. This viscometer is integrated with an IBM ps/2 model 70 data acquisition and analysis system. The signal from the viscometer are monitored twice per second and converted to torque and rotational speeds. Viscosity as a function of shear rate were computed using one of the following flow models: Power law, yield power law, Bingham plastic, and modified Bingham plastic models. Three different viscosity standards (Cannon Viscosity Standards, Thomas Scientific, Swedesboro, NJ) having viscosities of 10,100 , and $1000 \mathrm{mPas}$ as well as glycerol, were used to calibrate the rheological instrumentation. After calibration, the viscosity of each fluid under study was determined by fitting the measured shear stress-strain rate curve to one of the several rheological models available on the data acquisition software. The analysis fitted the data to the 
Herschel-Bulkley viscosity model (Equation 3-5). This model accurately represented the rheological properties of the three classes of fluids used in this study.

Also, the coal samples were ground to a distribution as shown in Table 2-2, and the packing concentration of a number of blended distributions also, shown in Table 3-1, were calculated using a computer program that has been developed at Adelphi University. The data indicate that the packing concentration increased with increase in the number of fines $(<-325$ mesh) to a value of $40 \%$ fines. Above $40 \%$ fines, the packing concentration decreased.

Table 3-1

\section{Weight Fractions And Packing Concentrations}

$\mathrm{Wt} \%>200$ Mesh

53.7

47.7

41.7

43.6

53

36.2

26.5

9.6

58.1
Wt \% -200/325 Mesh

8.5

14.4

19.0

9.4

12.4

15.4

18.1

15.6

8.2

Wt $\%<325$ Mesh

37.8

37.9

39.3

47.0

35.7

48.4

55.4

74.8

33.7

80.1

Figures 3-3 through 3-14, show representative samples of the flow curves of several of the slurries studied. The rheological data obtained from the shear stress versus shear rate curves using Equation 3-5, are as listed in Tables 3-2 through 3-4. 
FIGURE 3-3. Flow Behavior of $57 \%$ CWS (PSOC-1472)






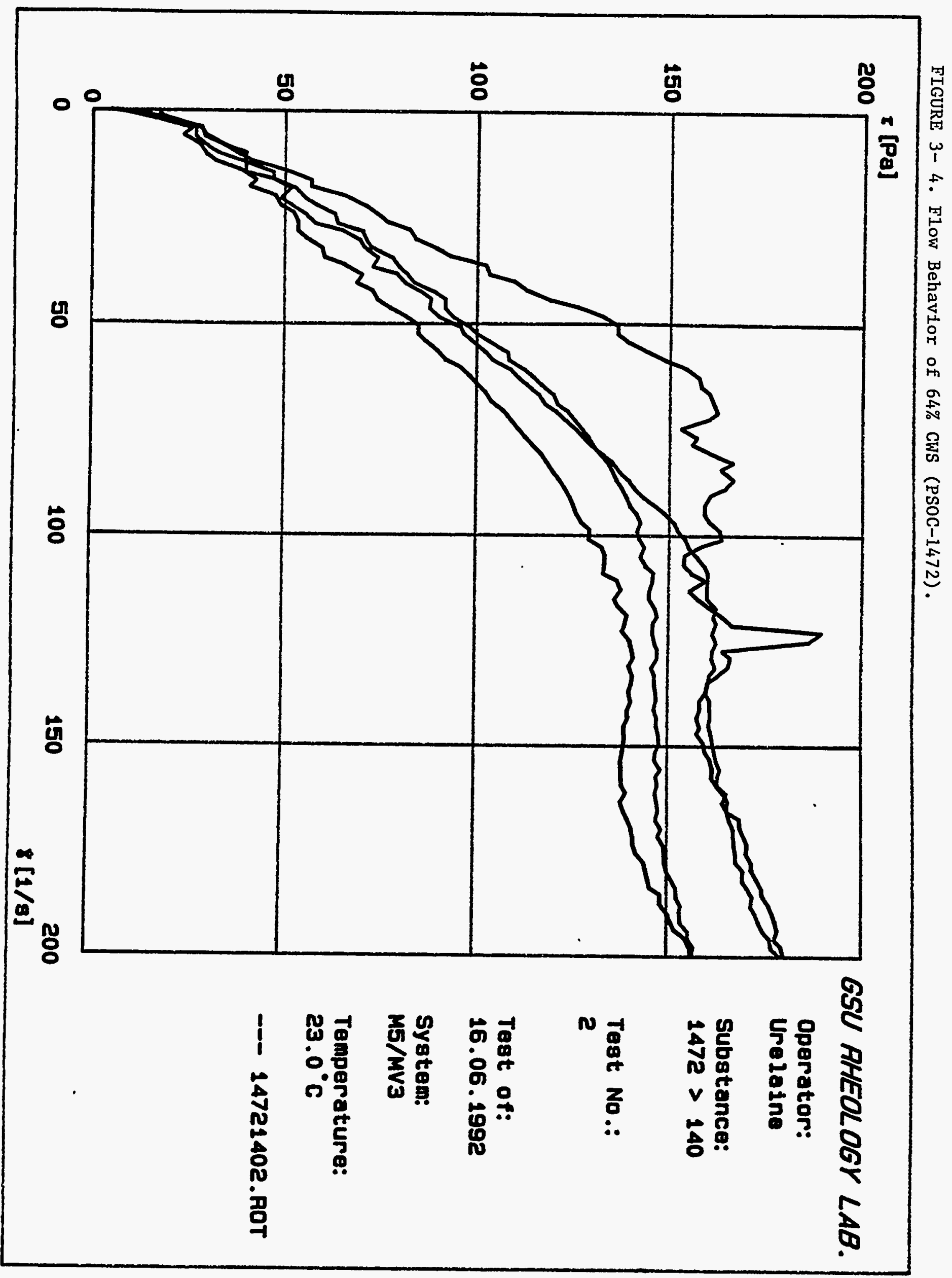




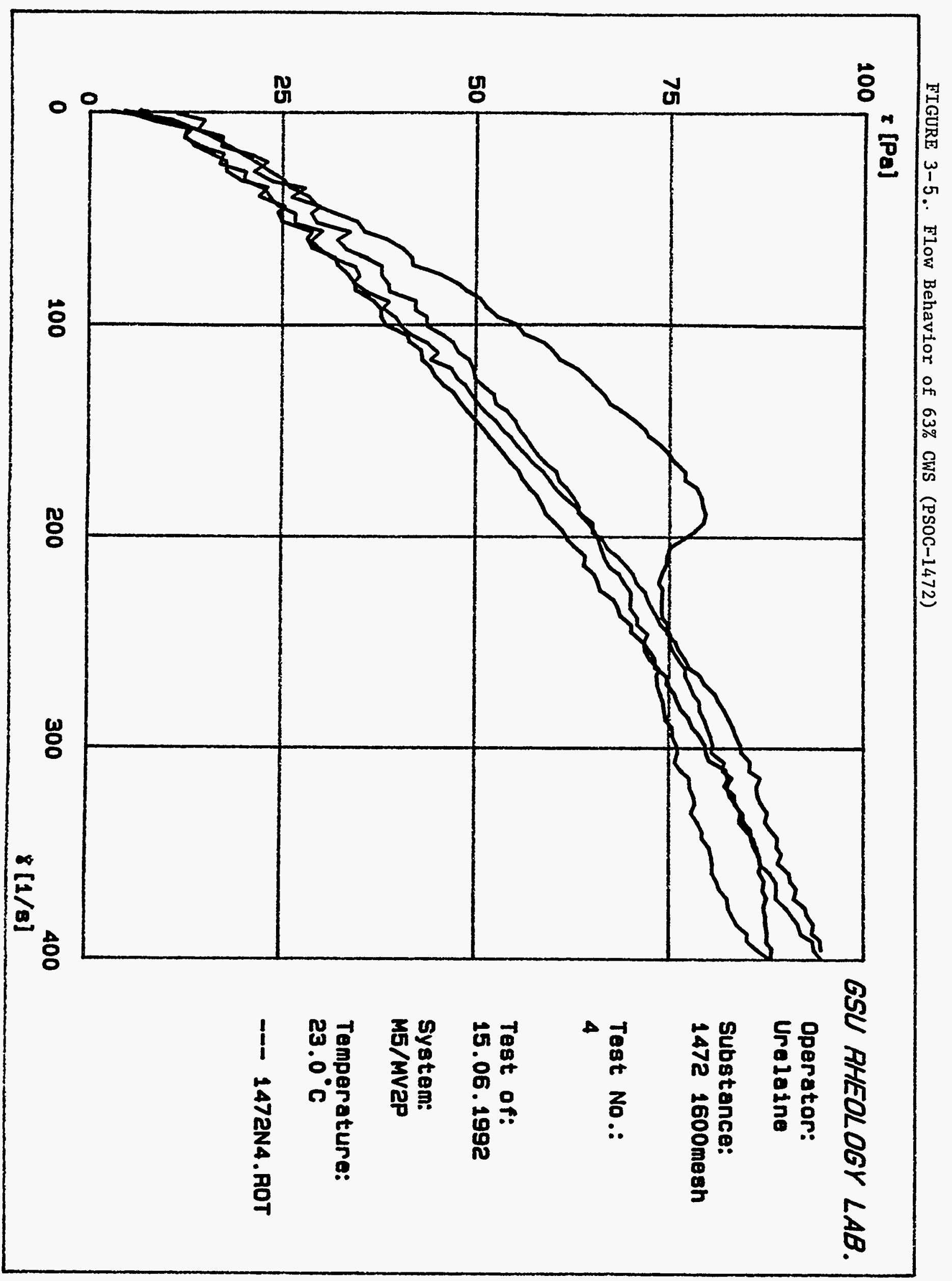




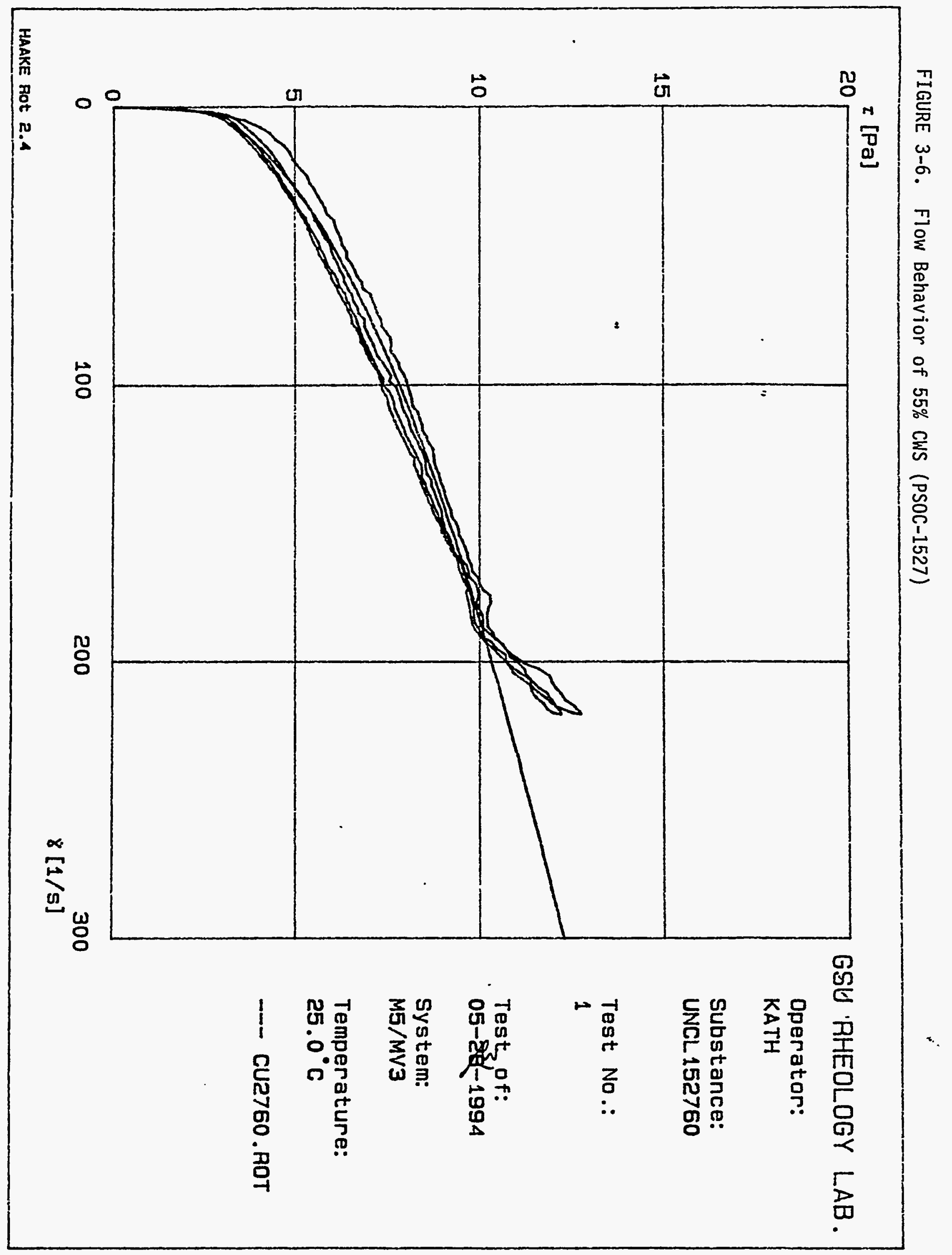




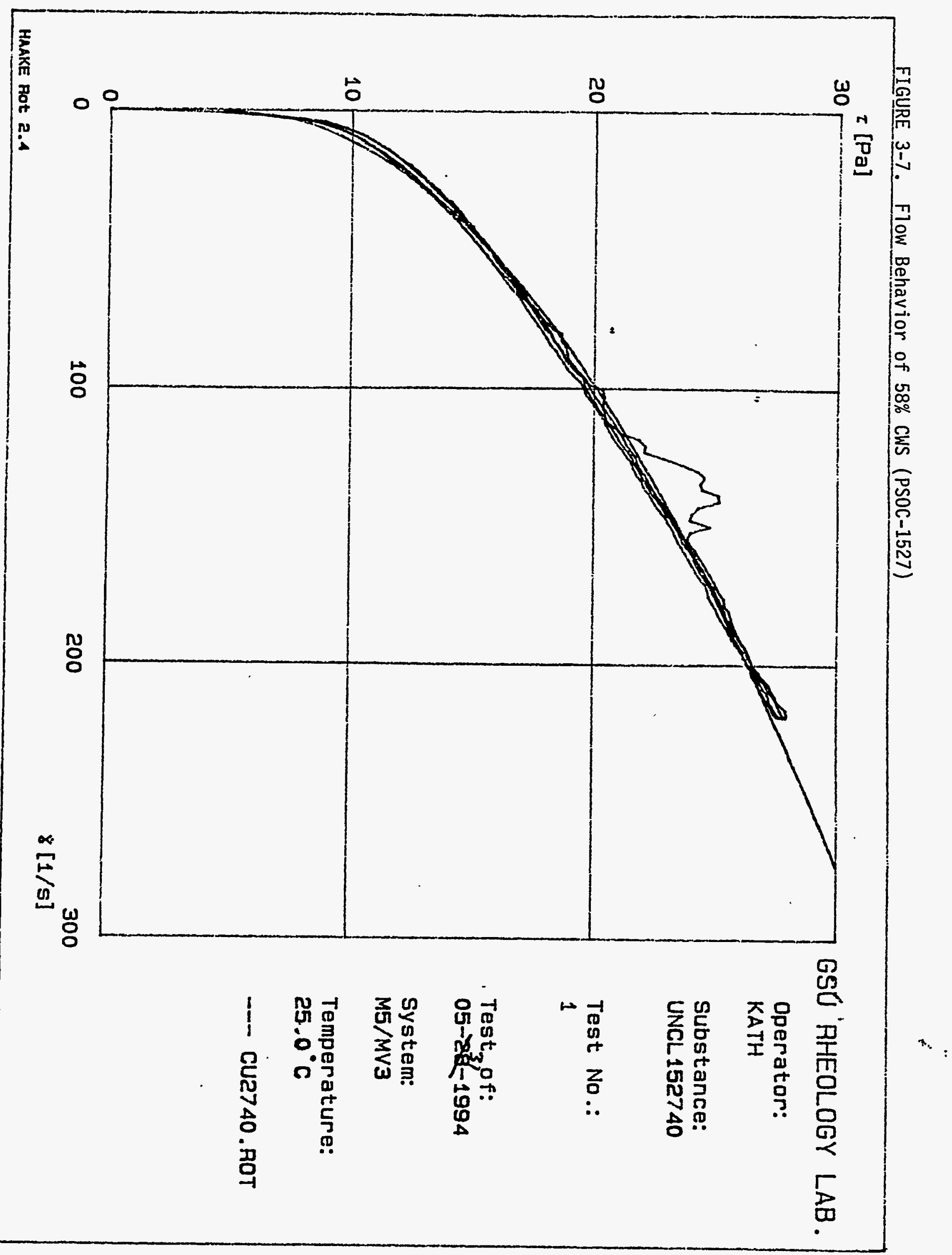




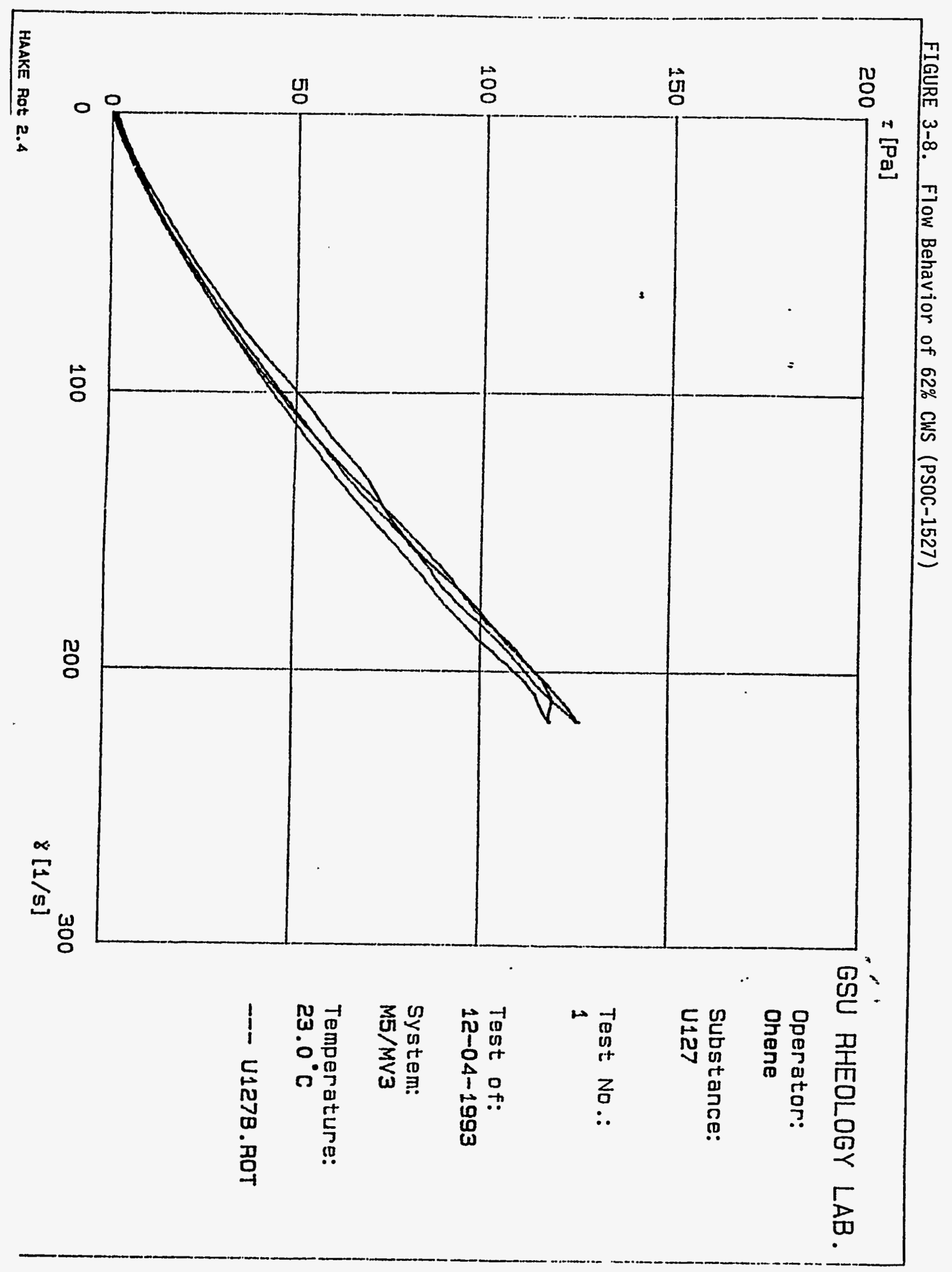




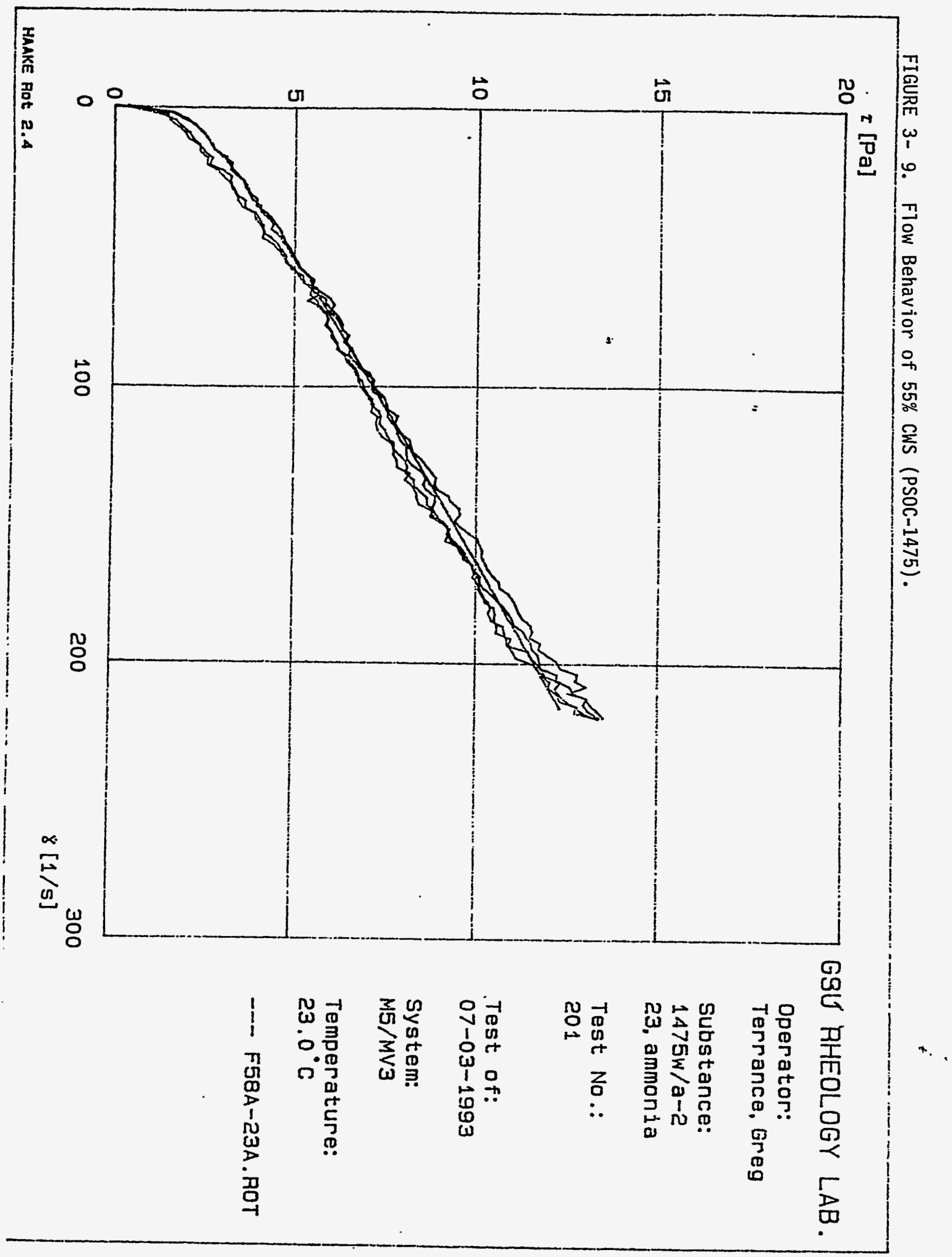


FIGURE 3-10. Flow Behavior of 56\% Elkhorn \# 3.

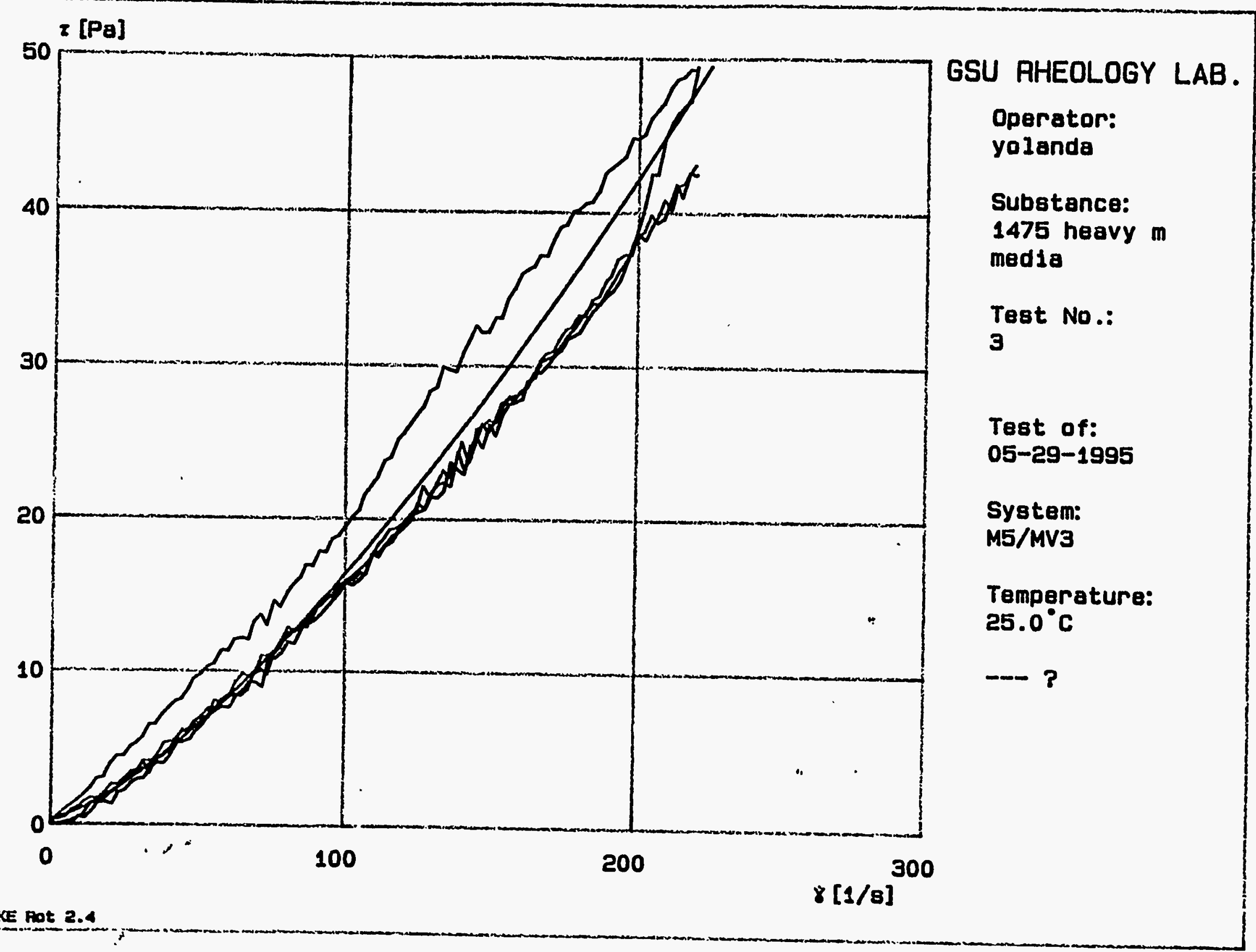




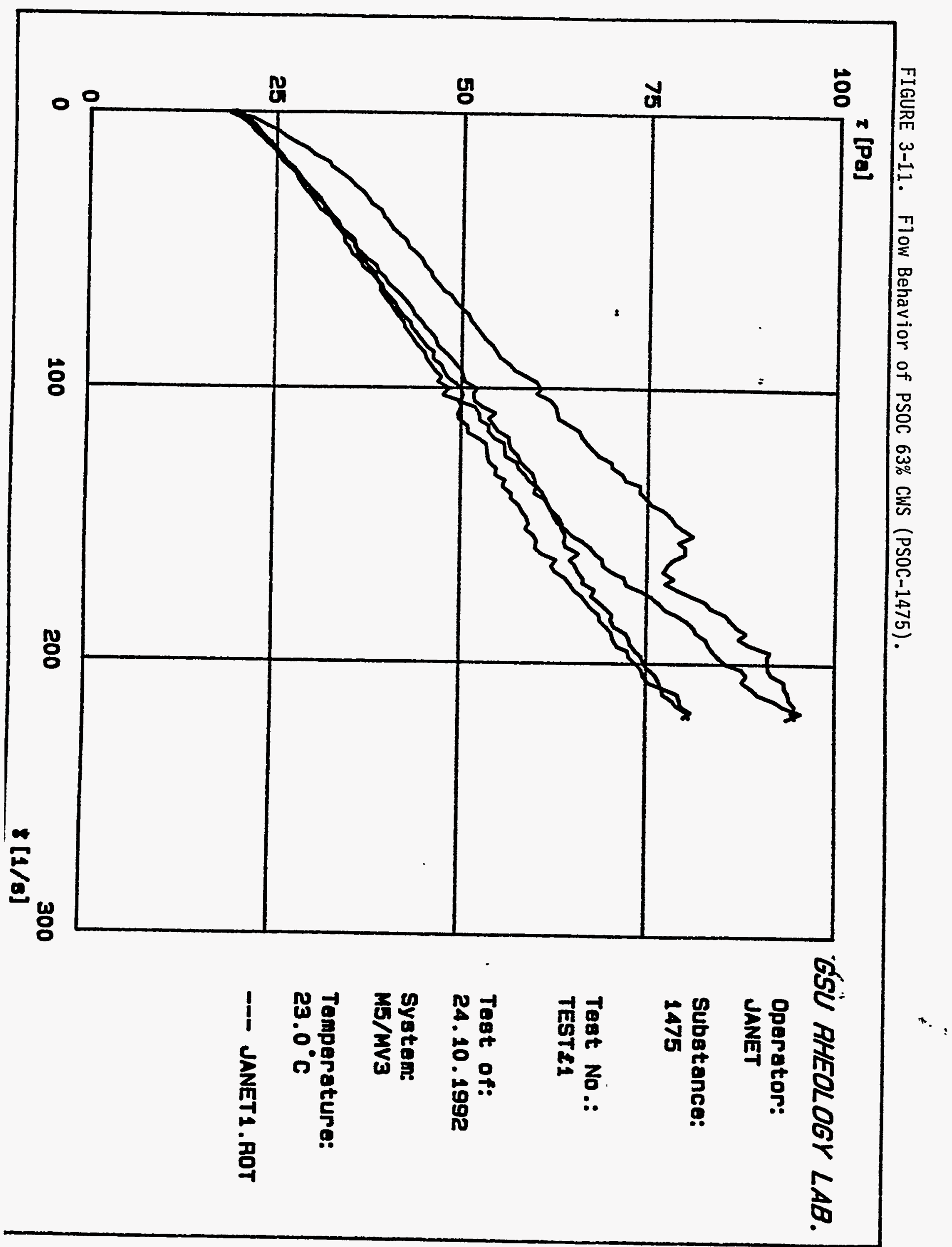


FIGURE 3-12. Flow Behavior of 64\% CWS (PSOC-1475).

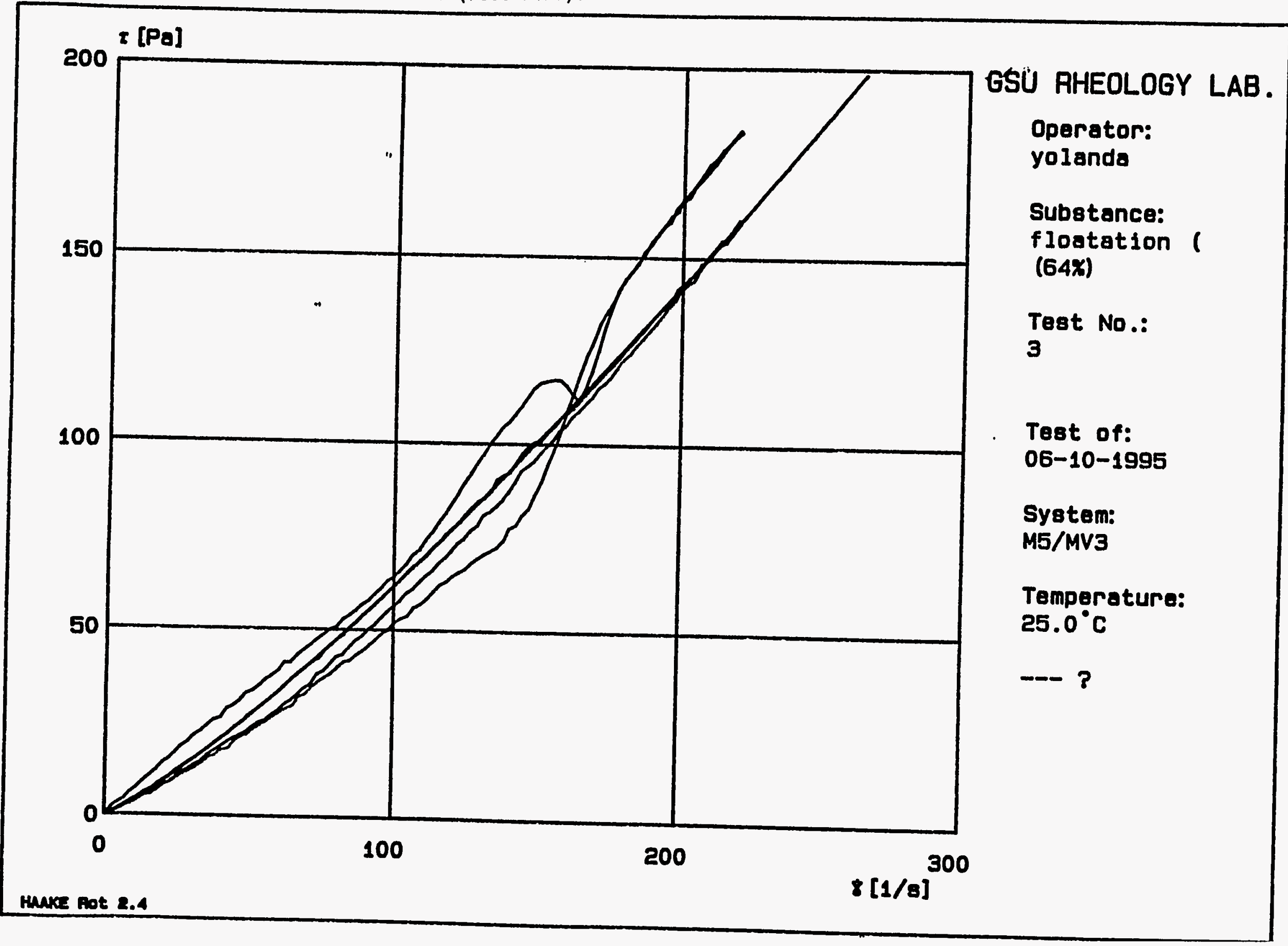


FIGURE 3-13. Flow Behavior of 65\% CWS (PSOC-1475).

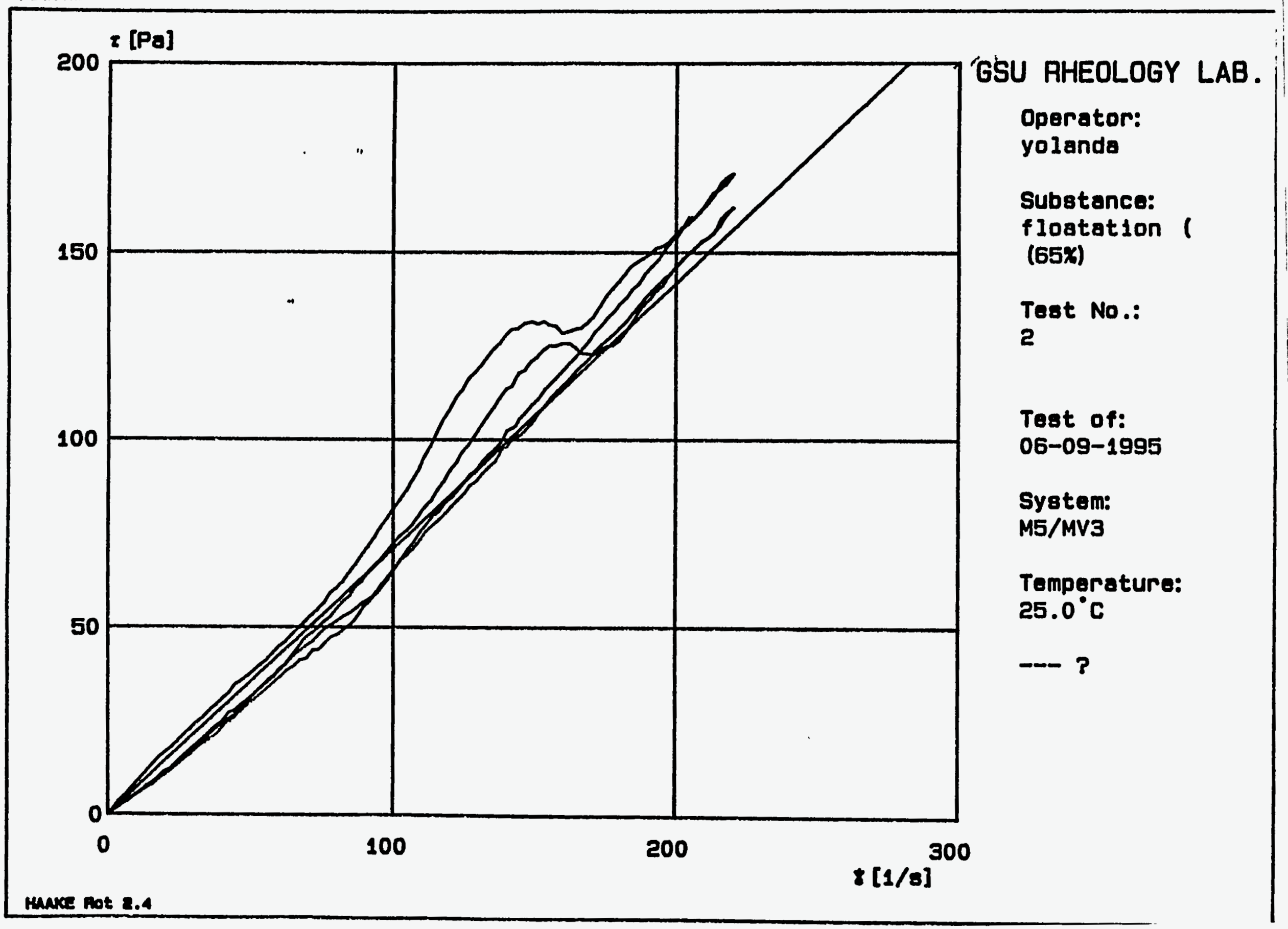




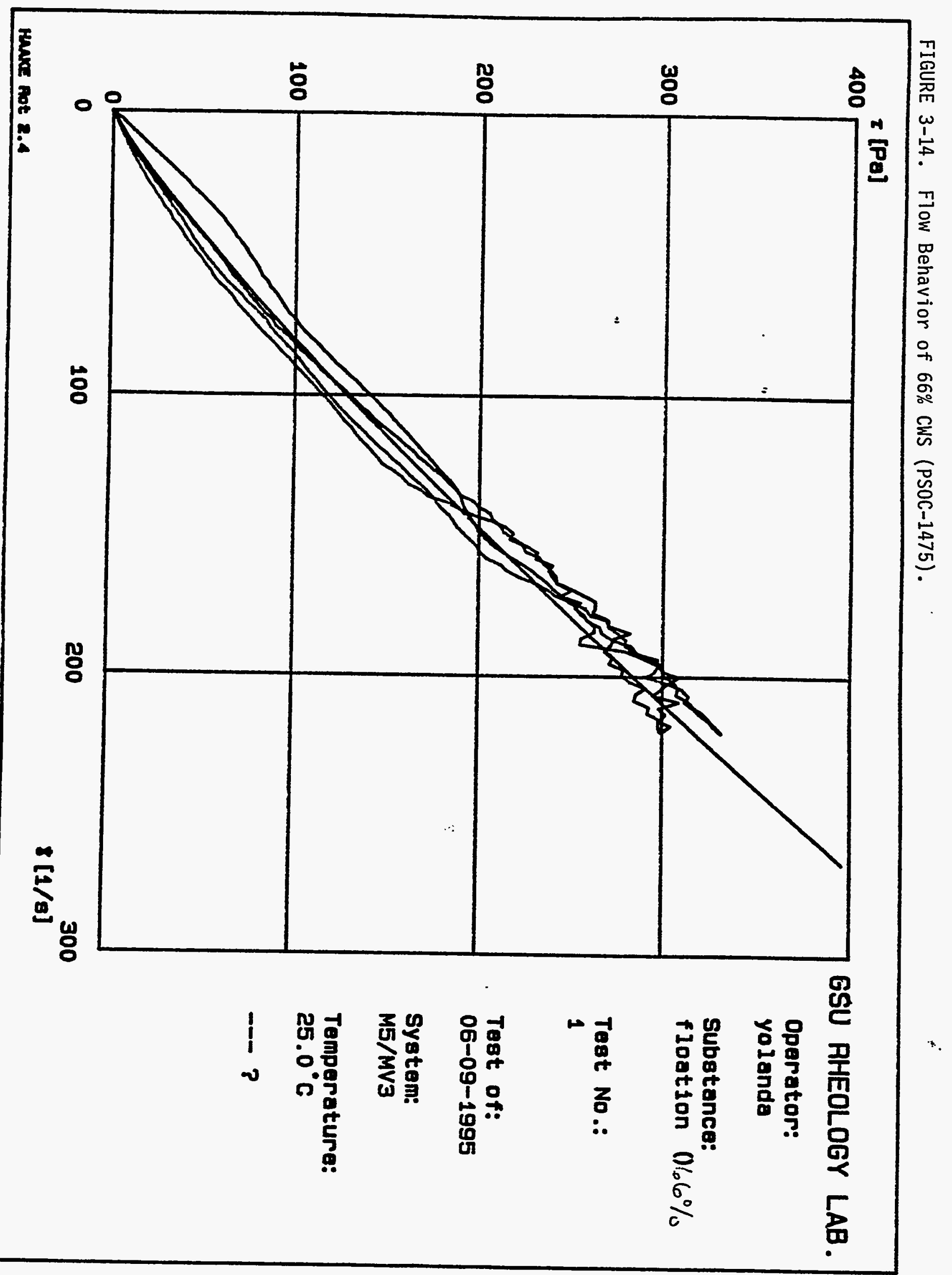


Table 3-2

RHEOLOGICAL PROPERTIES OF CWS (PSOC-1475).

COAL SAMPLE PSOC-1475, $\mathrm{pH}=9.5$

$\begin{array}{lllllcl}\text { Temp } & \mathrm{R}^{2} & \mathrm{n} & \tau_{0} & \mathrm{~K} & \begin{array}{l}\text { Coal } \\ \text { Content (\%) }\end{array} & \begin{array}{l}\eta_{100} \\ \mathrm{mPaS}\end{array} \\ 25 \mathrm{C} & 0.99 & 0.93 & 1.38 & .123 & 55 & 70 \\ 25 \mathrm{C} & 0.95 & 1.02 & 0.3261 & .099 & 56 & 175 \\ 25 \mathrm{C} & 0.96 & 0.94 & 0.774 & .0557 & 57 & 185 \\ 25 \mathrm{C} & 0.95 & 0.86 & 7.42 & .0326 & 58 & 200 \\ 25 \mathrm{C} & 0.98 & 1.10 & .023 & .088 & 62 & 350 \\ 25 \mathrm{C} & 0.99 & 0.93 & 1.38 & .123 & 63 & 495 \\ 25 \mathrm{C} & 0.99 & 1.12 & 0.048 & .123 & 66 & 1365 \\ 25 \mathrm{C} & 0.99 & 1.02 & .023 & .123 & 65 & 670\end{array}$

Table 3-3

RHEOLOGICAL PROPERTIES OF CWS (PSOC-1527)

\begin{tabular}{|c|c|c|c|c|c|c|}
\hline \multicolumn{7}{|c|}{ COAL SAMPLE PSOC-1527, $\mathrm{pH}=9.5$} \\
\hline Temp & $\mathbf{R}^{2}$ & $\mathrm{n}$ & $\tau_{0}$ & $\mathbf{K}$ & $\begin{array}{l}\text { Coal } \\
\text { Content (\%) }\end{array}$ & $\begin{array}{l}\eta_{100} \\
\mathrm{mPas}\end{array}$ \\
\hline $25 \mathrm{C}$ & 0.98 & 0.92 & 0.3261 & .099 & 55 & 75 \\
\hline $25 \mathrm{C}$ & 0.96 & 1.08 & 0.074 & .0557 & 62 & 450 \\
\hline $25 \mathrm{C}$ & 0.95 & 0.86 & 7.42 & .0326 & 59 & 200 \\
\hline $25 \mathrm{C}$ & 0.98 & 1.20 & .797 & .088 & 63 & 211 \\
\hline $25 \mathrm{C}$ & 0.99 & 1.12 & 0.381 & .123 & 63 & 258 \\
\hline
\end{tabular}


Table 3-4

RHEOLOGICAL PROPERTIES OF CWS (PSOC-1472).

COAL SAMPLE PSOC-1472, $\mathrm{pH}=9.5$

$\begin{array}{lllllll}\text { Temp } & \mathbf{R}^{2} & \mathbf{n} & \tau_{\mathrm{o}} & \mathbf{K} & \begin{array}{l}\text { Coal } \\ \text { Content (\%) }\end{array} & \begin{array}{l}\eta_{100} \\ \text { mPas }\end{array} \\ 25 \mathrm{C} & 0.92 & 0.621 & 10.4 & 7.285 & 63 & 1303 \\ 25 \mathrm{C} & 0.92 & 0.578 & 3.92 & 0.635 & 50 & 134 \\ 25 \mathrm{C} & 0.95 & 0.645 & 6.04 & 4.56 & 57 & 381 \\ 25 \mathrm{C} & 0.95 & 0.86 & 7.42 & 5.25 & 58 & 200 \\ 25 \mathrm{C} & 0.98 & 0.643 & 7.55 & 6.38 & 62 & 1221 \\ & & & 46 & & & \end{array}$


The incorporation of the yield stress term in Equation 3-5, was necessary to minimize the error when curve-fitting the equation to the data. When the yield stress was not included (Equation 3-4), the curve-fit was forced to predict a zero shear stress at a zero strain rate which produced a poor fit. Unfortunately, the magnitude of the yield stress varied from one mixture to the next with no consistency between the different formulations of the Coal-water slurries. It was therefore, concluded that the instrumentation could not accurately measure the yield stress, but that the analysis could not accurately predict $\mathrm{n}$ and $\mathrm{K}$ without it. As a result, yield stress values were used to facilitate curve fitting but were considered unreliable for analyzing the subsequent spray data.

Com Syrup and glycerol solutions as well as, glycerol-xantham gum solutions were used as model Newtonian and non-Newtonian liquids. The low shear behavior of some of these solutions generated in our viscometer are as shown in Figures 3-15 through 3-18 and the viscosities are listed in Tables 3-5 , 5-1 and 5-2. The corn syrup was purchased from a local supermaket and the Glycerol was obtained from Aldrich Chemical Co. Milwaukee, WI). Newtonian liquids of high viscosity were formulated for use in this study by decanting a known volume of either the glycerol or the corn syrup and then diluting it with distilled water until the desired composition was obtained. Homogeneity was insured by agitating the mixture with a stirrer (Eberbach Corporation, Ann Arbor, Mi., propeller driven by a Bodine Electric Motor, type NS1-12, Chicago, III). After complete mixing was obtained, the surface tension and rheological measurements were made. 


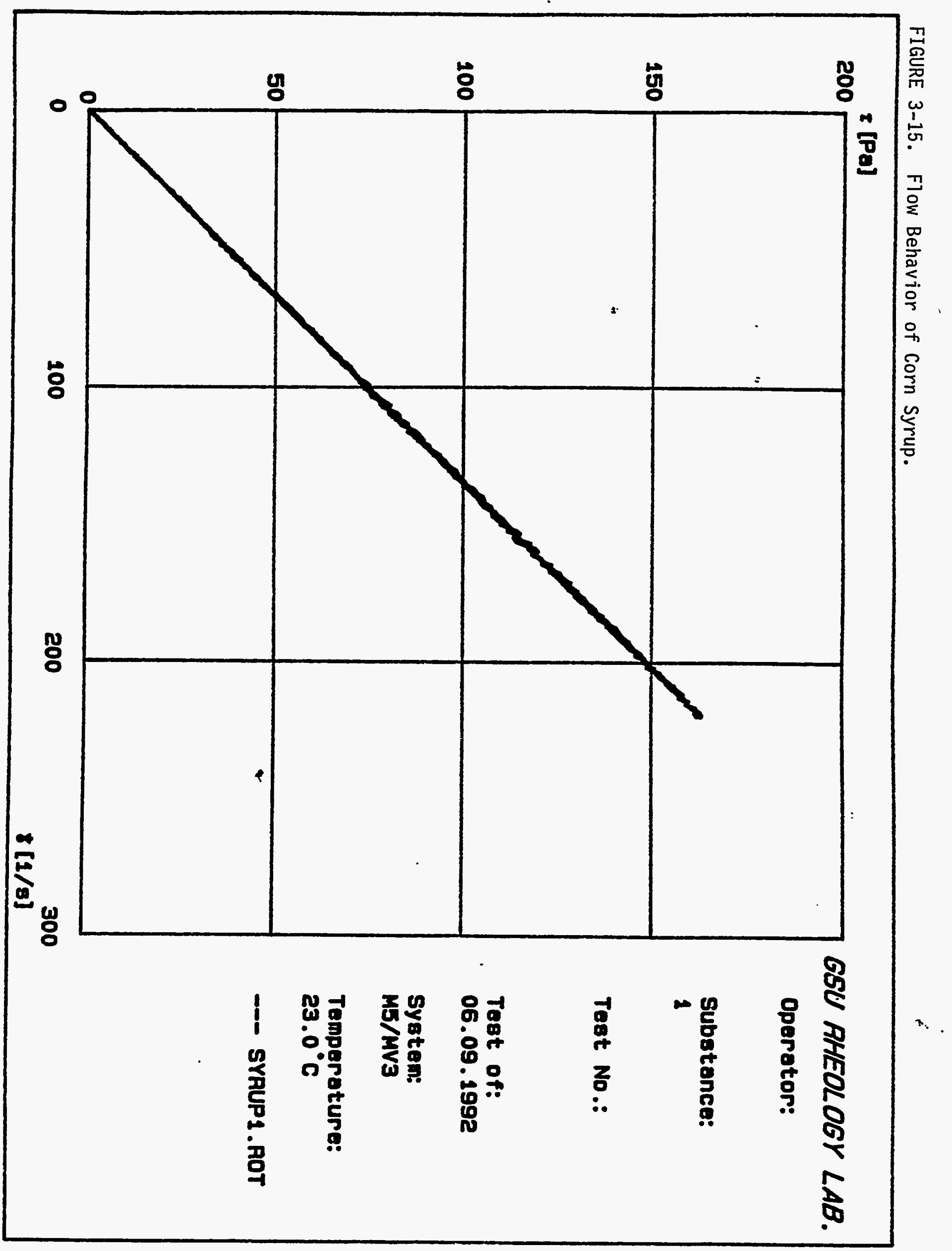




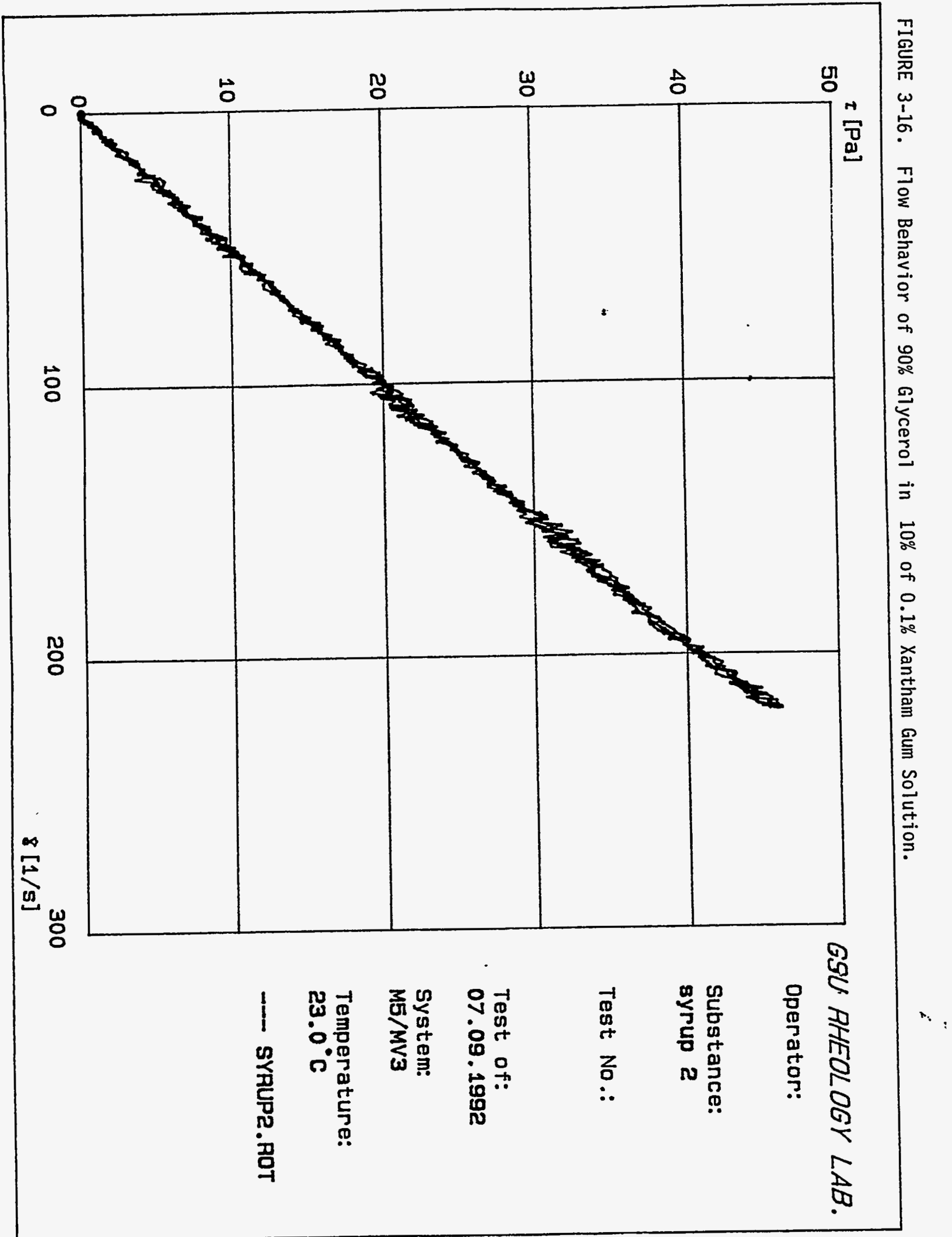


FIGURE 3-17. Flow Behavior of $80 \%$ Glycerol and $20 \% 0.1 \%$ Xantham Gum Solution.

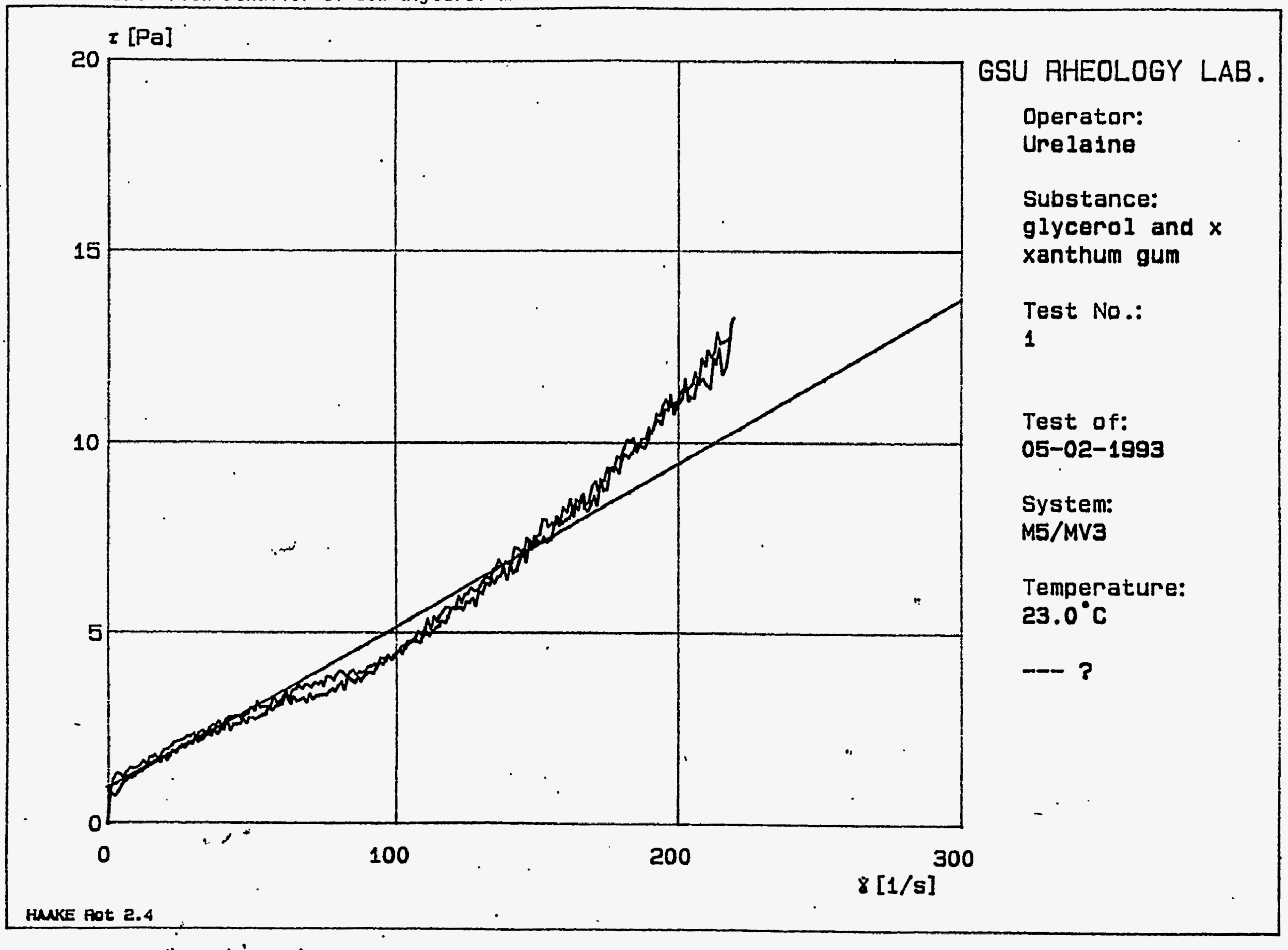




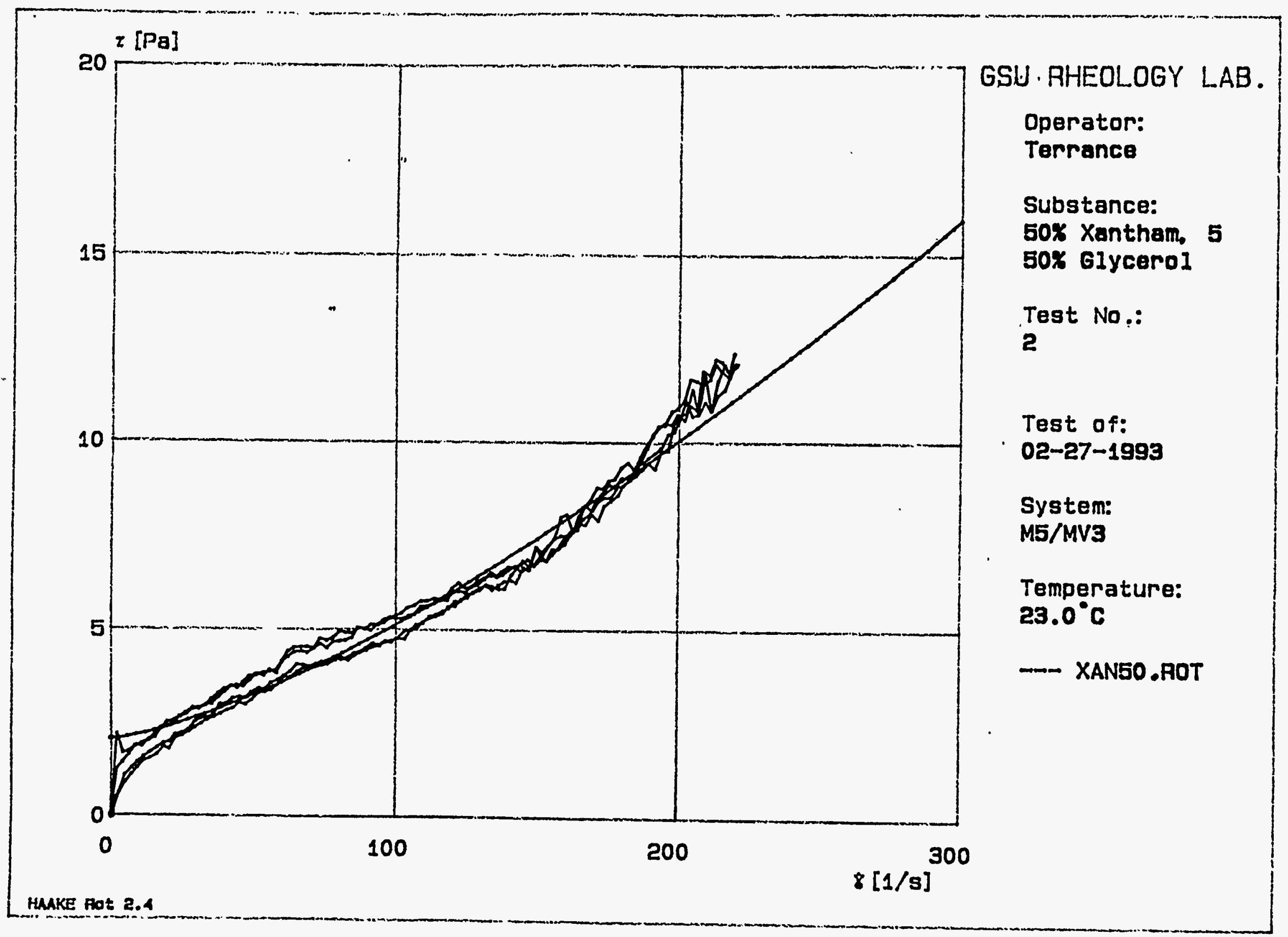




\section{3-14 Surface Tension Measurements.}

Surface tensions was measured by using a du-Nuoy type ring tensiometer (Fisher Model 21). The tensiometer was calibrated by placing known weights (as determined by a Mettler $P 400$ balance) on the instrument's Pt-Ir ring and measuring the resulting gravitational force. The instrument's performance was verified by determining the surface tension of de-ionized water. Excellent agreement was obtained between the measured value and the literature value of 72 dynes $/ \mathrm{cm}$. After each measurement, the Pt-Ir ring was washed in a water bath, dipped in alcohol, and heated thoroughly over a bunsen burner flame before the next measurement.

Table 3-5 and Tables 5-1 through Table 5-9 list the surface tension data obtained for the simulated fluids as well as the CWS studied. The data indicate that the surface tension decreases as the percent amount of either the glycerol or the corn syrup decreases. The surface tension data for the formulated Newtonian fluids are however, lower than the corresponding values for the glycerol-xantham gum solutions.

\section{3-15 Viscoelastic Behavior of CWS}

Viscoelastic studies were performed using the RV20-CV20 with PQ45 sensor in order to investigate the relationship between interparticle structure and the relationship to rheological behavior. The viscoelastic behavior was determined in an oscillatory mode. The linear viscoelasticity was measured by subjecting the sample through a small amplitude oscillatory test. Measurement of the phase difference between the shear stress and strain and the amplitude ratio of the stress and strain wave forms, allowed the viscoelastic behavior of the CWS as a function of frequency to be determined. Figure 3-19 shows plots of storage modulus as a function of frequency for 56\% CWS prepared from PSOC-1527, 1472 and 1475. Also, Figure 3-20 shows 


\section{Table 3-5}

Physical Data For the Corn Syrup Solution.

\begin{tabular}{lrcl}
$\begin{array}{l}\text { Corn Syrup } \\
\text { Concentration(\%) }\end{array}$ & \multicolumn{1}{l}{$\begin{array}{l}\text { Density } \\
(\mathbf{g m} / \mathbf{m L})\end{array}$} & $\begin{array}{c}\text { Surface Tension } \\
\text { (dynes/cm) }\end{array}$ & $\begin{array}{l}\text { Viscosity } \\
(\mathbf{m P a} . S)\end{array}$ \\
100 & 1.37 & 80.64 & 750 \\
90 & 1.31 & 76.1 & 234 \\
80 & 1.26 & 73.8 & 196 \\
70 & 1.23 & 70.9 & 103 \\
60 & 1.19 & 59.8 & 72.4 \\
50 & 1.14 & 53.4 & 45.2 \\
30 & 1.08 & 51.2 & 34.2
\end{tabular}


G' [Pa]

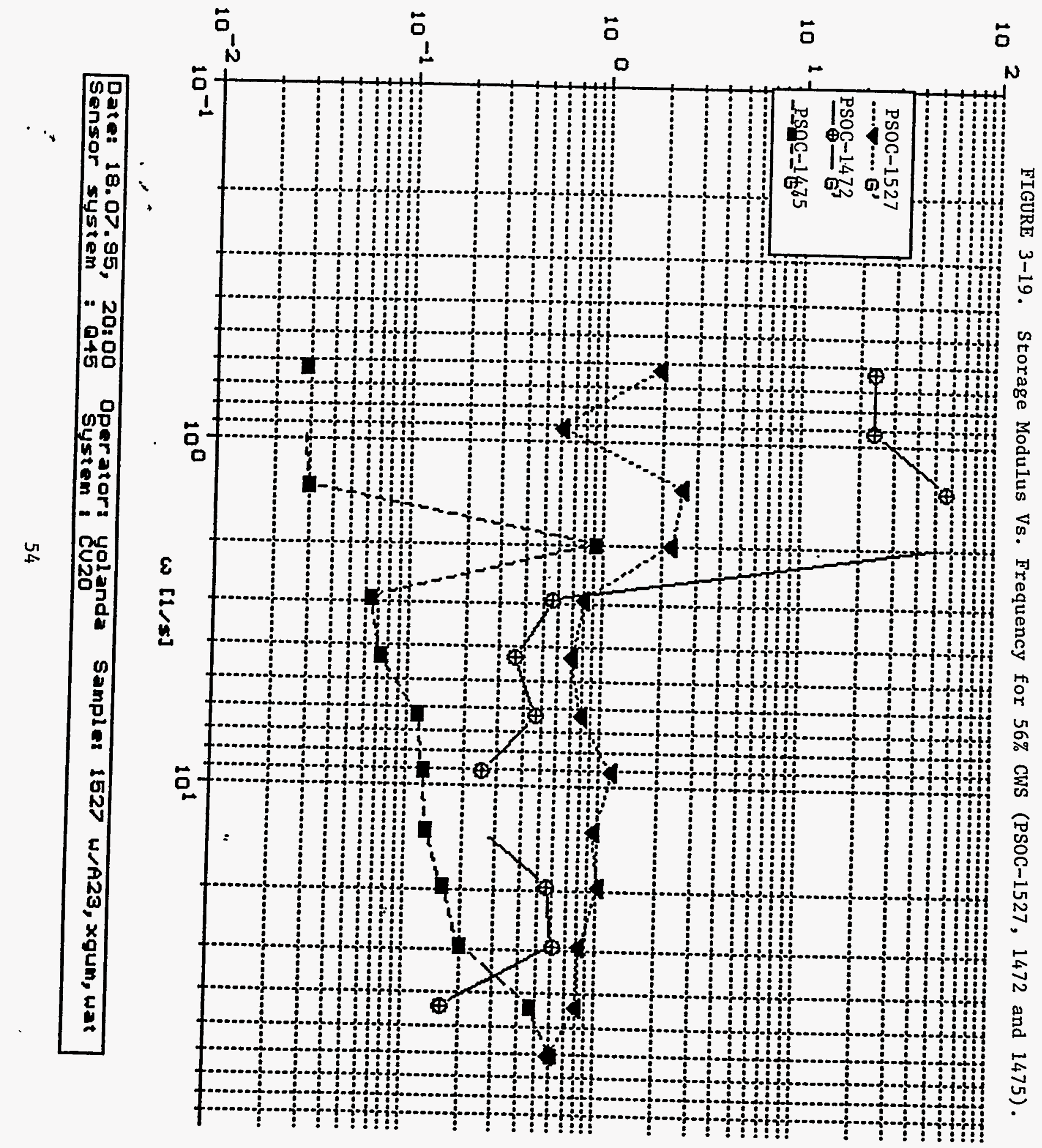




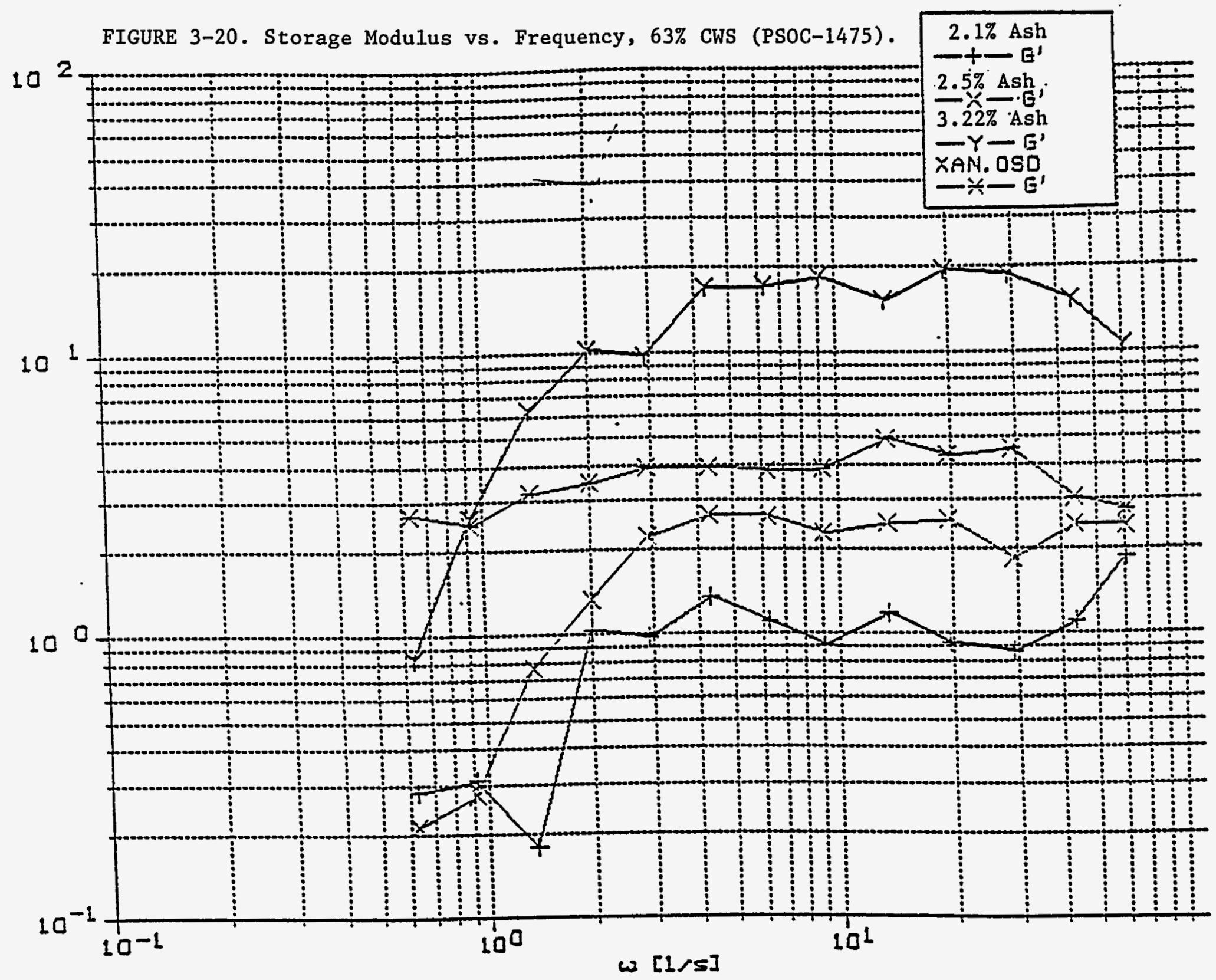

Dava: 29.07.53, 03:07 Operator: Sumple:
Sensor sustem : 045 Sustem : cuzo 
the storage modulus as a function of frequency of different formulations of Elkorn \# 3 CWS samples. These samples varied in their ash content. The data indicate that the slurry which contained the highest amount of ash content, had the highest storage modulus.

The HVA-6 Capillary Viscometer was used to determine the dynamic flow rates of the slurries. The HVA-6 automated high shear viscometer (Figure 3-21) permits measurements from low to high flow rates. Capillary tubes of diameters $0.8 \mathrm{~mm}, 1.5 \mathrm{~mm}$ and $3.0 \mathrm{~mm}$ and $100 \mathrm{~mm}$ in length were used in these measurements. In this device, the sample to be measured is forced through a capillary tube at definite pre-adjusted pressure and pressed into a burette where the flow rate is measured.

\section{3-16 Results of High Shear Rheological Measurements}

Figures 3-22 and 3-23 are the plots of the simulated Newtonian and non-Newtonian samples ( $0.1 \%$ xantham gum solution), and Figures 3-24 and 3-25 show plots of the variation of viscosity as function of shear rate. The xantham gum solution exhibited turbulence over the shear rate regime investigated. This was accompanied by abrupt changes in viscosity within the shear rate regime of 100,000/s (Figure3-25). Comparison of the data in Figures 3-26 and 3-27 show that, the addition of more than $0.1 \%$ amount (coal weight) of xantham gum to stabilize the CWS results in the flow behavior changing from Newtonian to Dilatant behavior. This change in flow behavior is also accompanied by changes in viscosity in the neighborhood of 100,000/s (Figures 3-28 and 3-29).

Comparison of Figures 3-26 and 3-30, reveal that the flow behavior of all the CWS samples having soilids concentration of less than $63 \%$ solids with less than $0.1 \%$ (coal weight) xantham gum were all Newtonian in the high shear rate regime when a capillary size of $0.8 \mathrm{~mm}$ 


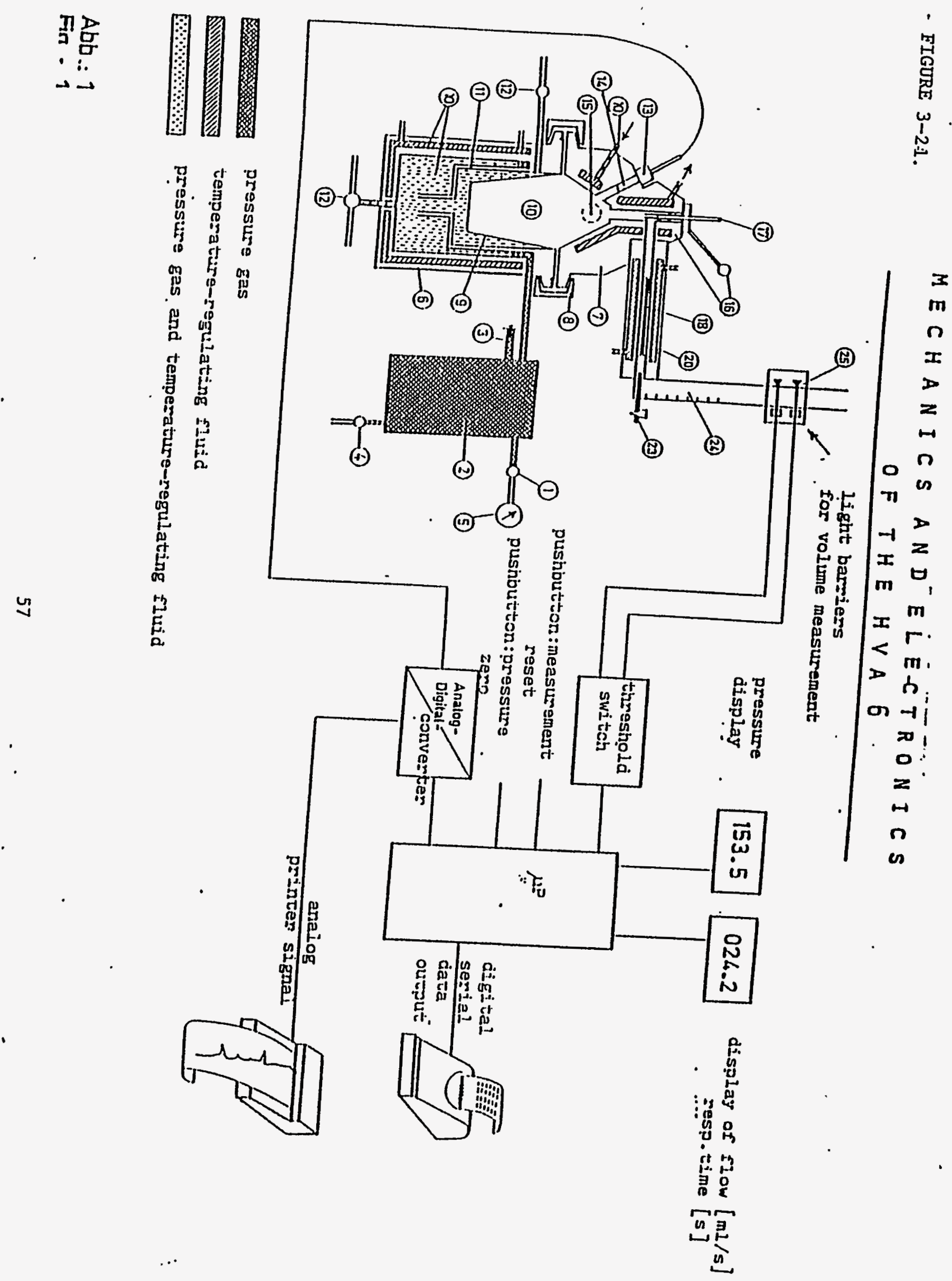


FIGURE 3-22. High Shear Flow Behavior of Glycerol Solution.
* * *
A P PAAR
$H V A-6$
$* * *$

Ig TN Pa.s)

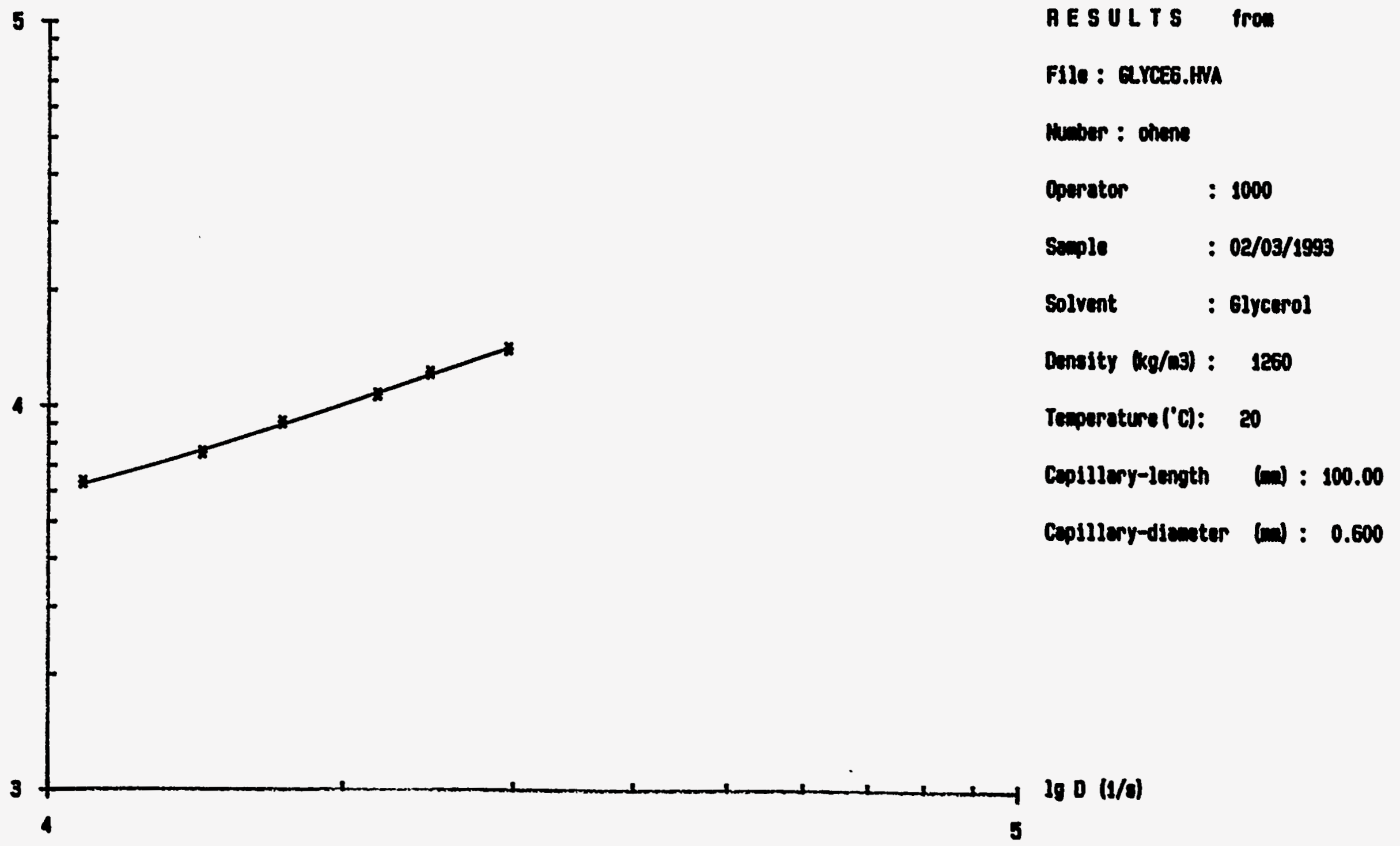




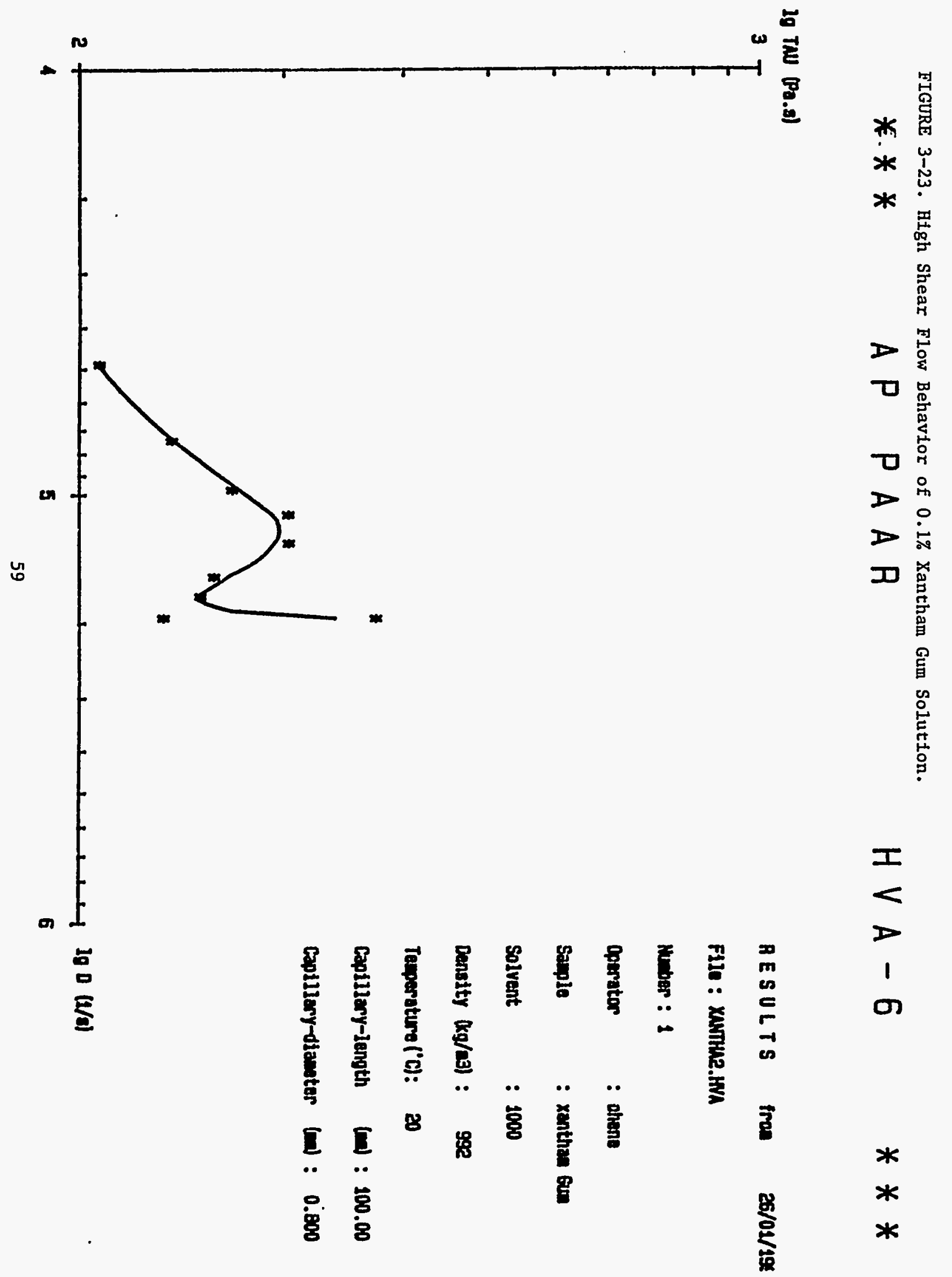


FIGURE 3-24. High Shear Viscosity of Glycerol As a Function of Shear Rate.
* * *
A P PA A R
$H \vee A-6$
***

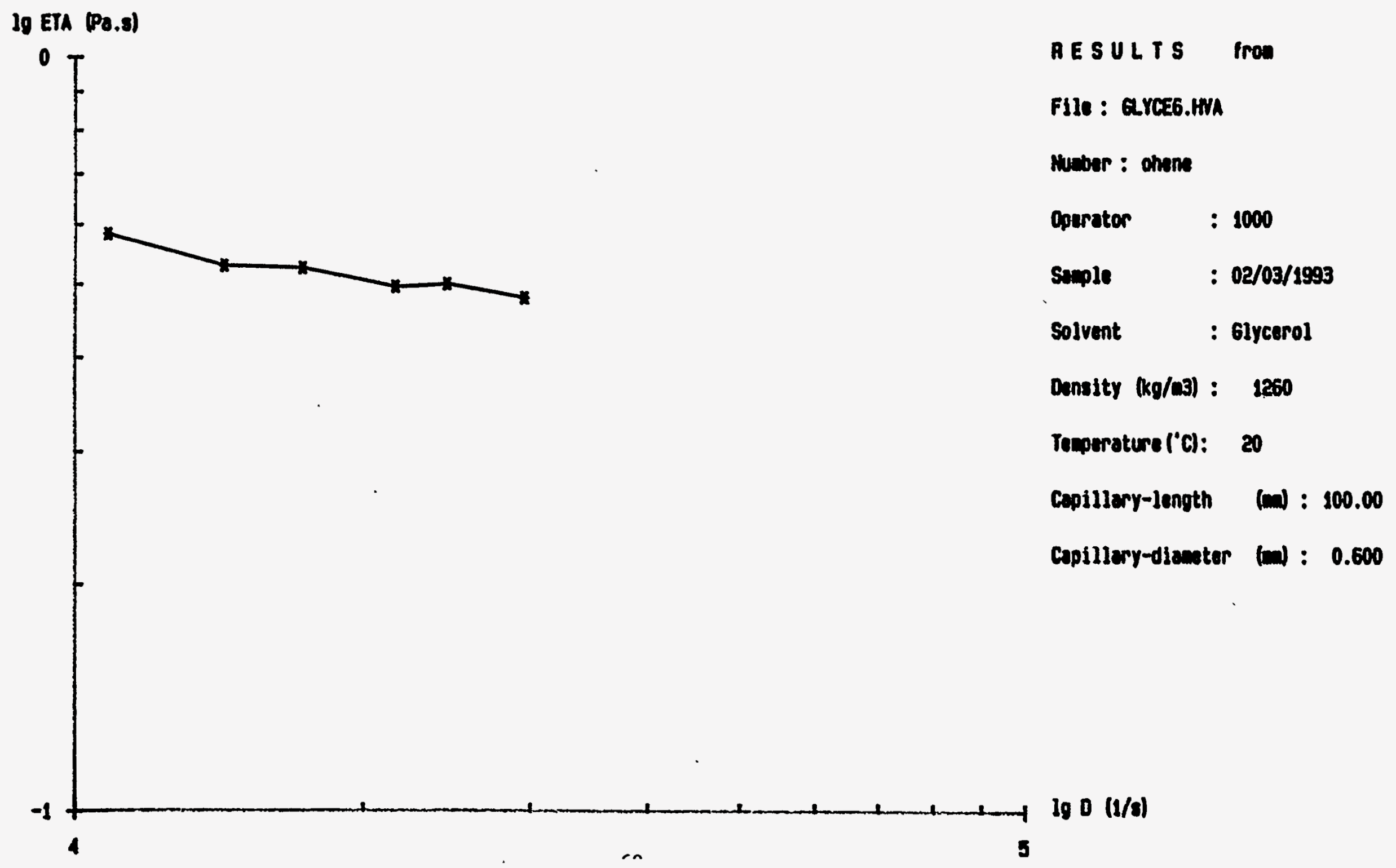




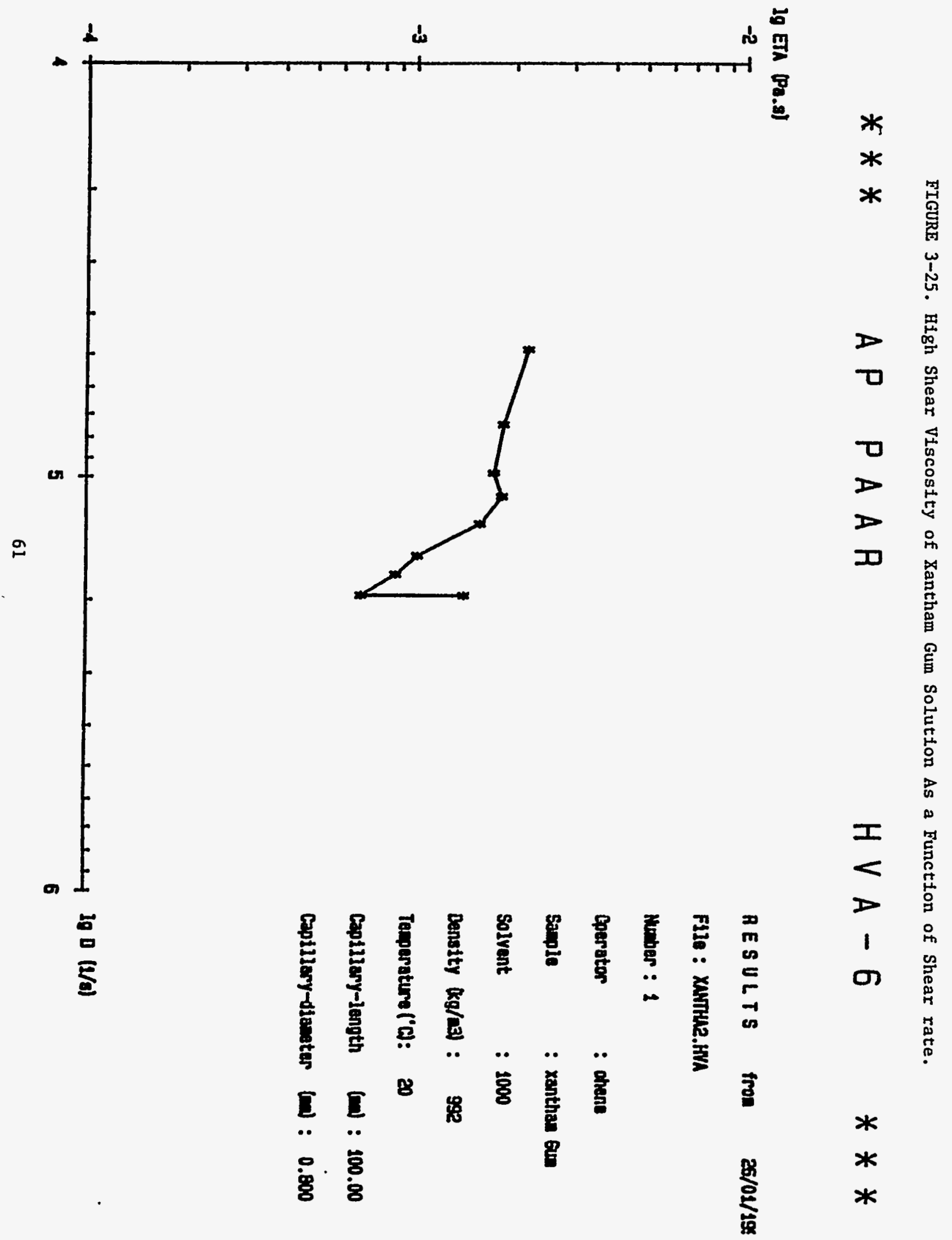


FIGURE 3-26. High Shear Flow Behavior of $63 \%$ CWS (PSOC-1475)

*** AP PAAR

\section{lg TAN (Po.s)}

5

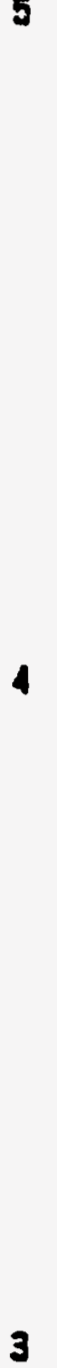

3

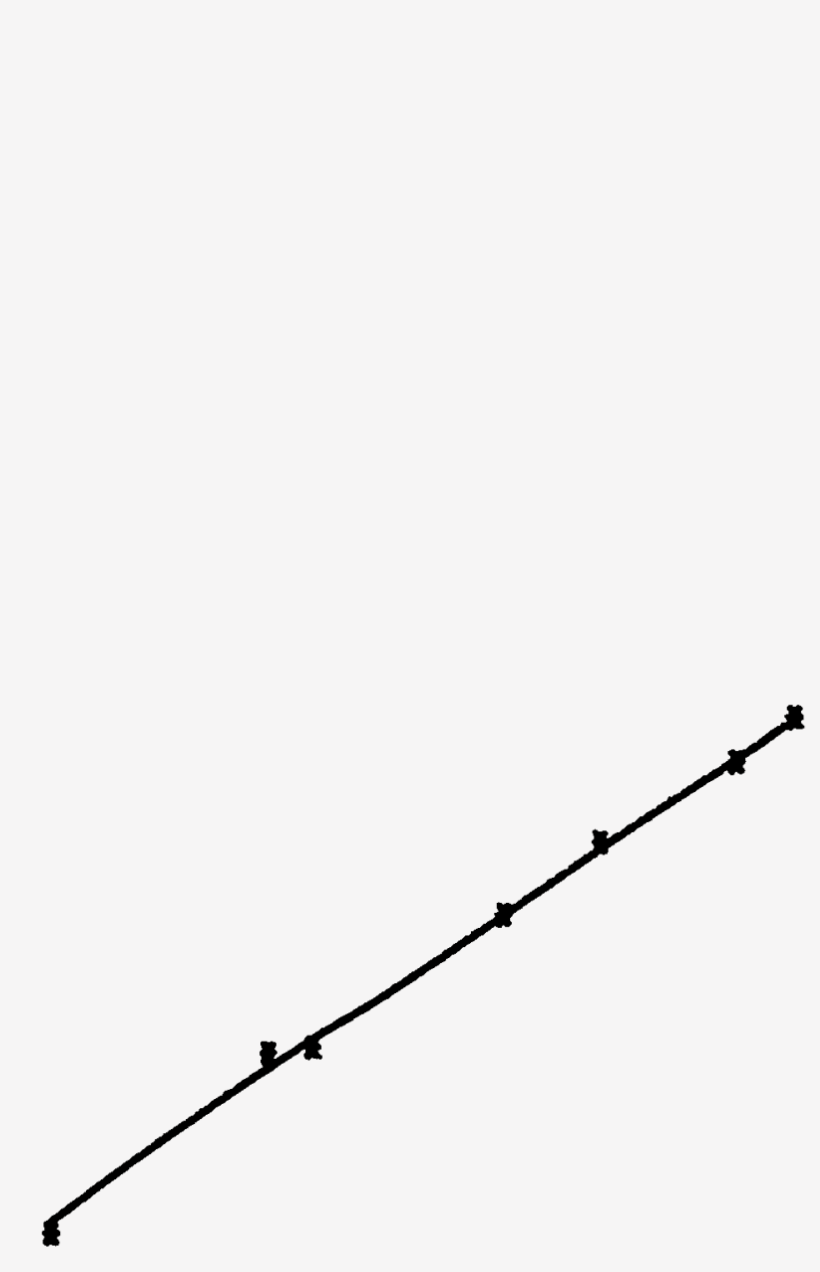

$H \vee A-6$

$* * *$

File : 75Y18.hWA

Number: 1

Operator : yolanda

Samplo : 1475 .

Solvent $\quad: 1000$

Dunsity $\mathrm{Mg} / \mathrm{na}): 1180$

Toperature ('Cl: 25

Capillasy-length (n): 100.00

Capll1ary-diantor (n) : 1.500 


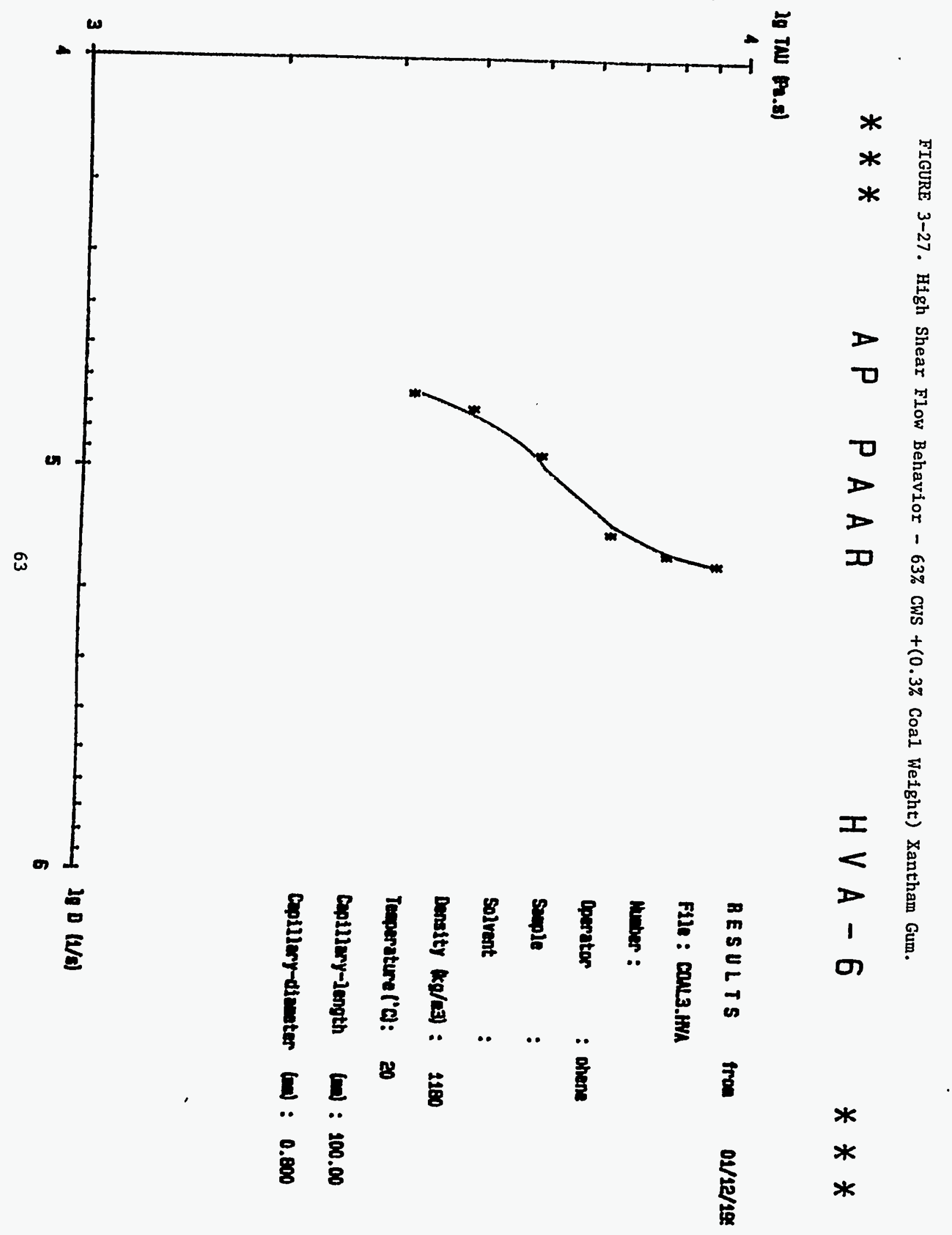




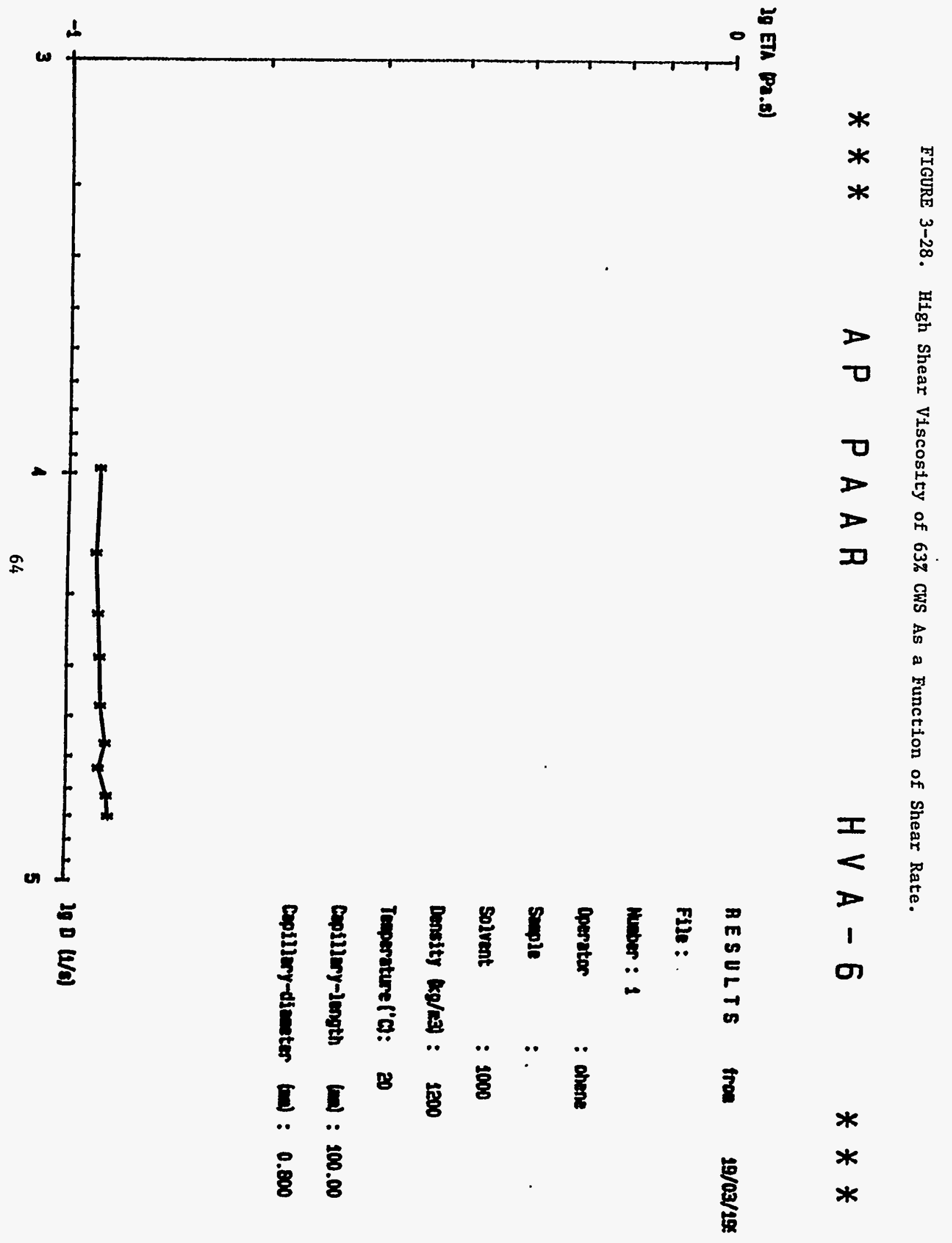




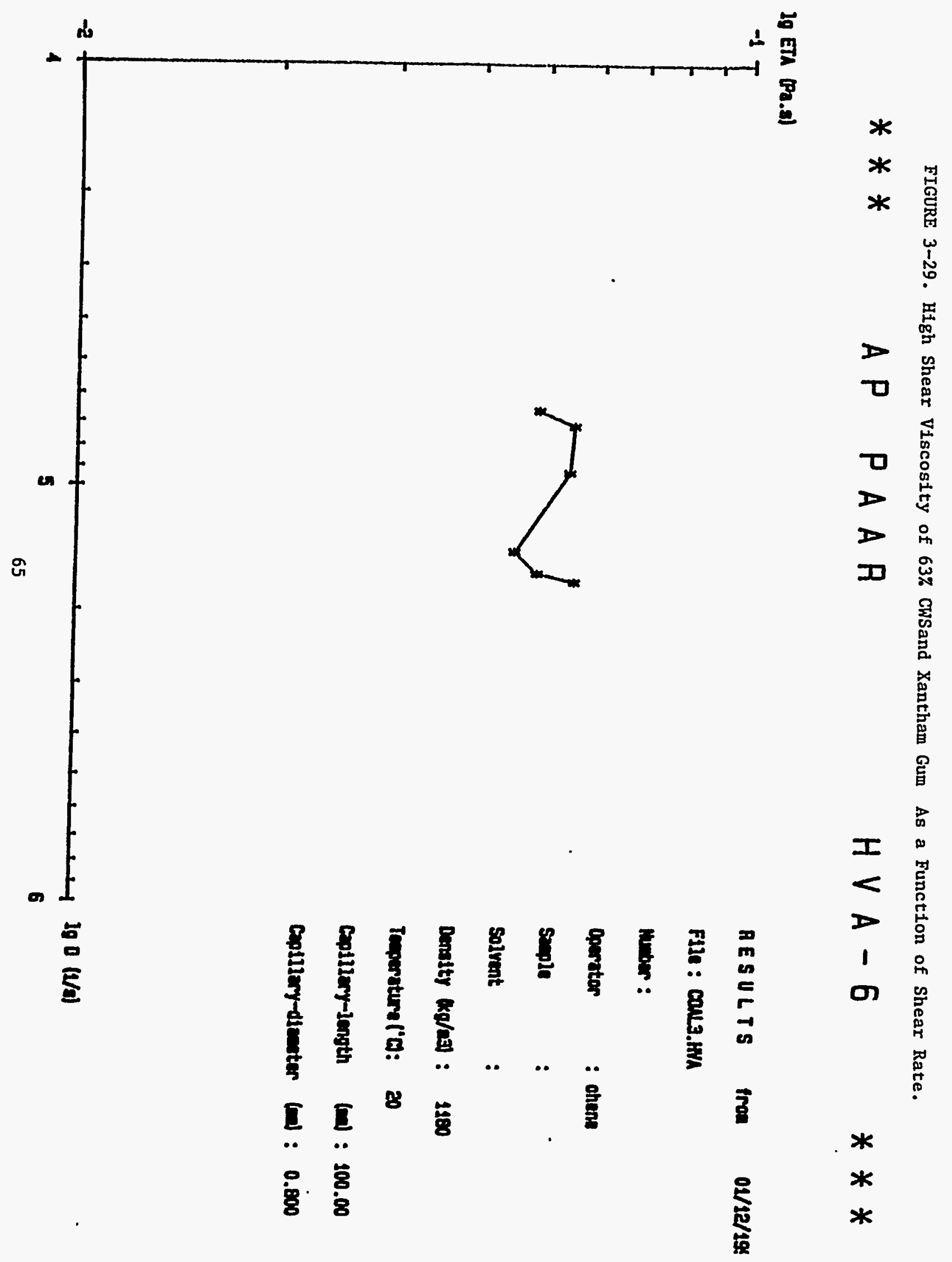




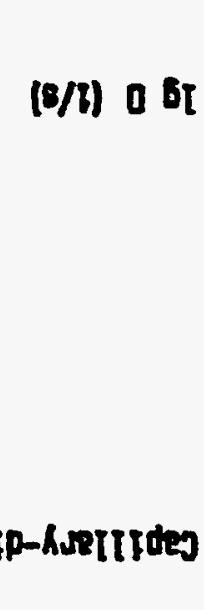

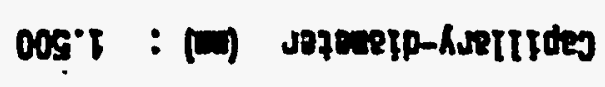

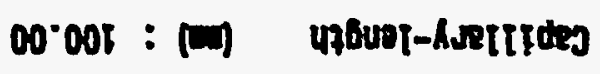

$\infty \quad:$ : 0.1 empesadel

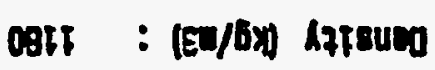

0001 : $\quad$ zuentos

sent : volus

epretol : Jozededo

Q9: : arqun

vareance : otfd

i65/50/92 woJ $517 n 534$

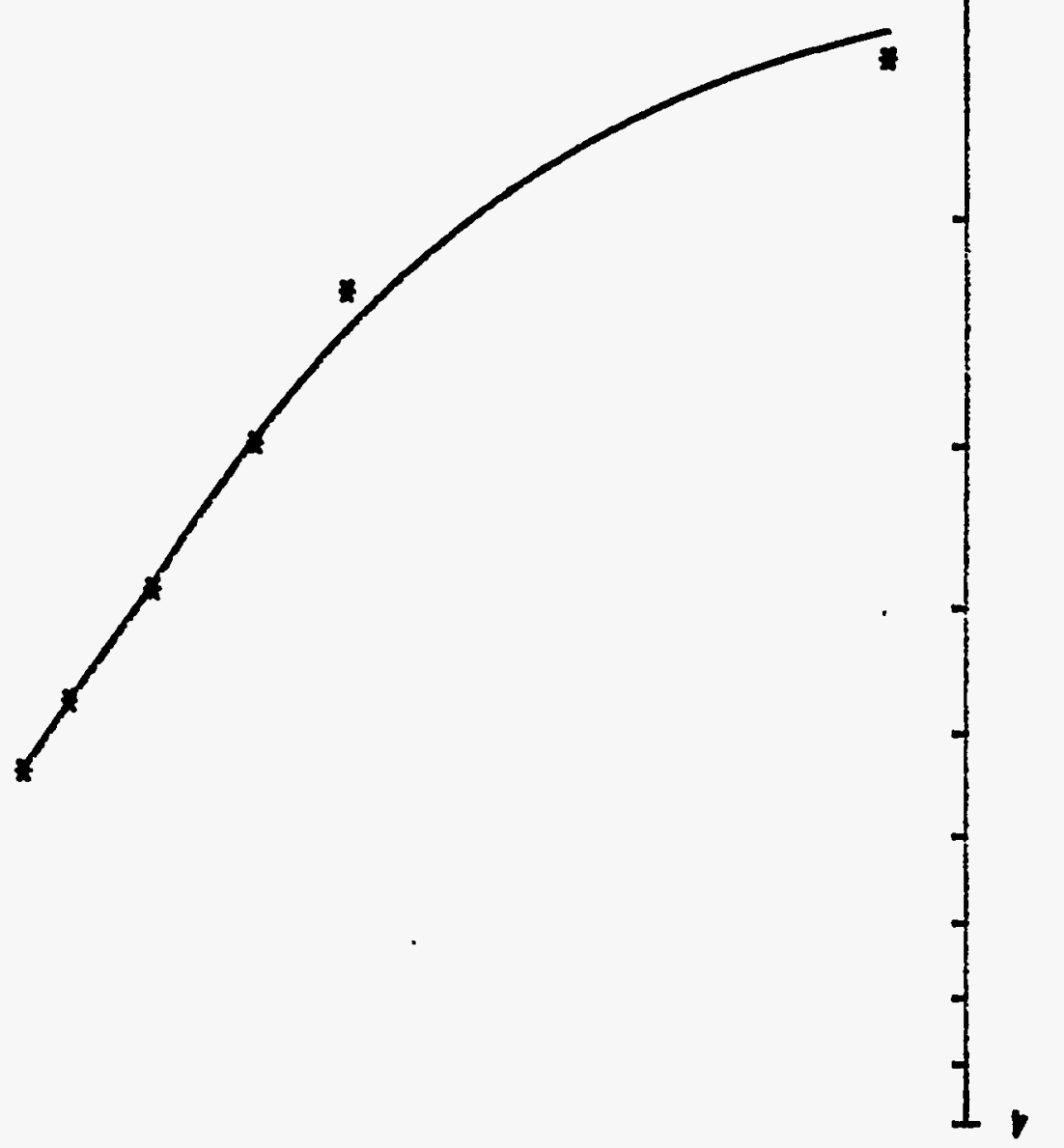

(8.8) $\mathrm{ML}$ bI
$* * *$
$9-\forall \wedge H$
$\forall \forall \forall d \quad d \forall$
$* * *$

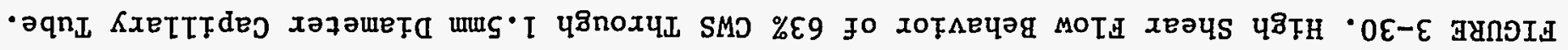


diameter and $100 \mathrm{~mm}$ in length was used. There is however, deviation from Newtonian behavior when the capillary tube is increased (Figures 3-30). This is due to the higher shear rates that can be obtained by using the smaller capillary tube diameters.

It is also important to analyse slippage in the capillary flow. Thus, an approach based on the method of Lupton and Regester [31] was used. The apparent wall stress at the wall can be expressed as:

$\frac{1 Q}{\pi R^{3}}=4 V_{R} \cdot \frac{1}{R}+\frac{4}{\tau_{10}^{3}} \int_{\tau}^{\tau_{1}} \tau^{2} \gamma d \tau$

Figure 3-31 is a plot of the apparent shear rate as a function of the reciprocal radius (1/R) at a fixed shear stress of 3,000 Pa. The lack of a horizontal line indicate the presence of slip at the capillary wall.

Figure 3-32 compares the high shear flow behavior of the three different slurries whose viscoelastic behavior is shown in Figure 3-20. All the slurries exhibit identical flow behavior in the high shear flow regime. Comparison of this data with that in Figure 3-20, indicate that the viscoelastic measurements are able to delineate any significant differences in the rheological behavior and that these differences are leveled off in the high shear rate regime.

The contraction flow method of determining extensional properties was applied to determine the extensional viscosity. Specifically, the test fluid was forced to flow under pressure from a larger tube into a smaller tube of fixed diameter, $(0.8 \mathrm{~mm})$ and varying length, $(10 \mathrm{~mm}$, $50 \mathrm{~mm}$ and $100 \mathrm{~mm}$ ), in the HVA-6 capillary viscometer. A plot of Pressure as a function of L/D, and extrapolating to $\mathrm{L}=0$ allowed the Bagley correction [30] to be made and thus, the extensional viscosity to be determined. The data obtained were, found to be unreliable since it was difficult to reproduce the results of the measurements. The data obtained was therefore not utilized in subsequent analysis of the atomization data. 
Figure 3-31. Analysis of Slippage in a Capillary Flow. Constont Shear Stress of 3,000 Pa.

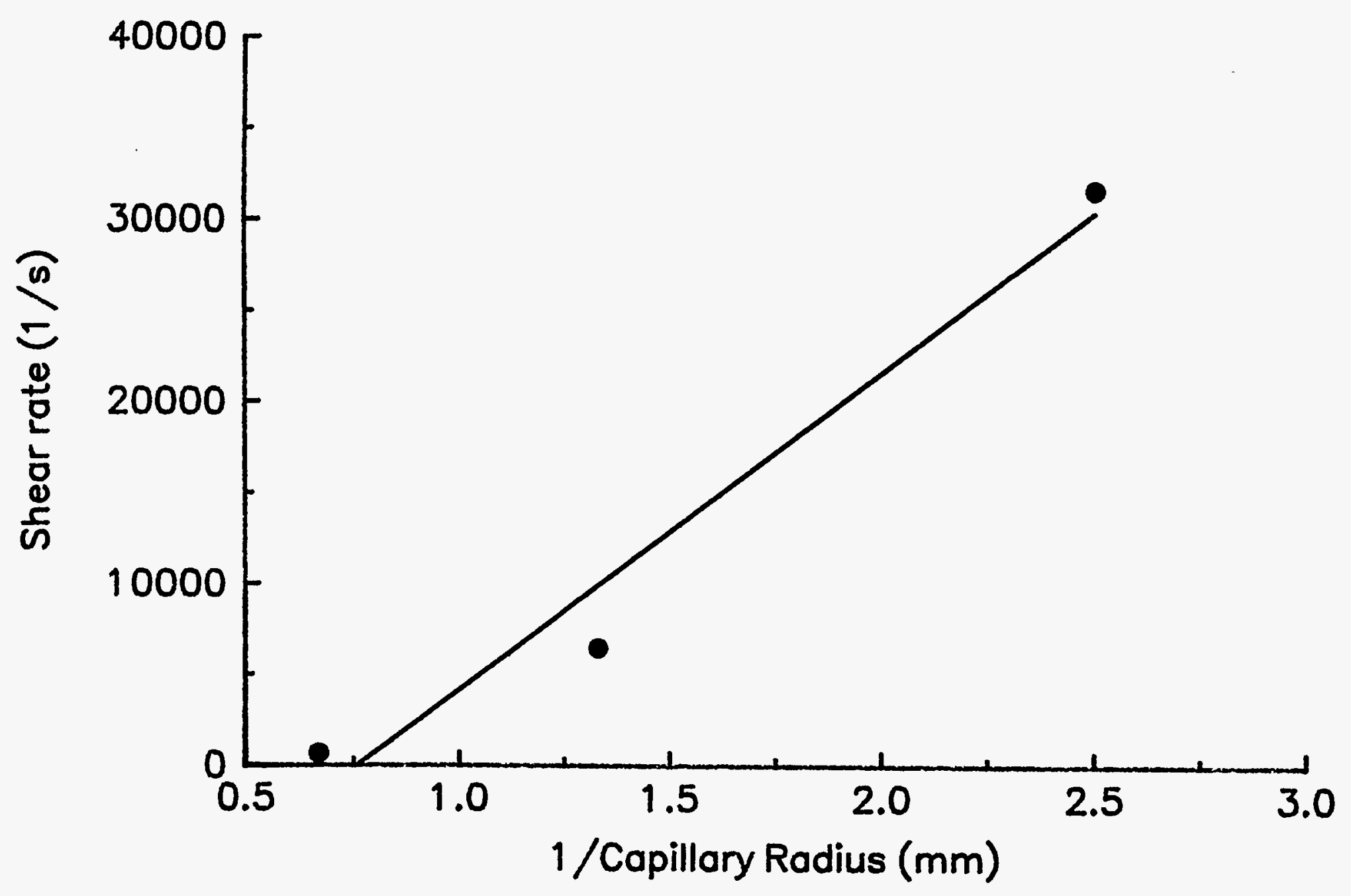




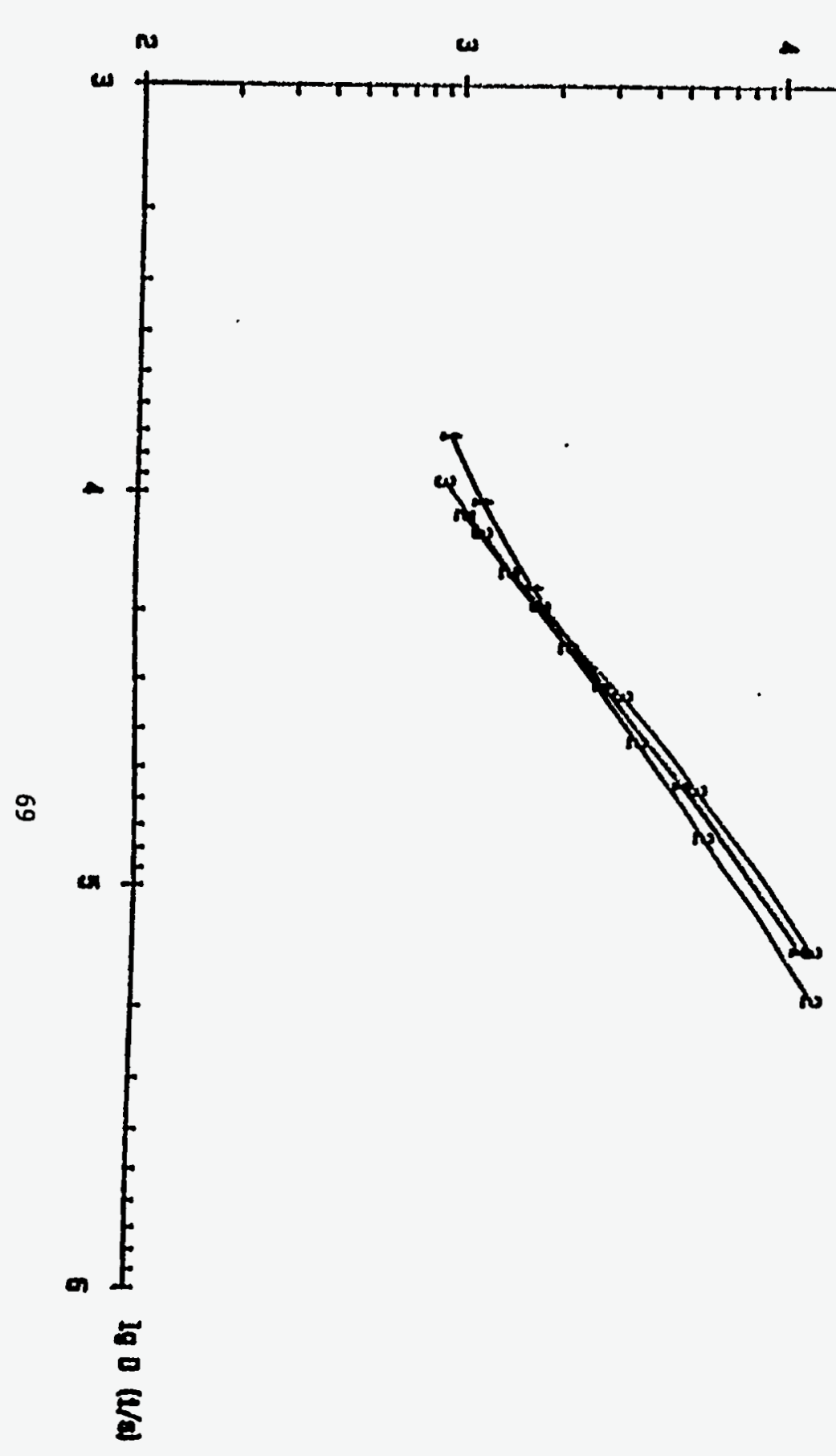




\section{CHAPTER 4}

\section{Atomization Studies}

\section{4-1 Summary of Atomization Experimental Set-up}

This section explains in detail the operation of the atomizer and experimental apparatus as well the operation and calibration of the instrumentation used to acquire the atomization data. The description of the nozzle begins at the liquid and air inlets and proceeds to the final orifice. It includes descriptions of the various components and the flow path of the fluids. The description of the experimental apparatus begins with the air and fuel supply systems and ends at the nozzle inlets. The systems used to analyze the spray are than described and the theory behind their operation summarized. Equipment calibration procedures are also included.

\section{4-2 Flow Pattern Exiting The Nozzle}

During operation, it was often important to determine the two-phase flow pattern exiting the nozzle. Experiments were therefore, conducted for coal-water slurry flows in a series of horizontal capillary tubes of diameters $0.8,1.5$ and $3.0 \mathrm{~mm}$ and $100 \mathrm{~mm}$ in length, in order to simulate the effect of concentration, pressure drop, and the transitional Reynolds number from laminar to turbulent flow for the two-phase flow pattern existing the nozzle.

The analysis of flow characteristics of coal-water slurries can go through different grades of complexity depending on the concentration profile of the dispersed phase, the rheological properties of the system and on the intensity of the flow $[32,33]$.

The flow of a slurry can be influenced by several factors including drag, turbulence, the particles free fall velocity, particle-particle interaction, and the rheological properties of the carrier 
fluid [34 ]. Although a large number of experimental investigations have been conducted for the determination of one more of these effects, the complexity of the two-phase flow, limit the ability to describe the exact flow behavior for such systems [35 ].

Although many numerical models have been developed for multiphase flow, their application is still very limited, The dependence of empirically-determined stress expressions are not very clear due to lack of complete elucidation of the mechanism of the complex flow through numerical modeling [36].

In this work, the coal concentration was varied from $15 \%$ to $63 \%$ in $0.1 \%$ xantham gum solution. Pressure drop and the volume flow measurement were made using HVA-6 Capillary viscometer. The experimental parameters were chosen in order to emphasize the effect of turbulence, so as to allow the determination of possible transitional Reynolds number from laminar to turbulent flow.

The HVA-6 Capillary Viscometer was used to determine the flow rates of the slurries. The HVA-6 automated high shear viscometer permits measurements from low to high flow rates. Capillary tubes of diameters $0.8 \mathrm{~mm}, 1.5 \mathrm{~mm}$ and $3.0 \mathrm{~mm}$ and $100 \mathrm{~mm}$ in length were used in these measurements. The exit samples were collected and the coal content determined at each applied pressure.

The pressure drop in slurry flows is a key design parameter since it governs the pumping power required to move the slurry through the system. The change from laminar to turbulent flow results in a change in the flow resistance or friction loss. The prediction of the transition from laminar to turbulent flow can be inferred from the variation in the friction factor, which is 
dependent on the pipe diameter, the rate of flow, the length of the pipe, and the acceleration due to gravity.

In a horizontal flow, the actual deposition of the suspended particles is determined by the competing effects of gravity, particle-particle interaction and the rheological properties of the carrier fluid. As a result, either concentric or eccentric plug flow may result.

The CWS utilized in this work followed either the Power law or the Herschel- Bulkley model (Figure 3- 1). The power law and the Herschel-Buckley models can be represented by: $\tau=k \gamma^{n}$ ( Power Law Model)

where $\mathrm{k}$ and $\mathrm{n}$ are rheological constants, and $\tau$ and $\gamma$ are the shear stress and shear rate respectively.

For slurries whose properties are time independent, the dependence of the shear stress $(\tau)$ on the shear rate $(\gamma)$ can be expressed as $\gamma=f(\tau)$. The distribution of velocity in the radiant direction and the relation between volumetric flow rate, $Q$ and loss of pressure $\Delta P$, can be easily obtained through Rabinowitsch's Equation [37].

$\frac{Q}{\pi R^{3}}=\frac{1}{\tau_{\omega}^{3}} \tau_{0}^{\tau_{\omega}} \tau^{2} f(\tau) d \tau$

Where $\tau_{\omega}$ is the wall stress.

For a fluid described by the Herschel-Bulkley model,

The Constitutive Equation is [38]

$\gamma=\left\{\begin{array}{c}0 \text { when } \tau<\tau_{o} \\ {\left[\frac{\tau-\tau_{o}}{k}\right]^{c} \text { when } \tau>\tau_{0} \text { and } c=\frac{1}{n}}\end{array}\right\}$

From the equation of force equilibrium on a cylindrical element given the radius, $r$ and length, $L$, the shear stress, is:

$\tau=r \frac{\Delta P}{2 L}$

By substituting equation (4-5) in equation (4-4), we obtain

$\tau=\left\{\begin{array}{c}0 \text { when } r<r_{p} \\ \Gamma\left(\frac{\Delta P}{2 L}-\tau_{o}\right)^{c} \text { when } r>r_{p} \text { where } \Gamma=(1 / k)^{c} \text { and } r_{p}=\frac{2 L}{\Delta} \tau_{o}\end{array}\right\}$ 
By integration of equation (4-6), with the boundary conditions

$$
\int_{0}^{U} d u=-\Gamma \int_{R}^{r}\left(r \frac{\Delta P}{2 L}-\tau_{0}\right)^{c} d r
$$

$\mathrm{U}(\mathrm{R})=0$, gives the velocity profile.

$$
U(r)=\frac{\Gamma}{c+1} \frac{2 L}{\Delta P}\left\{\left(R \frac{\Delta P}{2 L}-\tau_{o}\right)^{c+1}-\left(r \frac{\Delta P}{2 L}-\tau_{o}\right)^{c+1}\right.
$$

Near the pipe axis, where $\tau<\tau_{o}$ the slurry displacement can be treated as a solid plug with radius $r_{p}$. By substituting the value of $r_{p}$ in the above equation, we obtain the plug velocity as:

$U_{p}=\frac{\Gamma}{c+1} \frac{2 L}{\Delta P}\left(R \frac{\Delta P}{2 L}-\tau\right)^{C+1} ; \tau_{\infty}=R \frac{\Delta P}{2 L}$

Figure 4-1 compares the flow curves of the slurries studied, and Tables 4-1 through 4-5 list the experimental data obtained. The data show a transitional Reynolds number of 1500 . The results indicate that the turbulence intensity is damped as the solids concentration increase.

The coal content in the exit slurry at each applied pressure did not differ significantly from the initial slurry concentration. This suggests a concentric flow through the capillary tubes.

Increasing the applied pressure increases the flow rate and thus, the kinetic energy. For slurry concentration greater than $25 \%$ solids, the effect of increasing the initial applied pressure had no significant effect on the Reynolds number. This effect is however, pronounced in slurries having solids concentration less than $20 \%$ solids. The effect of increasing the capillary size, for the high solids concentration slurries, had no significant effect on the Reynolds Number.

This is an indication that within the solids concentration regime employed in this study, the flow pattern exiting the nozzle could be described as concentric plug flow. 


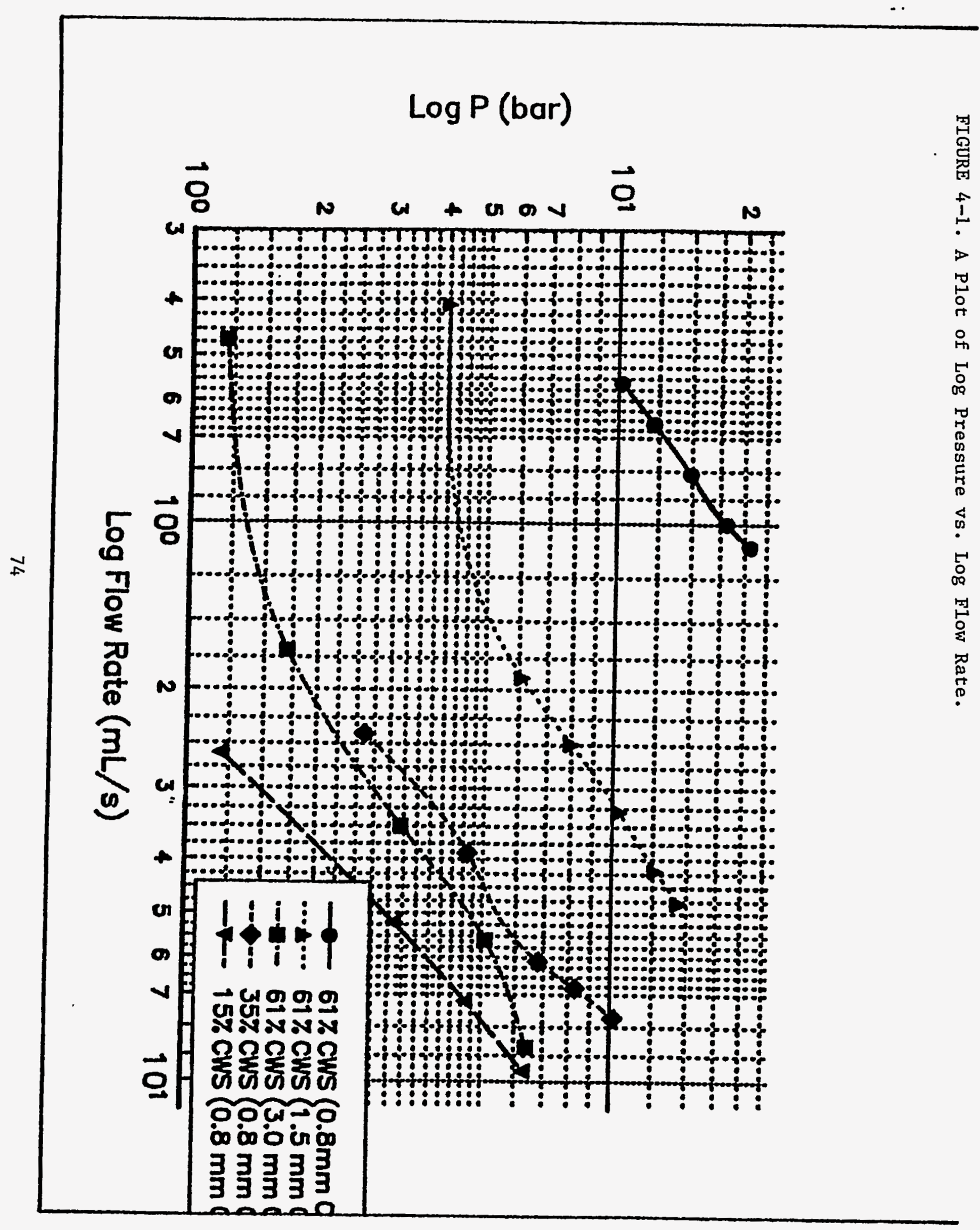


Table 4-1.

Flow Rate of $61 \%$ CWS Through $0.8 \mathrm{~mm}$ Capillary Tube

$\begin{array}{lccc}\text { P(bar) } & \text { Flow Rate(ml/s) } & \text { Reynolds Number } & \text { Coal Content in Exit Sample(\%) } \\ 10.2 & .56 & 6 & 62 \\ 12.2 & .66 & 7 & 60 \\ 14.9 & .81 & 8 & 60 \\ 18.1 & 1.0 & 10 & 59 \\ 20.6 & 1.1 & 12 & 59\end{array}$

Table 4-2.

Flow Rate of $61 \%$ CWS Through $1.5 \mathrm{~mm}$ Capillary Tube

P(bar)

Flow Rate(ml/s)

Reynolds Number

Coal Content in Exit Sample(\%)

4.0

.41

0

59

6.1

1.9

5

61

8.0

2.5

6

59

10.4

3.3

8

59

12.7

4.2

11

60

14.4

4.8

13

60 


\section{Table 4-3}

Flow Rate of $61 \%$ CWS Through 3.0mm Capillary Tube

$\mathbf{P}($ bar) Flow Rate(ml/s)

Reynolds Number

Coal Content in Exit Sample(\%)

1.2

0.47

0

55

1.7

1.7

0

60

3.2

3.5

1

59

5.1

5.6

2

60

6.4

8.7

3

59

Table 4-4.

Flow Rate of $35 \%$ CWS Through $0.8 \mathrm{~mm}$ Capillary Tube

P(bar)

Flow Rate(ml/s)

Reynolds Number

Coal Content in Exit Sample(\%)

2.6

2.4

344

37

4.6

3.9

557

36

6.8

6.1

995

34

8.3

6.5

906

35

10.2

5.3

439

36 
Table 4-5.

Flow Rate of $15 \%$ CWS Through $0.8 \mathrm{~mm}$ Capillary Tube

P(bar)

1.2

3.1

4.6

6.3
Flow Rate(ml/s)

2.6

5.2

7.2

9.6
Reynolds Number

1047

1858

3851

4947
Coal Content in Exit Sample(\%)

14

13

14

14

\section{4-3 Atomization Unit}

The feed system for the fluid atomization consisted of a 5-gallon feed tank whose bottom feeds into a Monyo progressive cavity pump. The configuration of the fuel flow was chosen to allow an accurate flow measurements in a low flow regime of $1.44 \mathrm{gm} / \mathrm{sec}$ and a high flow regime of $34 \mathrm{gm} / \mathrm{sec}$. Calibration of the fluid flow was performed by collecting and timing tap water as it flows at a given setting of the pump. The accumulated water at each pump configuration setting, was then weighed on a Mettler balance ( model PJ6000) and the flow rate determined (Figure 4-3). This calibration allowed the measured and predicted flow rates to be matched at high, moderate and low values. The calibration curve for the fluid mass flow is shown in Figure 4-2.

Atomizing air was provided by a general purpose air compressor which cycles between 85 psig and 150 psig. Air flow was controlled manually by turning a valve to give a line pressure. Calibration of the air flow was performed by measuring the volume of water displaced by the air as it flowed through a rotameter at $23 \mathrm{C}$. The mass of the volume of water displaced by a given 


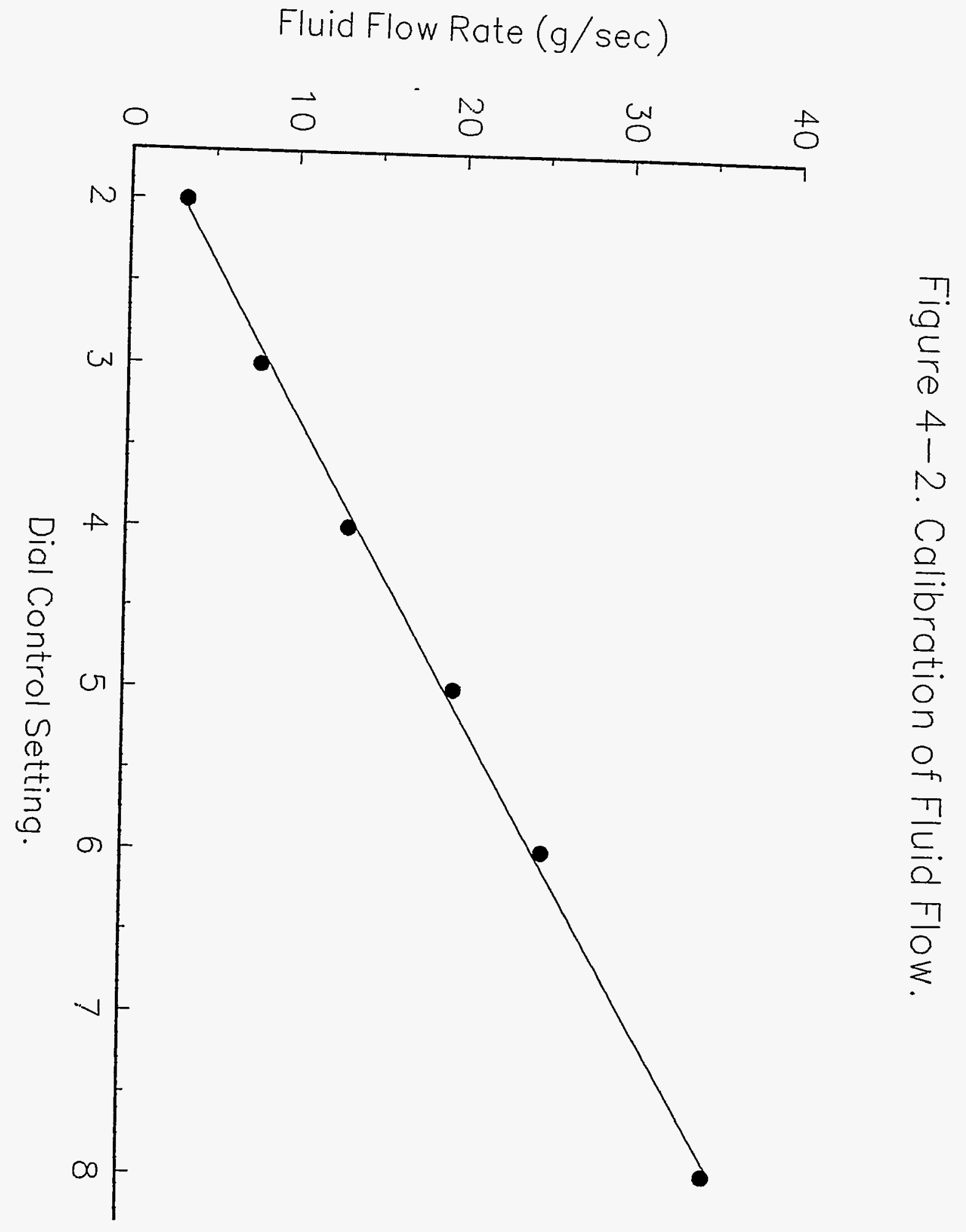


quantity of air flowing through the rotameter, was determined by multiplying the volume of water displaced by the density of water at $23 \mathrm{C}$, and a calibration curve for the air flow rate was determined (Figure 4-3). This calibration also, allowed the measured and predicted flow rates to be matched at high, moderate and low values.

The atomizer used in this study was the Delavan Airo Solid Cone Atomizing Nozzle (Figure 4-4). This is an internal mix atomizer. Air and fuel mix and breakup begins at the first contact between the air and the fuel. The nozzle assembly during the fuel atomization study was suspended over a $102 \mathrm{~cm}$ wide, $65 \mathrm{~cm}$ high, $153 \mathrm{~cm}$ long aluminum spray box. The box served as a collection vessel. Spray recirculation was minimized by exhausting the atomized fluid by a centrifugal blower whose volume flow rate was sufficient to draw all the atomizing air out of the atomizing chamber. The nozzle was mounted on a fixed table. The air enters the nozzle in an axial direction and the fluid enters in a perpendicular

The spray droplet sizing was determined using a Malvern Particle Size Analyzer (model 2600 , which operates on a laser diffraction principle. The laser diffraction principle and the sizer's application have been discussed previously [39]. The laser beam generator and receiver are positioned on each side of the spray chamber, with the longest focal length lens, $(300 \mathrm{~mm})$, fitted to the receiver by changing the relative position of the atomizer and the light guide tube, the particle size distribution of the spray within $300 \mathrm{~mm}$ radius can be measured from the sprays centerline to its edge. The atomizer nozzle was positioned $13.2 \mathrm{~cm}$ from the centerline of the laser beam. The bench scale atomization set-up is as shown in Figure 4-5. 


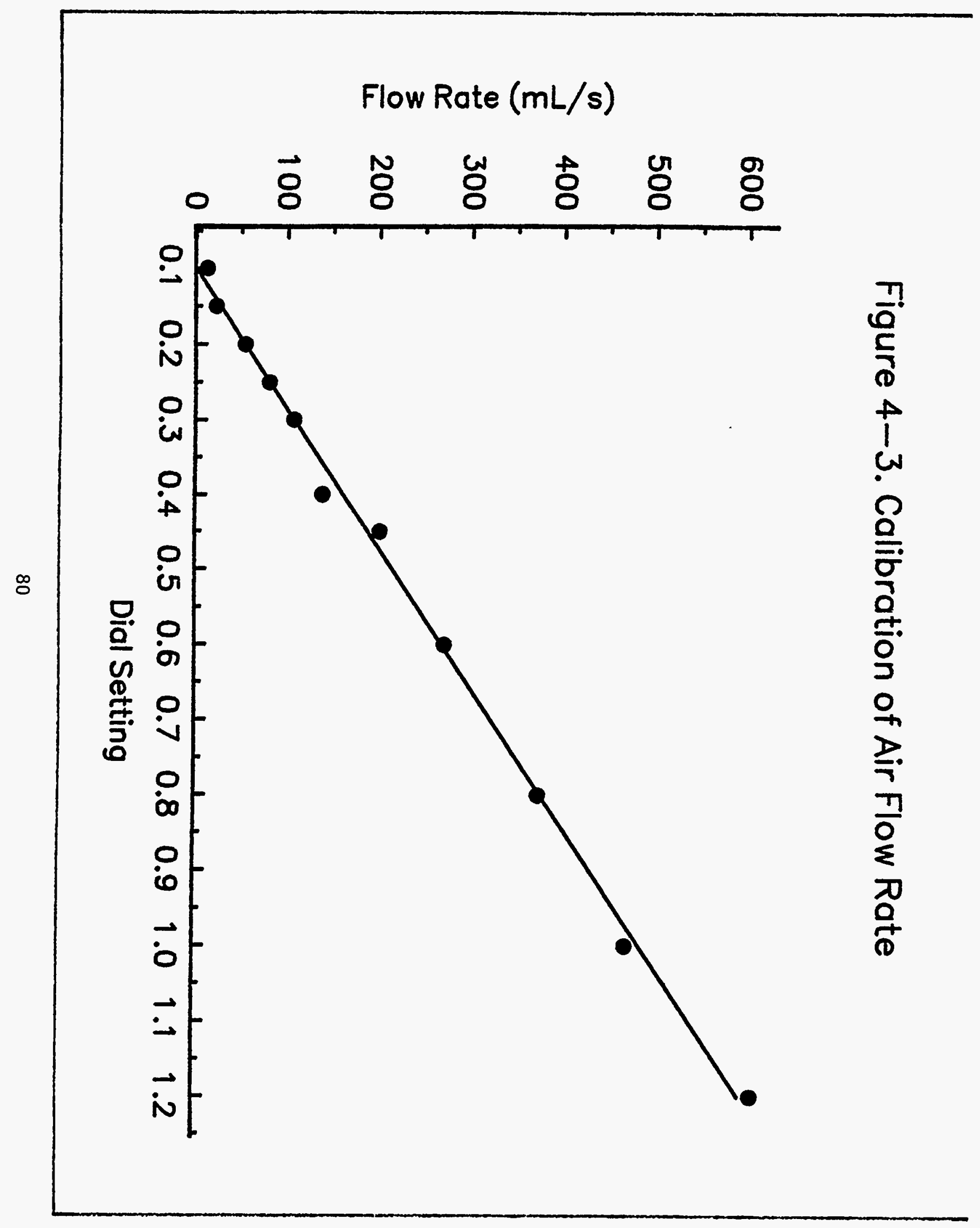


AIRO

Solid Cone Air Atomizing Nozzle

Aro

Max Deslon Pressurn: 100 polg (700 hP o)

Mex Dealon Temperalure: $180^{\circ} \mathrm{F}\left(82^{\circ} \mathrm{C}\right)$

AIRO

Nozzle Assembly

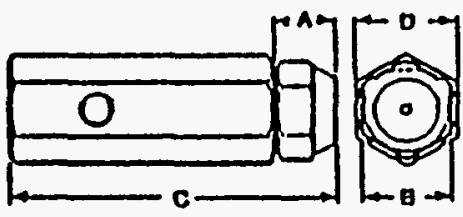

\begin{tabular}{|c|c|c|c|c|c|c|c|c|}
\hline \multirow{3}{*}{ 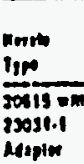 } & \multirow{3}{*}{ Mintu } & \multicolumn{4}{|c|}{ 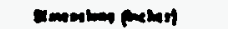 } & \multicolumn{2}{|c|}{ Mi Kin } & \multirow{2}{*}{ minum } \\
\hline & & 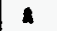 & 1 & e & - & $\boldsymbol{A}$ & Iyw & \\
\hline & & .119 & $\begin{array}{l}.119 \\
\mathrm{Hn}\end{array}$ & 9.113 & $\begin{array}{l}\text { IIS } \\
\text { Het }\end{array}$ & $\begin{array}{l}111 \\
\text { KrI }\end{array}$ & $\begin{array}{l}1 / 8 \\
\text { wrt }\end{array}$ & is \\
\hline 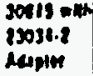 & $\begin{array}{l}\text { siondense } \\
\text { swint }\end{array}$ & .123 & ins & s.17s & $\begin{array}{l}\text { IIS } \\
\text { Mor }\end{array}$ & $\begin{array}{l}\text { III } \\
\text { nfI }\end{array}$ & $\begin{array}{l}\mathbf{1 / 1} \\
\mathrm{KPP}\end{array}$ & 39 \\
\hline 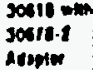 & $\begin{array}{l}\text { sinders } \\
\text { snit }\end{array}$ & & $\begin{array}{l}\text { I.ts } \\
\text { Mns }\end{array}$ & 9.600 & $\begin{array}{l}129 \\
\text { Kin }\end{array}$ & $\begin{array}{l}111 \\
\text { wpI }\end{array}$ & $\begin{array}{l}m / 1 \\
m i !\end{array}$ & 0.8 \\
\hline
\end{tabular}

spnaY cllanacrenistics:

- Fine atomization of many linulds that can't be alomized by hydraulle pressure olone.

- Unilorm solld cone. Spray angle vales wilh alt preasure and llow. Separale meteing dovice, such as atllice, metoing pump of valvo requlrod.

- Largo llow pasages - greally reduce clooging.

Constnuction ANa hateniale

part construclion

(i) Nozzle body - bresn of 353 sialnieses steel. Thinend slzes: 314".20 UNEF on Mo. 30015 and $1.1 / 8 " .16$ NEF on No. 30818

(2) Dlsirlbulor a Binss, 303 ginlniess, of Iungsion carbide frequires speclal body with replacenble iungsien carblde orlltes disc, Iningral wilh body)

(3) Screw oln- bress or 303 stalnless steal TYPICAL INSTALLATION

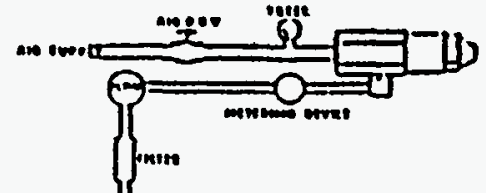

AIRO CAPACITY CHART

Gesed on Malen

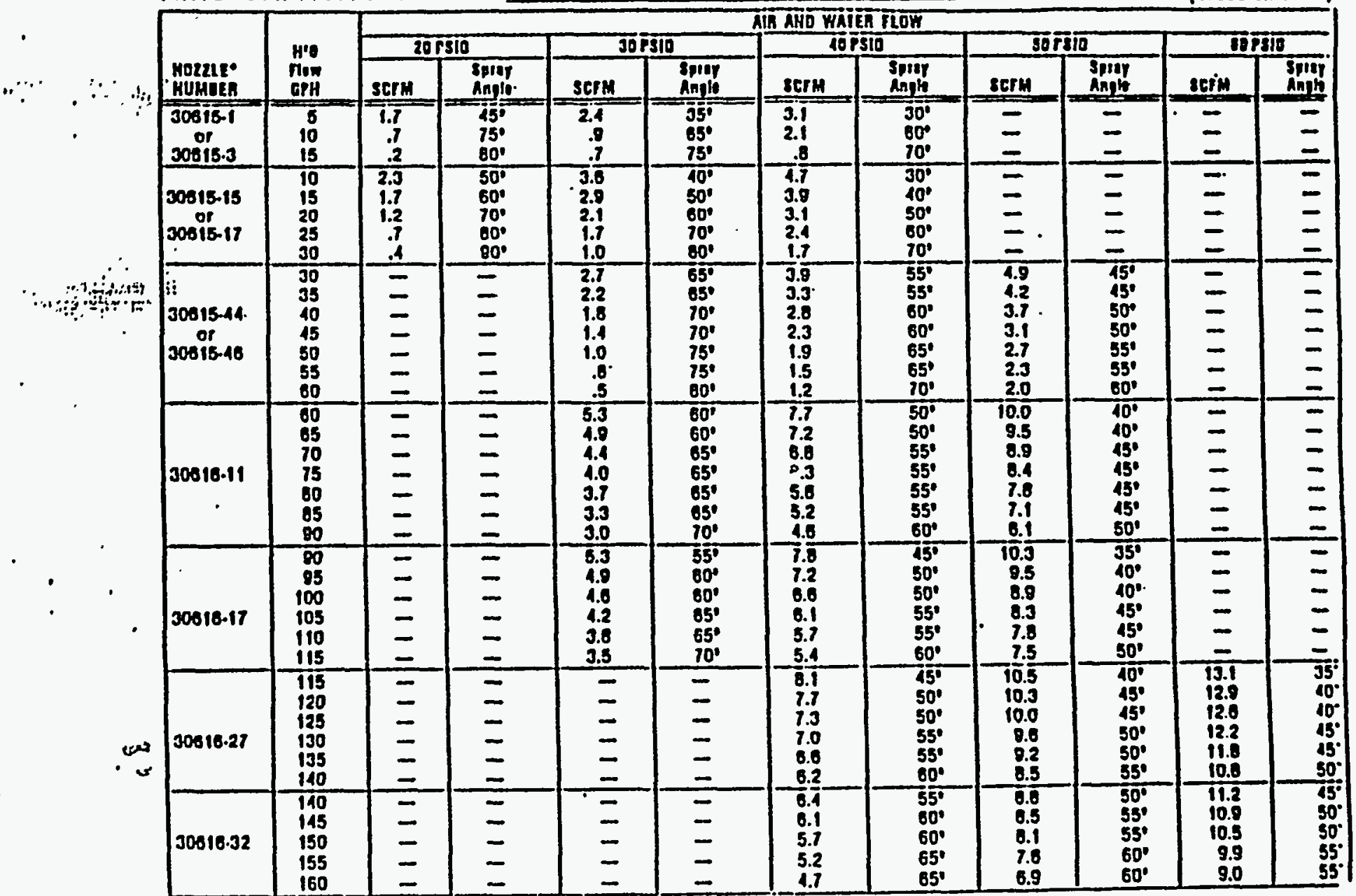

-No.30615.1, 15, .41 Biess (lor use wilh optlonal No. 23034.1 biass ndaplet).

Mo,J06 15.3, $\cdot 17, \cdot 16$ Hardonad sialnless steel (lor Use wlih opllonal No. 23034.2 slalniess steal adaplei).

Ma $30616-11, .17,-27,32$ llatdened alalnless sleel (for use wilh opllonal No. 30078.2 slalnless steel adapler). 


\section{Bench Scale Atomization Unit.}

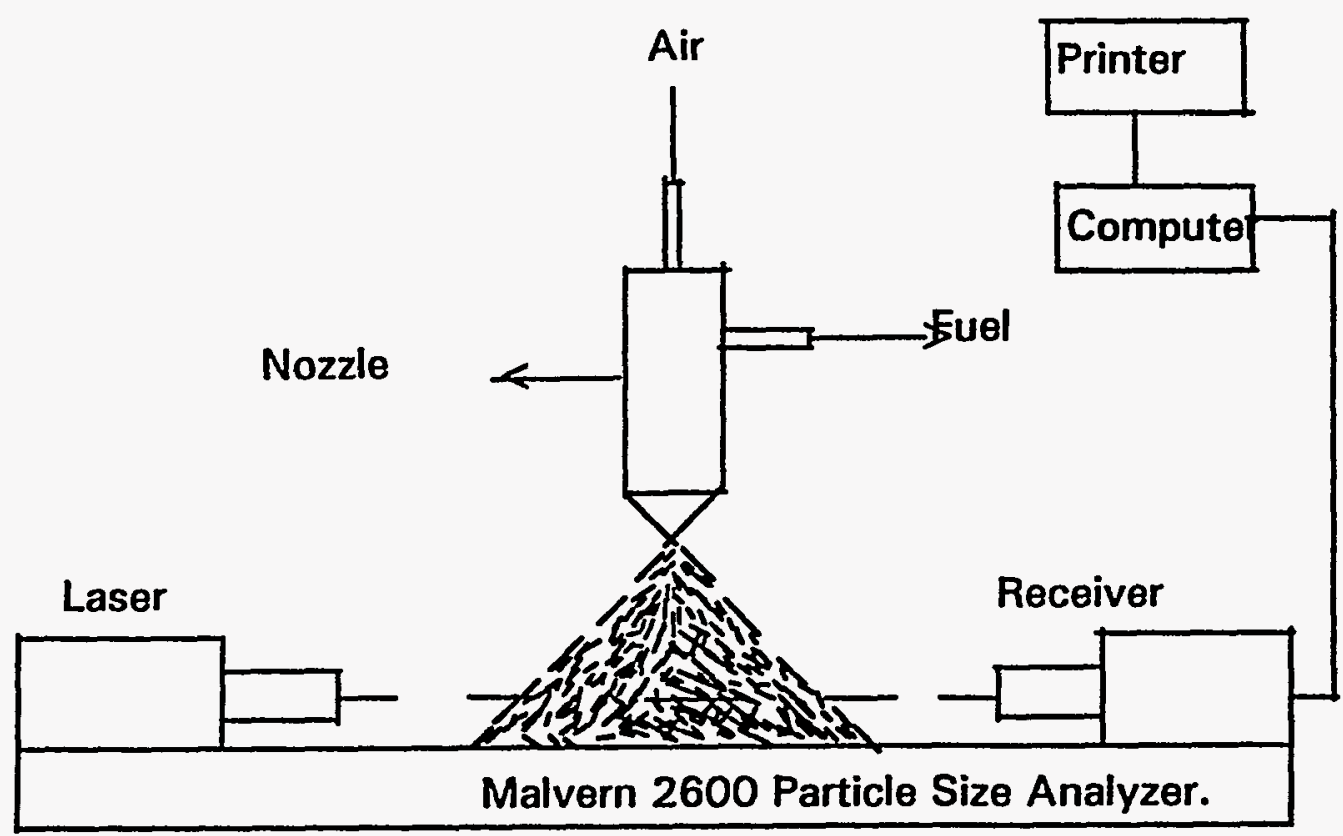




\section{4-4 Procedure For Malvern Instruments:}

Experimental measurements focussed on the region immediately downstream $(13.2 \mathrm{~cm})$

from the atomizer. A number of different arrangements were tested in order to optimize the drop size measurements. A guide was used to shield the laser beam from part of the spray. With this arrangement, there was minimal accumulation of the droplets on the collection lens surface.

However, slurry gradually accumulates outside the guide, and periodic cleanings were performed to keep a build up of the slurry from affecting the measurements. A wide range of air/fuel mass ratios were examined. Depending on the fuel flow rate, air to fuel ratios varied from 0.1 to 0.5 . Corn syrup solutions were used to test the atomization conditions. The data obtained for the com syrup soultions at a fixed Air/Fuel Ratio (AFR) of 0.302 is shown in Figure 4-6.

\section{4-5 Phenomenological Model}

The expression derived in this report relates the Sauter mean diameter, SMD, to the fluid surface tension and density, the initial air and fluid velocities and the air-fluid mass ratio, AFR

The development of the model is assumed that Mass of air, $M_{A}$ with velocity, $V_{A}$ and mass of fuel, $M_{F}$ with velocity, $V_{F}$ produces mass of air entraining $\mathrm{N}$ fuel droplets with diameter $\left(d_{i}\right)_{i=1, \ldots, N}$

The Conservation of momentum requires that the fuel-air collision produces a mass of fuel droplets and air moving with a center of mass having a velocity V. Since the mass is conserved, it follows that:

$M_{A} V_{A}+M_{F} V_{F}=\left(M_{A}+M_{F}\right) V$

where

$V=\frac{1}{\left(M_{A}+M_{F}\right)}\left(M_{A} V_{A}+M_{F} V_{A}\right)$

The sum of the initial total kinetic energy of the air the fuel can be expressed as:

$E_{\text {air }+ \text { Fuel }}=\frac{1}{2}\left(M_{A} V_{A}^{2}+M_{F} V_{F}^{2}\right)$

The kinetic energy of the entrained droplets is given by:

$E_{\text {droplets }}=\frac{1}{2}\left(M_{A}+M_{F}\right) V^{2}$ 


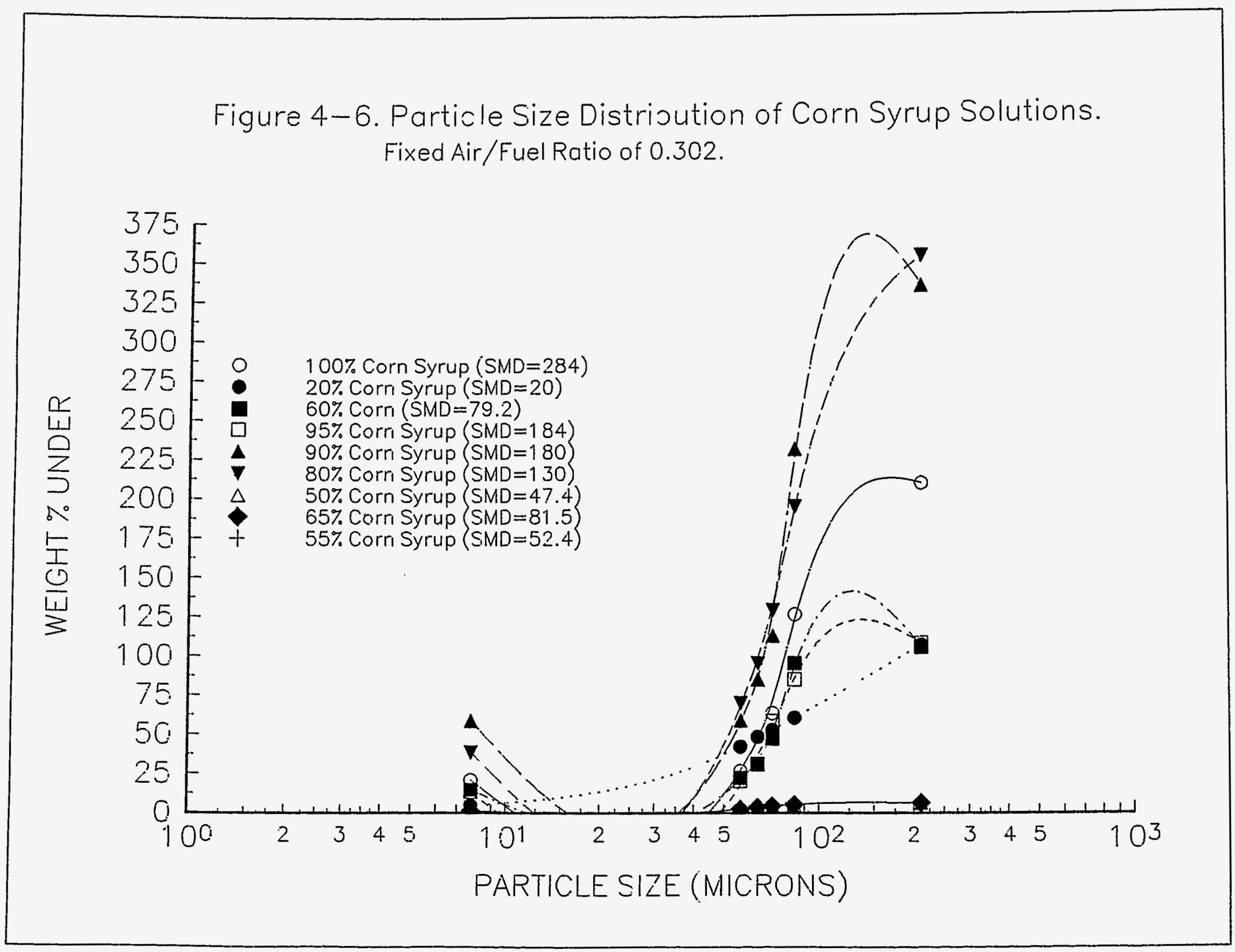


This loss of energy can be expressed as:

$\Delta E=\frac{1}{2}\left(M_{A} V_{A}^{2}+M_{F} V_{F}^{2}\right)-\frac{1}{2}\left(M_{A}+M_{F}\right) V^{2}$

Substituting equation 4-2 into equation 4-5, yields:

$\Delta E=\frac{1}{2} \frac{M_{A} M_{F}}{\left(M_{A}+M_{P}\right)}\left(V_{A-} V_{F}\right)^{2}$

The surface energy of the $\mathrm{N}$ droplets is given by:

$\Delta E_{\sigma}=\sigma \sum_{t=1}^{n} n_{i} d_{i}^{2 \pi}$

where $\sum_{i=1}^{n} n_{i}=N$

The total mass of the fuel droplets is given by:

$M_{F}=\rho_{F} \Sigma n_{i} d_{i}^{3} \frac{\pi}{6}$

where $\rho_{F}$ is the fuel density.

The Suater Mean Diameter, SMD, is defined as:

$S M D=\frac{\sum n_{1} d_{1}^{3}}{\sum n_{1} d_{l}^{2}}$

Combining Equations 4-15, 4-17, and 4-18, yields:

$\Delta E_{\sigma}=\frac{3 \sigma}{p_{F}} \frac{M_{p}}{S M D}$

Combining Equations 4-15 and 4-19, yields:

$S M D=\frac{3 \sigma}{P_{F}\left(V_{A}-V_{P}\right)^{2}}\left(1+\frac{M_{F}}{M_{A}}\right)$

For $\frac{V_{A}}{V_{p}} \sim \frac{\rho_{P}}{\rho_{A}} \sim 10^{3}$

$S M D=\frac{3}{p p} \frac{\sigma}{V_{A}^{2}}\left(1+\frac{M_{P}}{M_{A}}\right)$ 


\section{CHAPTER 5}

\section{Atomization Results}

The goal of this research program was to demonstrate the effect of rheological properties on atomization and how these properties influence the production of fine spray droplets and also, to determine a lower and upper limits of the droplets. Accomplishment of these goals required an analysis of the effect of coal-water slurry properties as well as, nozzle operating parameters on fine spray production. The CWS property analyses included the flow consistency index, coal particle size distribution, flow behavior in the high shear regime, viscoelastic characterization, surface tension and density.

Rheological characterization of simulated fluids were made and the flow behavior index and the consistency index were derived from either the Herschel Bulkley expression (Equation 3-5 ) or the Power law model expression (Equation 3-5). The composition of the simulated fluids were varied and the effect of the changes in the flow behavior index on the Sauter mean diameter, (SMD) observed. This was followed by similar studies on the CWS.

Rheological analysis of mixtures of glycerol-water, corn syrup-water, and polymer-glycerol were made to simplify analysis, minimize the number of independent variables in order to facilitate a fit of the data to the model equation expressed in Equation 4-21. The viscosities of the glycerol-water mixtures utilized on this study are as listed in Table 5-1. The glycerol-water mixtures were all Newtonian (Figures 3-15 and 3-22). The densities and surface tensions of the simulated fluids were identical to those obtained for the CWS. Thus, these mixtures allowed the influence of the flow behavior index on SMD to be studied while removing the influence associated with the coal particles. Data describing the physical properties of the 
simulated Newtonian fluids are reported in Table 5-1, and those of the simulated non-Newtonian fluids in Table 5-2. Figures 3-15 through 3-18 represents the low shear behavior of these simulated fluids. The properties relevant to this study were identified to be the flow behavior index (n), surface tension, density, and the flow consistency index (k).

\section{5-2 Newtonian Fluid Spray Data}

Several studies were undertaken using the glycerol-water solution. Five different compositions of the corn-syrup-water solutions were sprayed and drop sizes were measured using the instrumentation described in section 4-3. The sauter mean diameter of the corn syrup solution as a function of corn syrup concentration and a fixed air to fuel ratio (AFR) of 0.302 are as shown in Figure 4-6. The atomization data collected for the glycerol-water solution, glycerol-xantham gum solution and the coal-water slurries are listed in Tables 5-2 through 5-9, and a representative data sheet is found in Appendix A-1.

The spray data for the Glycerol solutions as a function of air-fuel ratio is shown in Figure 5-1 and that of the glycerol- xantham gum solution are shown in Figure 5-2. Figure 5-3 is a plot of the sauter mean diameter of the glycerol solutions as a function of viscosity at a constant AFR. The plots in Figures 5-1 and 5-2 indicate that the SMD for both the glycerol solution and the glycerol-xantham gum solution increase with a decrease in the AFR. Comparison of Figures 5-1 and 5-2 indicate that the addition of xantham gum to the glycerol solution increases the SMD values especially in the low AFR regime. In the high AFR, viscosity has no significant effect on SMD (Figure 5-3). This is due to the fact that at high AFR, energy losses associated with entrainment is large and reaches a plateau. Thus, any increase in AFR has no significant effect on SMD. At low AFR however, all the energy input goes to break up the fuel droplets since very 
TABLE 5-1

ATOMIZATION DATA

\section{GLYCEROLWATER SOLUTION}

\begin{tabular}{|c|c|c|c|c|}
\hline $\begin{array}{l}\text { VISCOSITY } \\
\text { (mPas) }\end{array}$ & $A / F$ & $\begin{array}{l}\text { SURFACE TENSION } \\
\text { dynes/cm }\end{array}$ & $\begin{array}{l}\text { DENSITY } \\
\mathbf{g} / \mathbf{m l}\end{array}$ & $\begin{array}{l}\text { SMD } \\
\boldsymbol{\mu M}\end{array}$ \\
\hline 384 & .387 & 63 & 1.23 & 19.1 \\
\hline 384 & .367 & 63 & 1.23 & 22.8 \\
\hline 384 & .364 & 63 & 1.23 & 21.8 \\
\hline 384 & .361 & 63 & 1.23 & 29.9 \\
\hline 384 & .356 & 63 & 1.23 & 34.2 \\
\hline 384 & .305 & 63 & 1.23 & 40.8 \\
\hline 384 & .274 & 63 & 1.23 & 64.2 \\
\hline 384 & .246 & 63 & 1.23 & 80.0 \\
\hline 384 & .186 & 63 & 1.23 & 105 \\
\hline 384 & .127 & 63 & 1.23 & 149 \\
\hline 410 & .392 & 65 & 1.26 & 22.8 \\
\hline 410 & .381 & 65 & 1.26 & 25.3 \\
\hline 410 & .361 & 65 & 1.26 & 32.8 \\
\hline 410 & .312 & 65 & 1.26 & 45.8 \\
\hline 410 & .288 & 65 & 1.26 & 67.3 \\
\hline 410 & .212 & 65 & 1.26 & 91.2 \\
\hline 410 & .174 & 65 & 1.26 & 131.2 \\
\hline 598 & .412 & 66 & 1.26 & 20.6 \\
\hline
\end{tabular}


TABLE 5-1 (CONTINUED)

ATOMIZATION DATA

GLYCEROL-WATER SOLUTION

\begin{tabular}{|c|c|c|c|c|}
\hline $\begin{array}{l}\text { VISCOSITY } \\
\text { (mPas.s) }\end{array}$ & $\mathbf{A} / \mathbf{F}$ & $\begin{array}{l}\text { SURFACE TENSION } \\
\text { dynes/cm }\end{array}$ & $\begin{array}{l}\text { DENSITY } \\
\mathrm{g} / \mathrm{ml}\end{array}$ & $\begin{array}{l}\text { SMD } \\
\boldsymbol{\mu M}\end{array}$ \\
\hline 598 & .392 & 66 & 1.26 & 24.3 \\
\hline 598 & .366 & 66 & 1.26 & 38.2 \\
\hline 598 & .343 & 66 & 1.26 & 44.2 \\
\hline 598 & .310 & 66 & 1.26 & 51.1 \\
\hline 598 & .300 & 66 & 1.26 & 52.4 \\
\hline 598 & .283 & 66 & 1.26 & 67.2 \\
\hline 598 & .233 & 66 & 1.26 & 91.2 \\
\hline 598 & .198 & 66 & 1.26 & 129 \\
\hline 760 & .425 & 66 & 1.28 & 18.9 \\
\hline 760 & .381 & 66 & 1.28 & 35.4 \\
\hline 760 & .362 & 66 & 1.28 & 47.2 \\
\hline 760 & .355 & 66 & 1.28 & 54.1 \\
\hline 760 & .341 & 66 & 1.28 & 59.6 \\
\hline 760 & .302 & 63 & 1.28 & 71.2 \\
\hline 760 & .288 & 66 & 1.28 & 83.7 \\
\hline 760 & .243 & 66 & 1.28 & 94.2 \\
\hline 812 & .393 & 67 & 1.28 & 22.8 \\
\hline 812 & .387 & 67 & 1.28 & 34.6 \\
\hline
\end{tabular}


TABLE 5-1 (CONTINUED)

ATOMIZATION DATA

\section{GLYCEROL-WATER SOLUTION}

VISCOSITY

(mPas.s)

812

812

812

812

812

836

836

836

836

836

836

836
$\mathbf{A} / \mathbf{F}$

.371

.321

.302

.279

.273

.411

.392

.386

.303

.286

.234

.189
SURFACE TENSION

dynes/cm

67

67

67

67

67

67

67

67

67

67

67

67
DENSITY SMD

$\mathbf{g} / \mathbf{m l} \quad \boldsymbol{\mu M}$

1.28

1.28

63.2

70.4

101.2

181.2

20.6

26.3

48.2

63.2

126.1

$1.29 \quad 209.4$

$1.29 \quad 231.3$ 
TABLE 5-2

ATOMIZATION DATA

\section{GLYCEROL-XANTHAM GUM MIXTURE}

\begin{tabular}{|c|c|c|c|c|}
\hline $\begin{array}{l}\text { VISCOSITY } \\
\text { (mPas) }\end{array}$ & $\mathbf{A} / \mathbf{F}$ & $\begin{array}{l}\text { SURFACE TENSION } \\
\text { dynes/cm }\end{array}$ & $\begin{array}{l}\text { DENSITYY } \\
\mathbf{g} / \mathbf{m l}\end{array}$ & $\begin{array}{l}\text { SMD } \\
\mu \mathrm{M}\end{array}$ \\
\hline 450 & .431 & 64 & 1.25 & 28.0 \\
\hline 450 & .386 & 64 & 1.25 & 34.2 \\
\hline 450 & .362 & 64 & 1.25 & 41.2 \\
\hline 450 & .303 & 64 & 1.25 & 61.0 \\
\hline 450 & .245 & 64 & 1.25 & 85.0 \\
\hline 450 & .186 & 64 & 1.25 & 132 \\
\hline 450 & .127 & 64 & 1.25 & 276 \\
\hline
\end{tabular}

TABLE 5-3

ATOMIZATION DATA

GLYCEROL-XANTILAM GUM MIXTURE

\begin{tabular}{|c|c|c|c|c|}
\hline $\begin{array}{l}\text { VISCOSITY } \\
\text { (InPas) }\end{array}$ & $A / F$ & $\begin{array}{l}\text { SURFACE TENSION } \\
\text { dynes/cm }\end{array}$ & $\begin{array}{l}\text { DENSITY } \\
\mathbf{g} / \mathbf{m l}\end{array}$ & $\begin{array}{l}\text { SMD } \\
\mu \mathrm{M}\end{array}$ \\
\hline 55.7 & .412 & 61 & 1.13 & 14.3 \\
\hline 55.7 & .386 & 61 & 1.13 & 22.0 \\
\hline 55.7 & .362 & 61 & 1.13 & 31.0 \\
\hline 55.7 & .303 & 61 & 1.13 & 47.0 \\
\hline 55.7 & .245 & 61 & 1.13 & 95.0 \\
\hline 55.7 & .186 & 61 & 1.13 & 105 \\
\hline 55.7 & .127 & 61 & 1.13 & 152 \\
\hline
\end{tabular}


TABLE 5-4

\section{A'TOMIZA'TION DATA}

\section{GLYCEIROI-XAN'TIIAM GUM MIXTURE}

\begin{tabular}{|c|c|c|c|c|}
\hline $\begin{array}{l}\text { VISCOSIIYY } \\
\text { (ml'ras) }\end{array}$ & $\mathbf{\Lambda} / \mathbf{F}$ & $\begin{array}{l}\text { SURTACE 'TENSION } \\
\text { dynes/cm }\end{array}$ & $\begin{array}{l}\text { DENSTYY } \\
\text { g/ml }\end{array}$ & $\begin{array}{l}\text { SMI) } \\
\boldsymbol{\mu M}\end{array}$ \\
\hline 200 & .402 & 61 & 1.13 & 24.5 \\
\hline 200 & .386 & 61 & 1.13 & 26.7 \\
\hline 200 & .362 & 61 & 1.13 & 33.0 \\
\hline 200 & .303 & 61 & 1.13 & 41.0 \\
\hline 200 & .245 & 61 & 1.13 & 72.0 \\
\hline 200 & .186 & 61 & 1.13 & 113 \\
\hline 200 & .127 & 61 & 1.13 & 211 \\
\hline
\end{tabular}

'TABLE 5-5

A'TOMIZATION DATA

COAL-WA'TER SLURIRY (ISOC-1527)

\begin{tabular}{|c|c|c|c|c|}
\hline $\begin{array}{l}\text { VISCOSITY } \\
\text { (mIPas.s) }{ }^{\star \star}\end{array}$ & $\mathbf{A} / \mathbf{F}$ & $\begin{array}{l}\text { SURTACE TENSION } \\
\text { dynes/cm }\end{array}$ & $\begin{array}{l}\text { DENSITY } \\
\text { g/ml }\end{array}$ & $\begin{array}{l}\text { SMU } \\
\mu \mathrm{M}\end{array}$ \\
\hline 98.2 & .437 & 68 & 1.19 & 48.3 \\
\hline 98.2 & .411 & 68 & 1.19 & 81.2 \\
\hline 98.2 & .386 & 68 & 1.19 & 104.6 \\
\hline 98.2 & .301 & 68 & 1.19 & 154 \\
\hline 98.2 & .217 & 68 & 1.19 & 193 \\
\hline 98.2 & .165 & 68 & 1.19 & 391.4 \\
\hline
\end{tabular}

** VISCOSITY AT A SIIEAR RATE OF 100,000/S. 
TABLE 5-6

\section{ATOMIZATION DATA}

COALWWTER SLURRY MIXIURE (PSOC-1472)

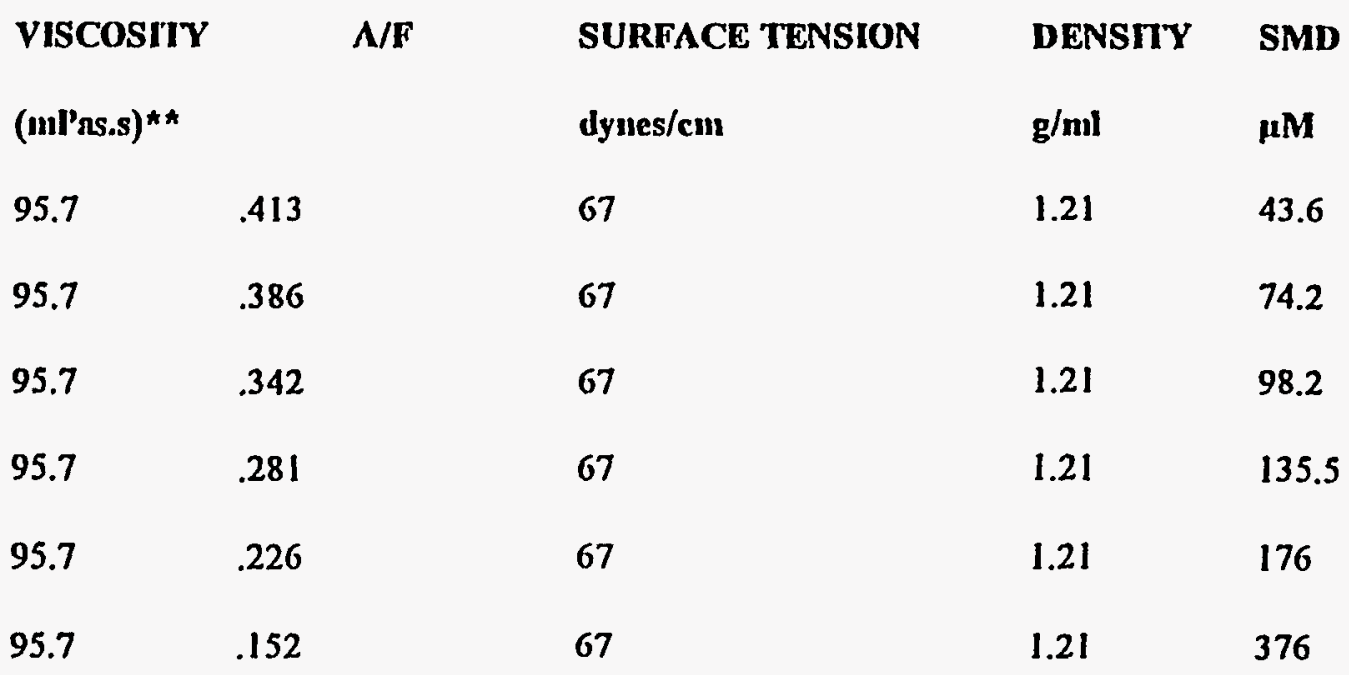

** VISCOSITY AT A SHEAR RATE OF 100,000/S.

TABLE 5-7

\section{ATOMIZATION DATA}

COALWATER SLURRY MIXTURE (PSOC-1475; Ash Content=3.22\%)

$\begin{array}{lllll}\text { VISCOSTIY } & \text { A/F } & \text { SURFACE TENSION } & \text { DENSTIY } & \text { SMD } \\ (\mathrm{mPRS} . \mathrm{s})^{\star \star} & & \text { dynes/cm } & \mathrm{g} / \mathrm{mI} & \mu \mathrm{M} \\ 94.0 & .441 & 67 & 1.18 & 38.5 \\ 94.0 & .414 & 67 & 1.18 & 69.6 \\ 94.0 & .347 & 67 & 1.18 & 95 \\ 94.0 & .281 & 67 & 1.18 & 129 \\ 94.0 & .186 & 67 & 1.18 & 195 \\ 94.0 & .145 & 67 & 1.18 & 354\end{array}$

** VISCOSITY $\Lambda$ T $\wedge$ SHEAR RATE OF 100,000/S. 
TABLE 5-8

\section{ATOMIZATION DATA}

COAL-WATER SLURRY MIXTURE (PSOC-1475; Ash Content=2.5\%)

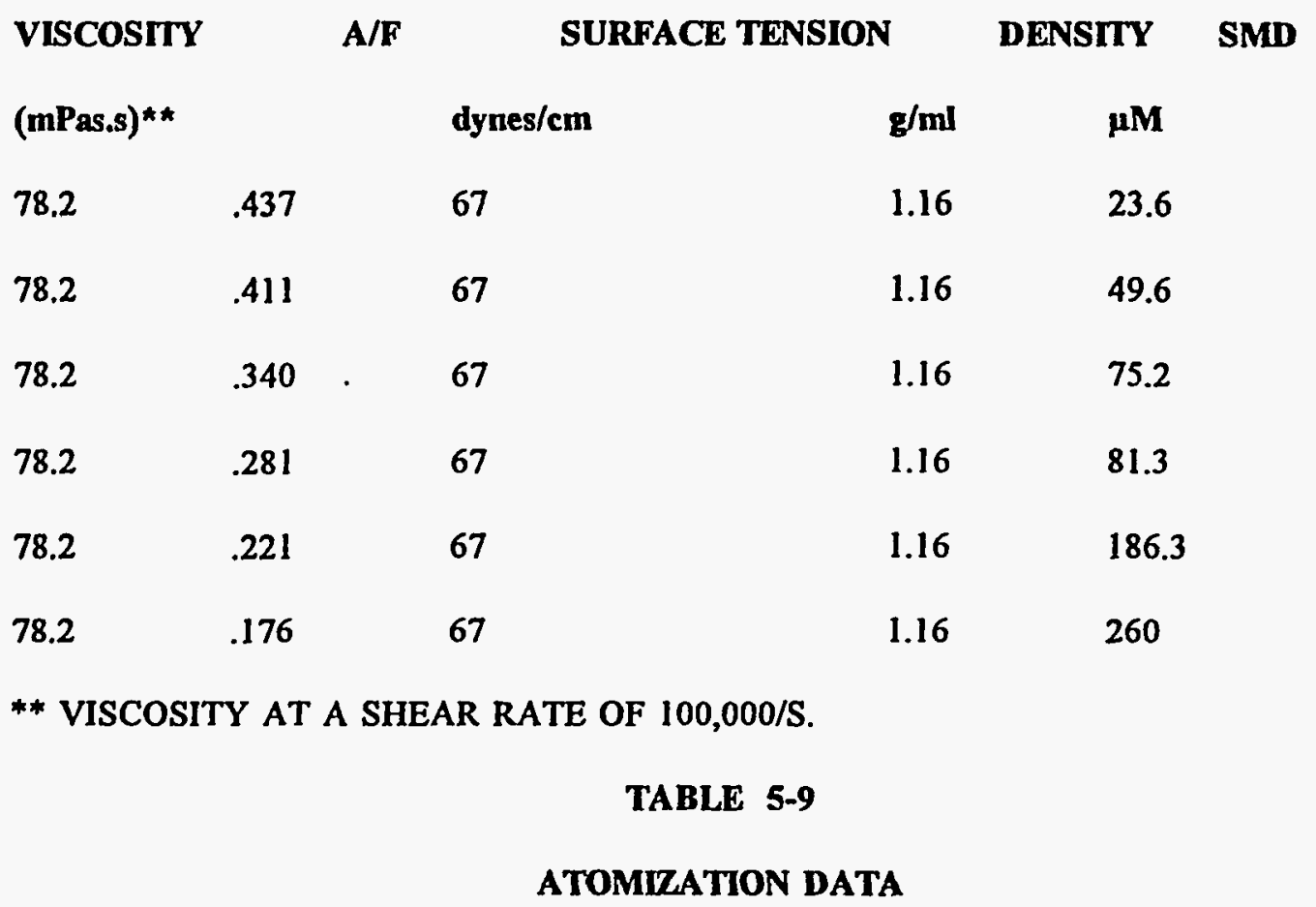

COALWATER SLURRY MIXTURE (PSOC-1475; Ash Content=2.1\%)

$\begin{array}{llcll}\text { VISCOSITY } & \text { A/F } & \text { SURFACE TENSION } & \text { DENSITY } & \text { SMD } \\ (\mathbf{m P a s . s} @ 100,000 / \mathrm{s}) & & \text { dynes/cm } & \mathrm{g} / \mathrm{ml} & \mu \mathrm{M} \\ 87.5 & .427 & 67 & 1.14 & 24.5 \\ 87.5 & .401 & 67 & 1.14 & 52.6 \\ 87.5 & .336 & 67 & 1.14 & 71 \\ 87.5 & .271 & 67 & 1.14 & 85 \\ 87.5 & .207 & 67 & 1.14 & 193 \\ 87.5 & .14 & 67 & 1.14 & 256\end{array}$




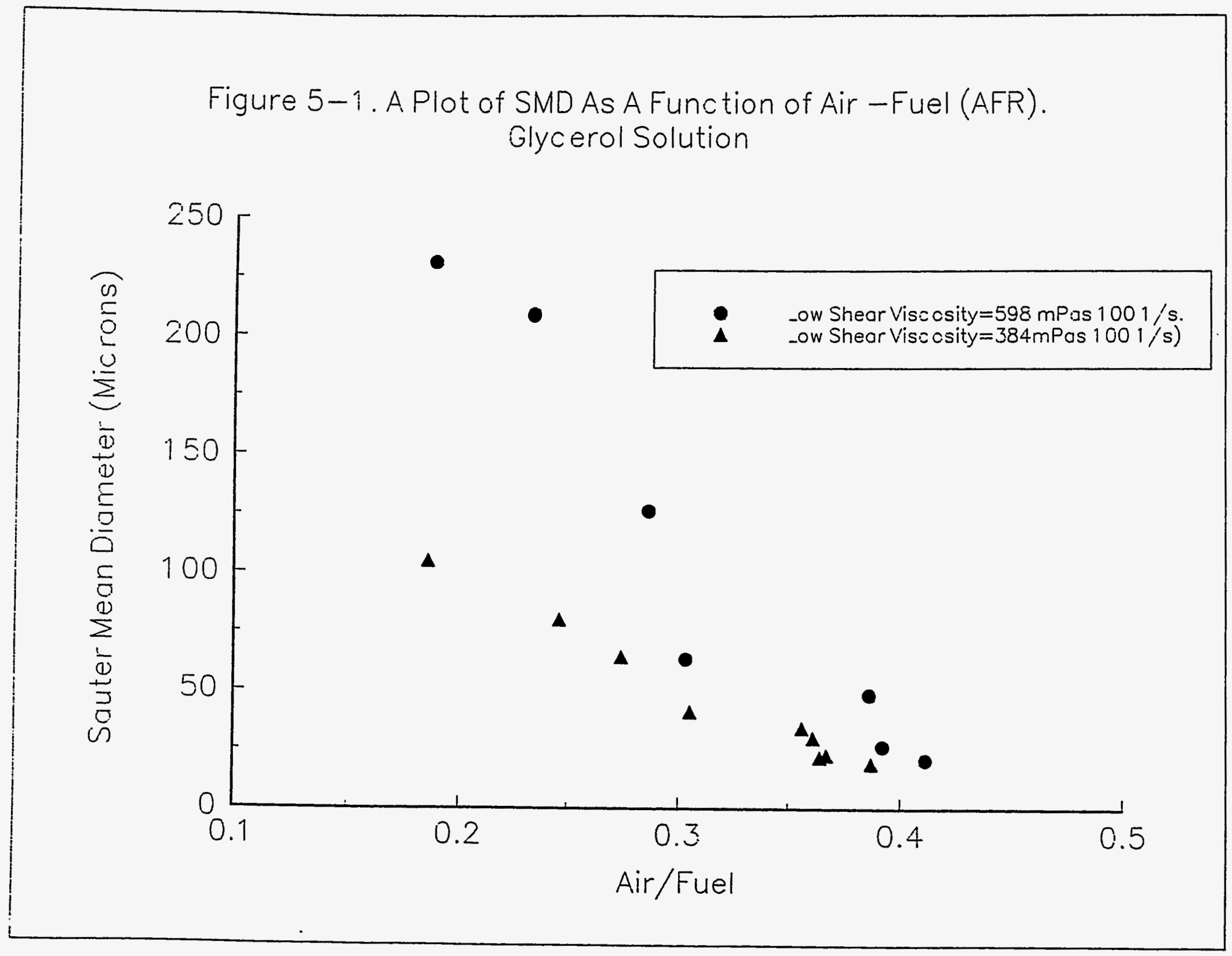


Sauter Mean Diameter (Microns).

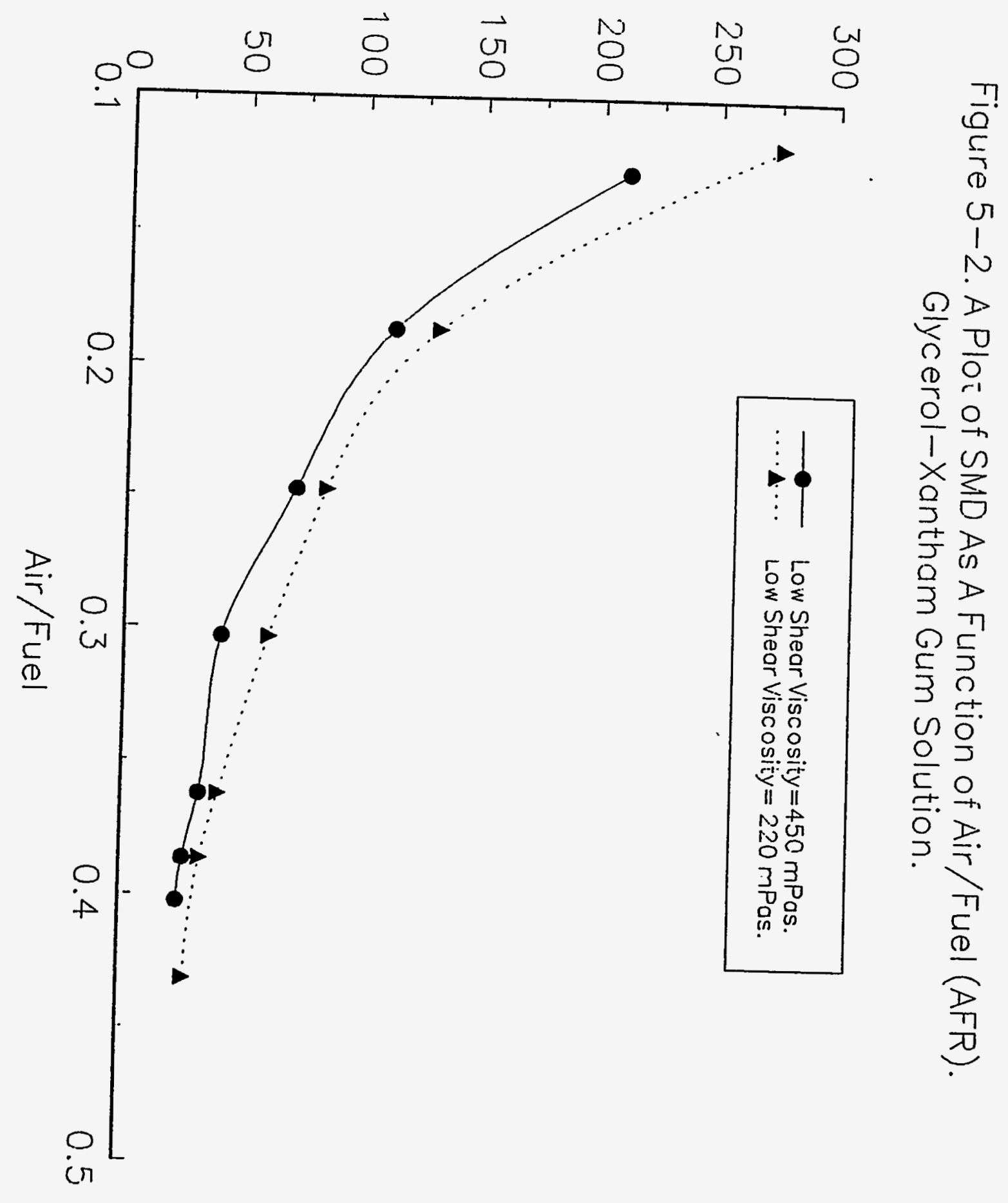



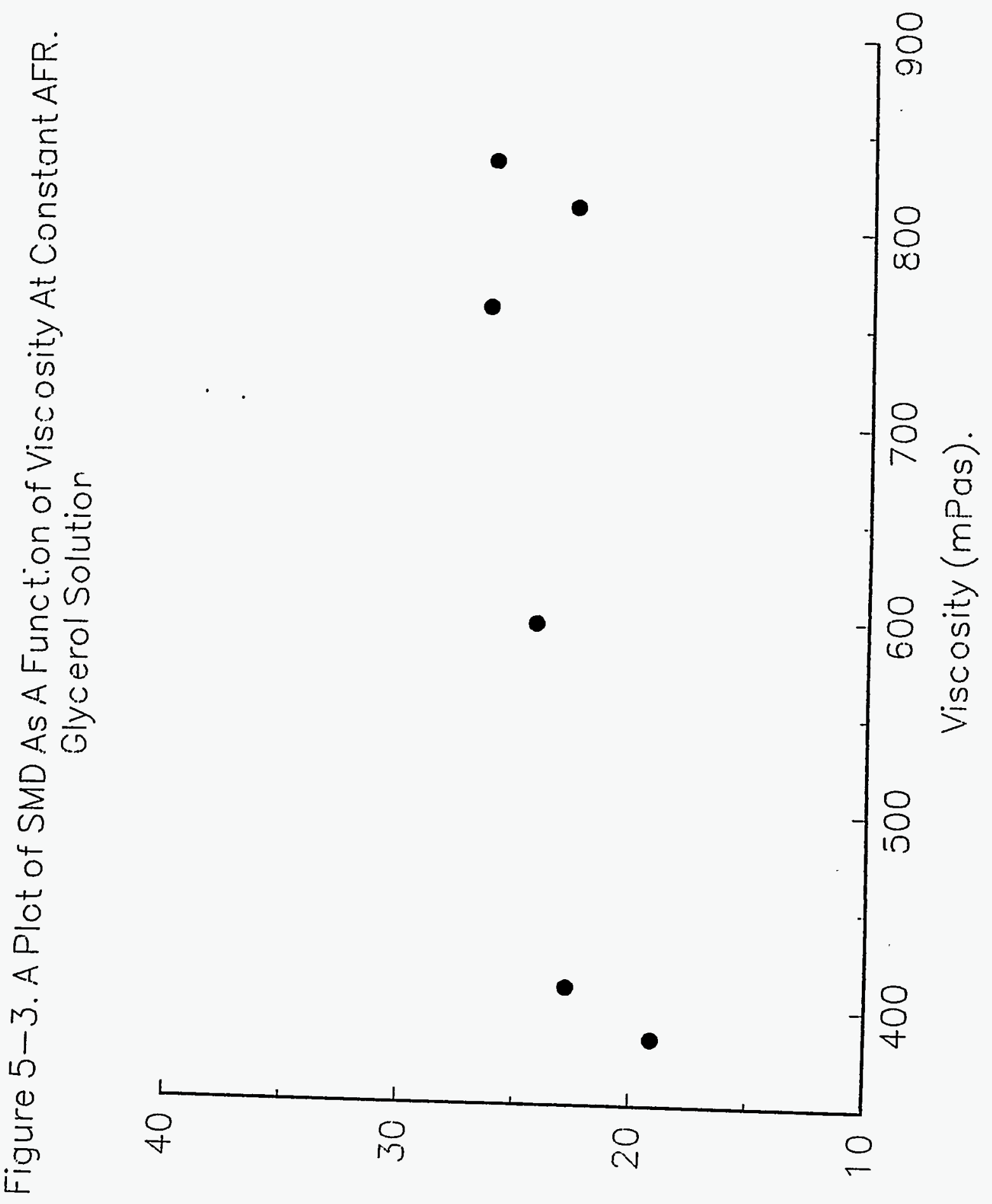

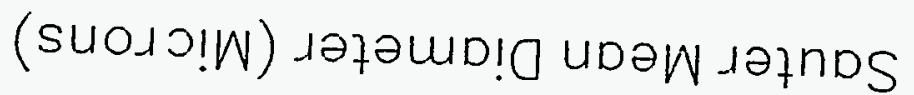


Sauter Mean Diameter (Microns)

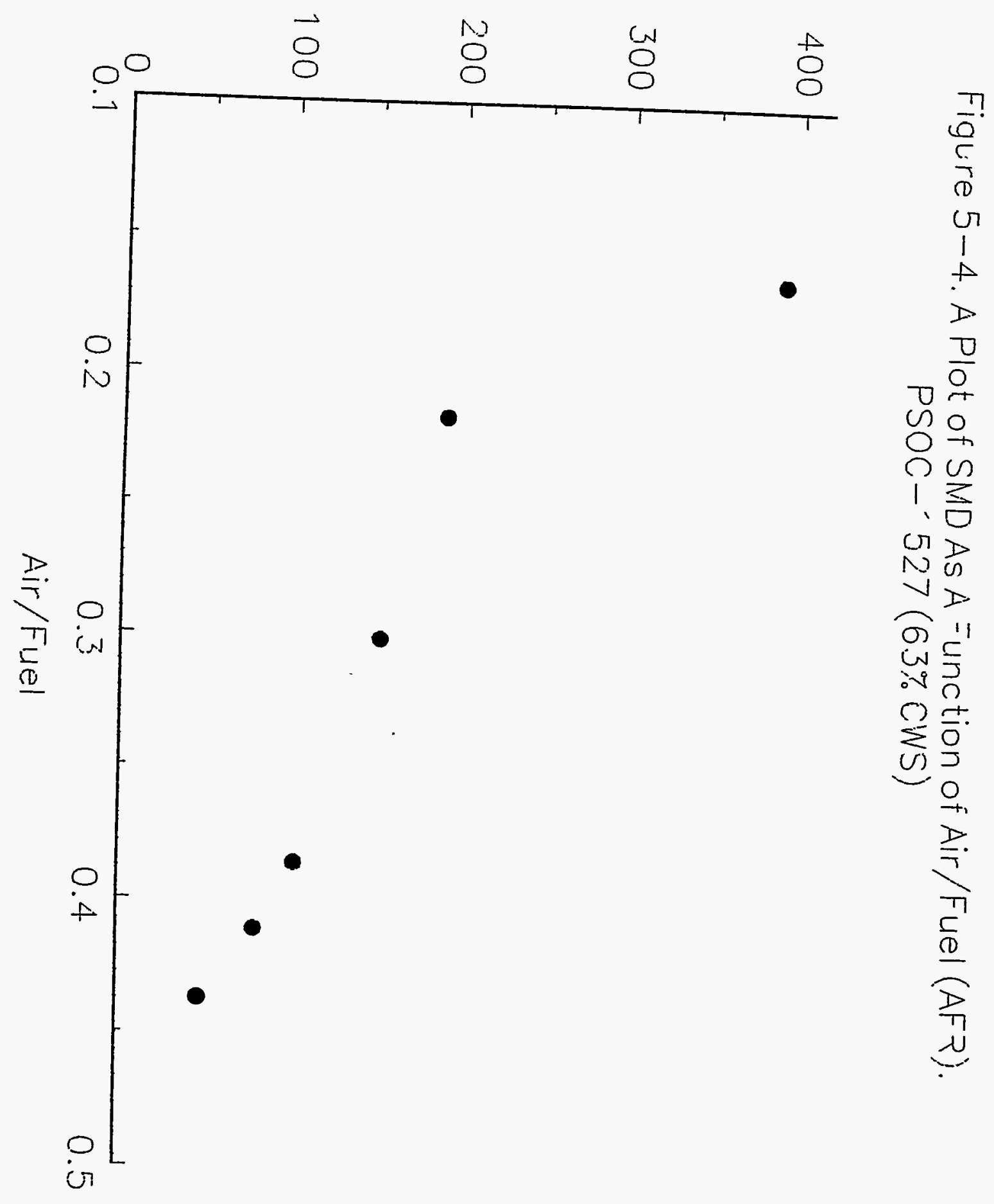




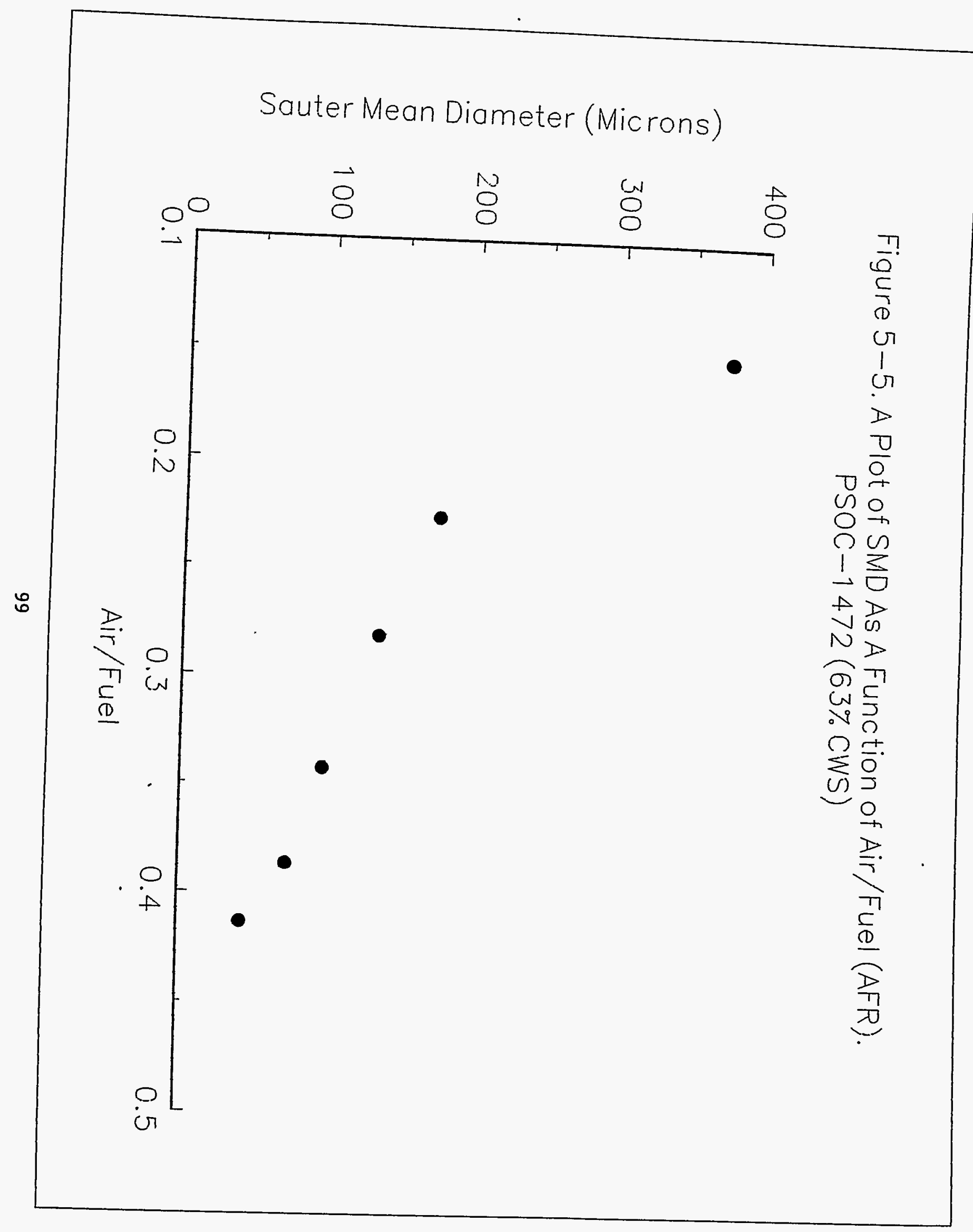


Sauter Mean Diameter (Microns)

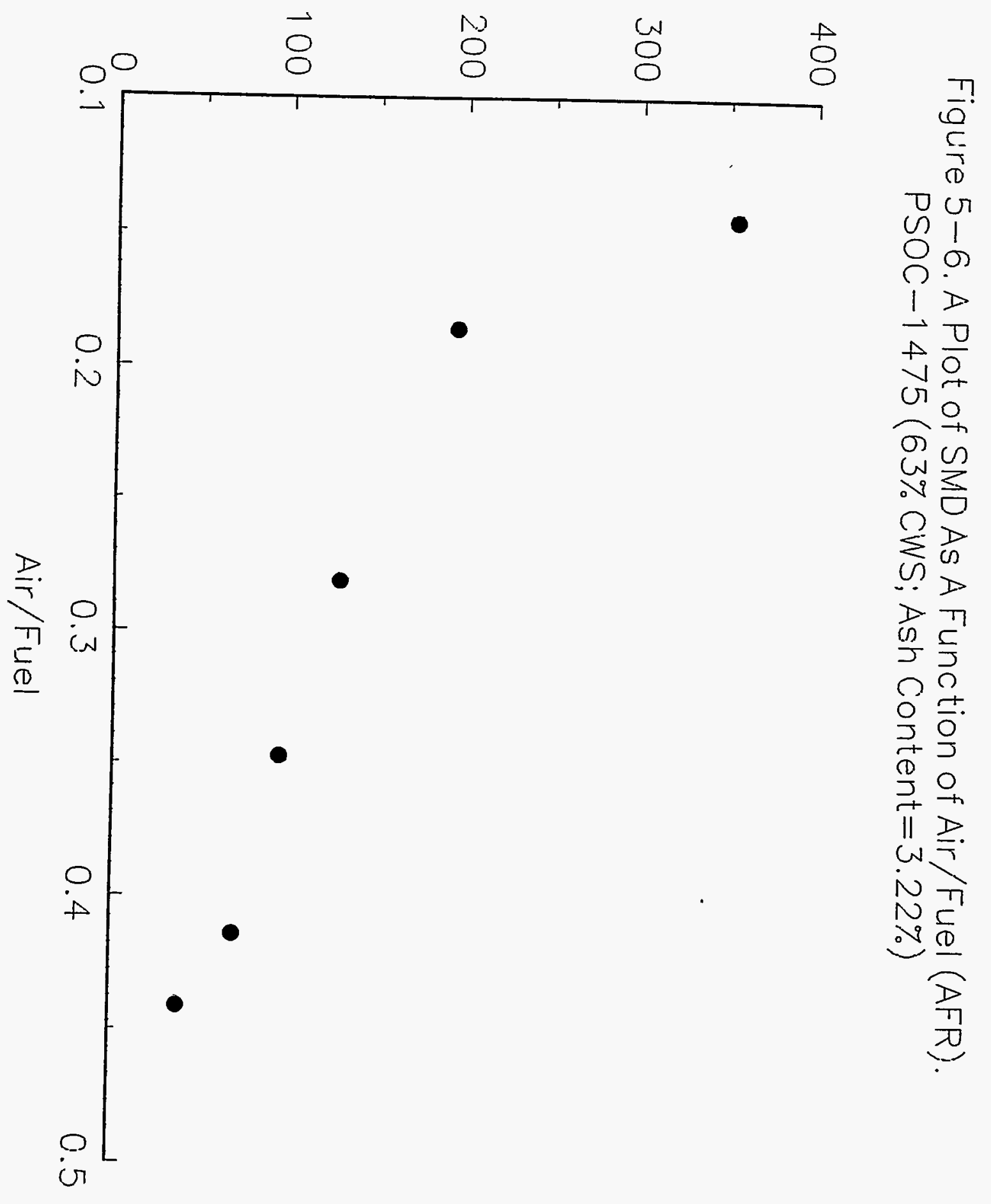




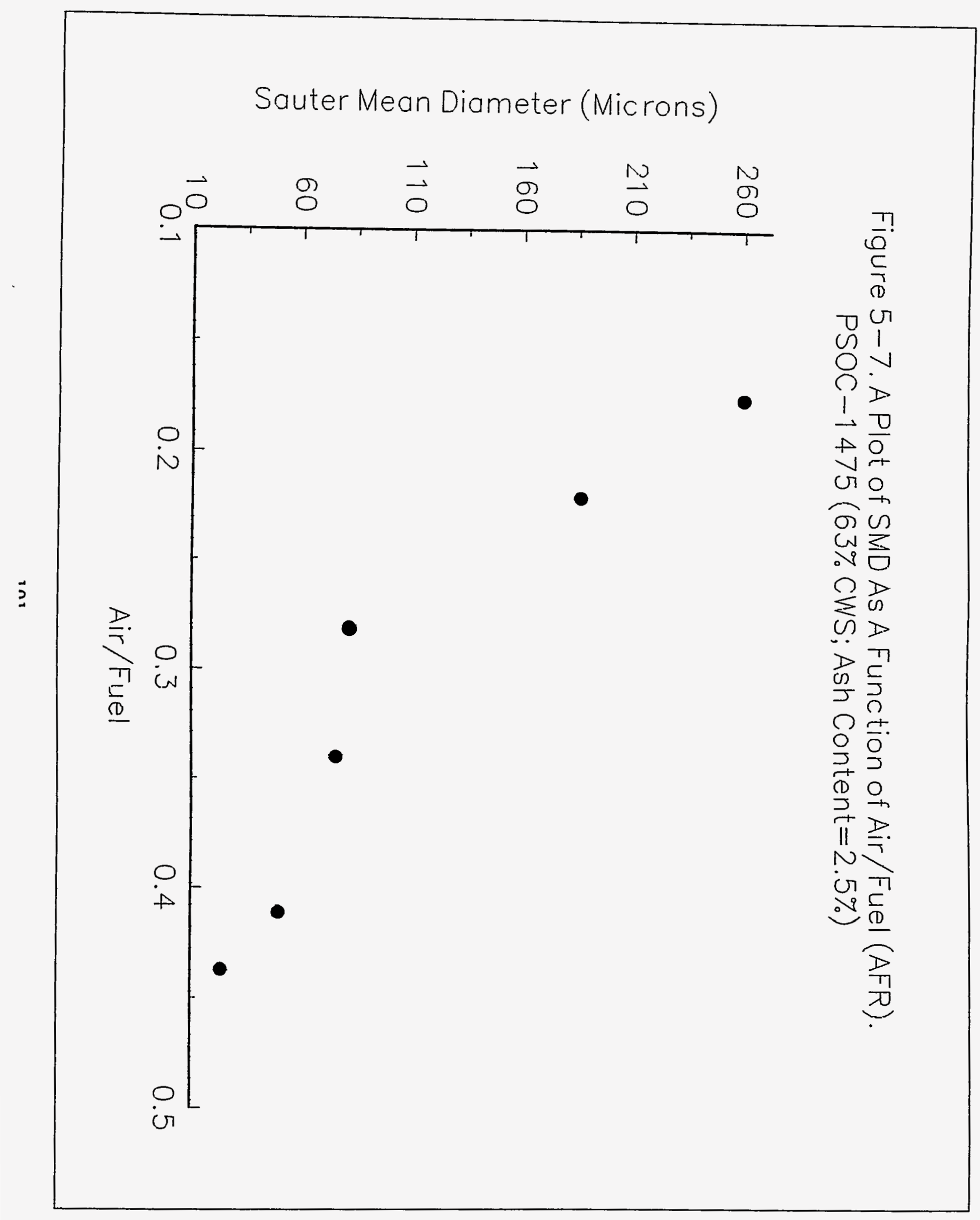




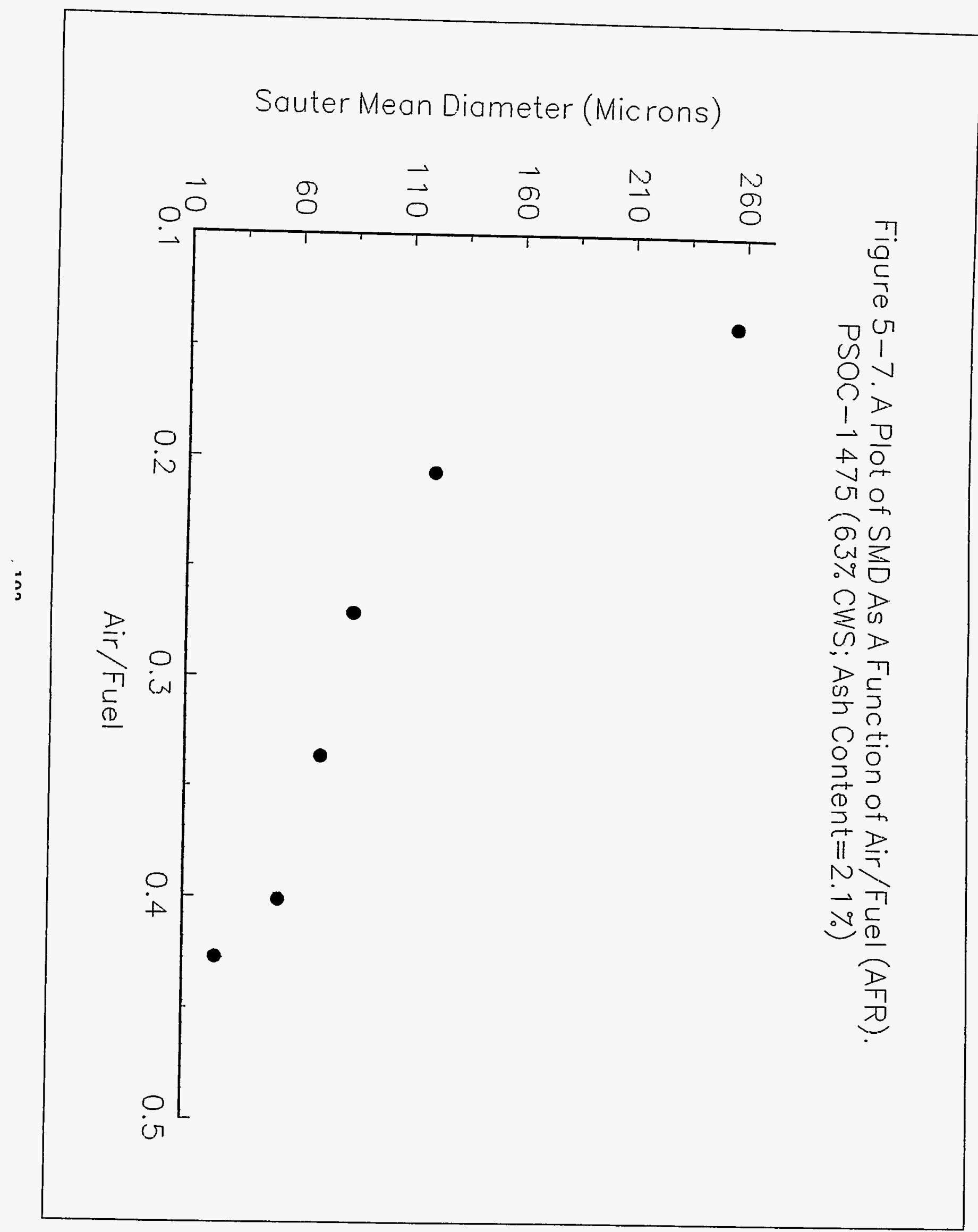


little energy is lost to the ambient. This is an indication that the fluid properties which include viscosity plays a significant role at low AFR, but at high AFR, the energy associated with the large mass of air, is able to dominate the atomization process and overcome the influence of the fluid properties.

The glycerol solution atomization data was further used to fit Equation 4-21. Figure 5-9 shows a plot of SMD as a function of (1+ AFR). Linear regression analysis was used to determine whether the empirical model, (Equation 4-21) could describe the atomization data effectively. A good correlation was obtained for the glycerol-water solution, but not for the glycerol- xantham gum solution.

High shear viscosity data obtained for the glycerol-xantham gum solution indicate that within the shear rate regime of 100,000/s, there is an abrupt change in viscosity (Figure 3-25). Thus, equation 4-21 has to be modified to take into account the variation in viscosity. According to Lefebvre [40], the average drop size is governed by air velocity, the AFR, viscosity and the surface tension of the fluid. The properties of the air are less significant and thus, the average drop size becomes more dependent on the fluid properties.

\section{5-3 Simulated non-Newtonian Spray Data.}

Figure 5-10 shows the plot of SMD as a function of AFR. There was a poor fit of the data to the model. Thus, this model equation was modified in order to explain the atomization process for the non-Newtonian fluids. The model equation was modified by assuming that the kinetic energy transfer goes into breaking the fluid into ligaments which requires an increase in surface energy.

$\Delta E=\Delta E_{\sigma}+\Delta E_{\mu}$ 5-1

where $\Delta E_{\sigma}$ is the increased surface energy of the spray and $\Delta E_{\mu}$ is the dissipative viscous energy. 
Sauter Mean Diameter (Microns).

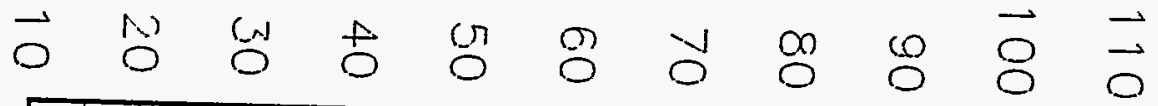

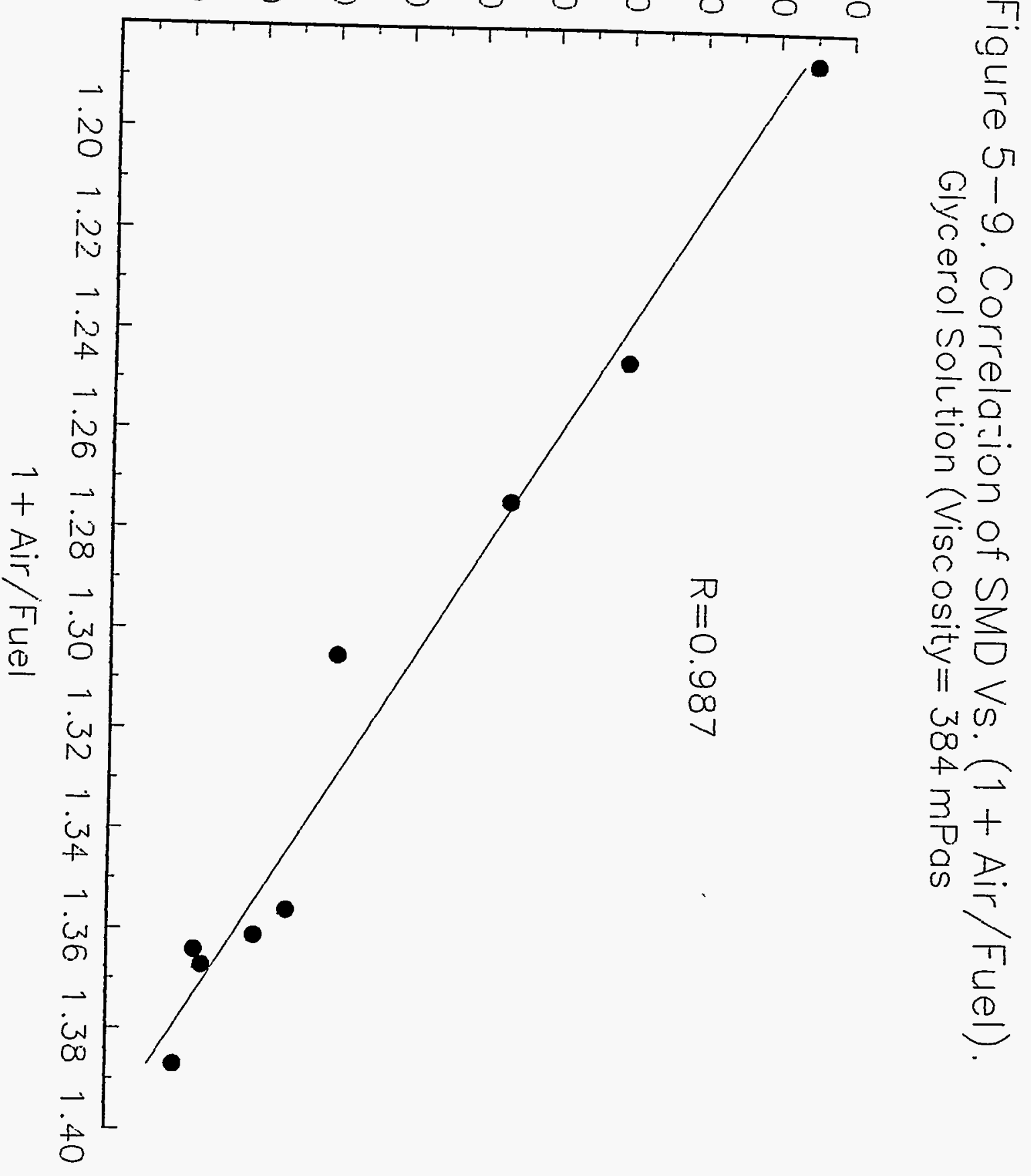


Sauter Mean Diameter (Microns).

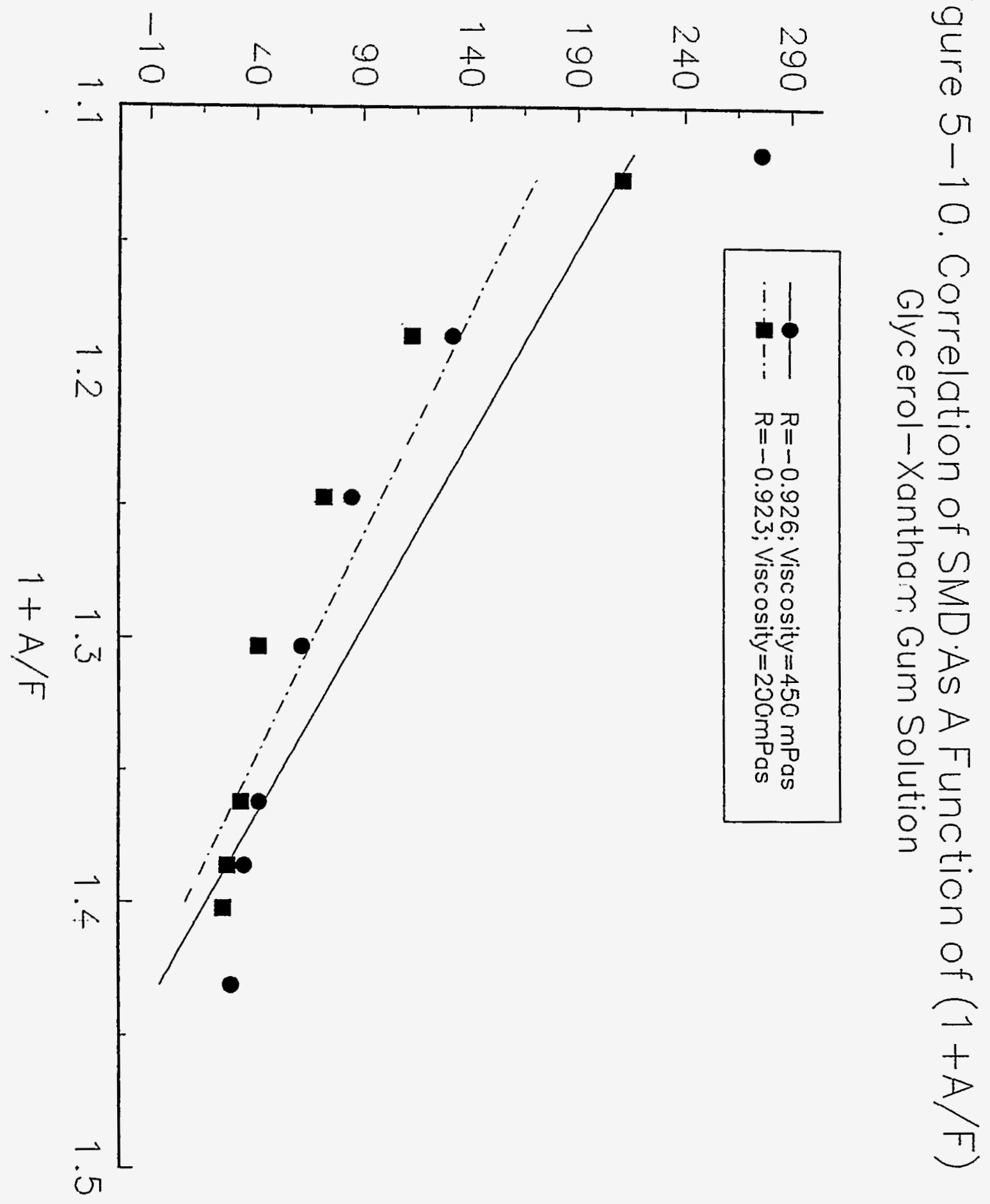




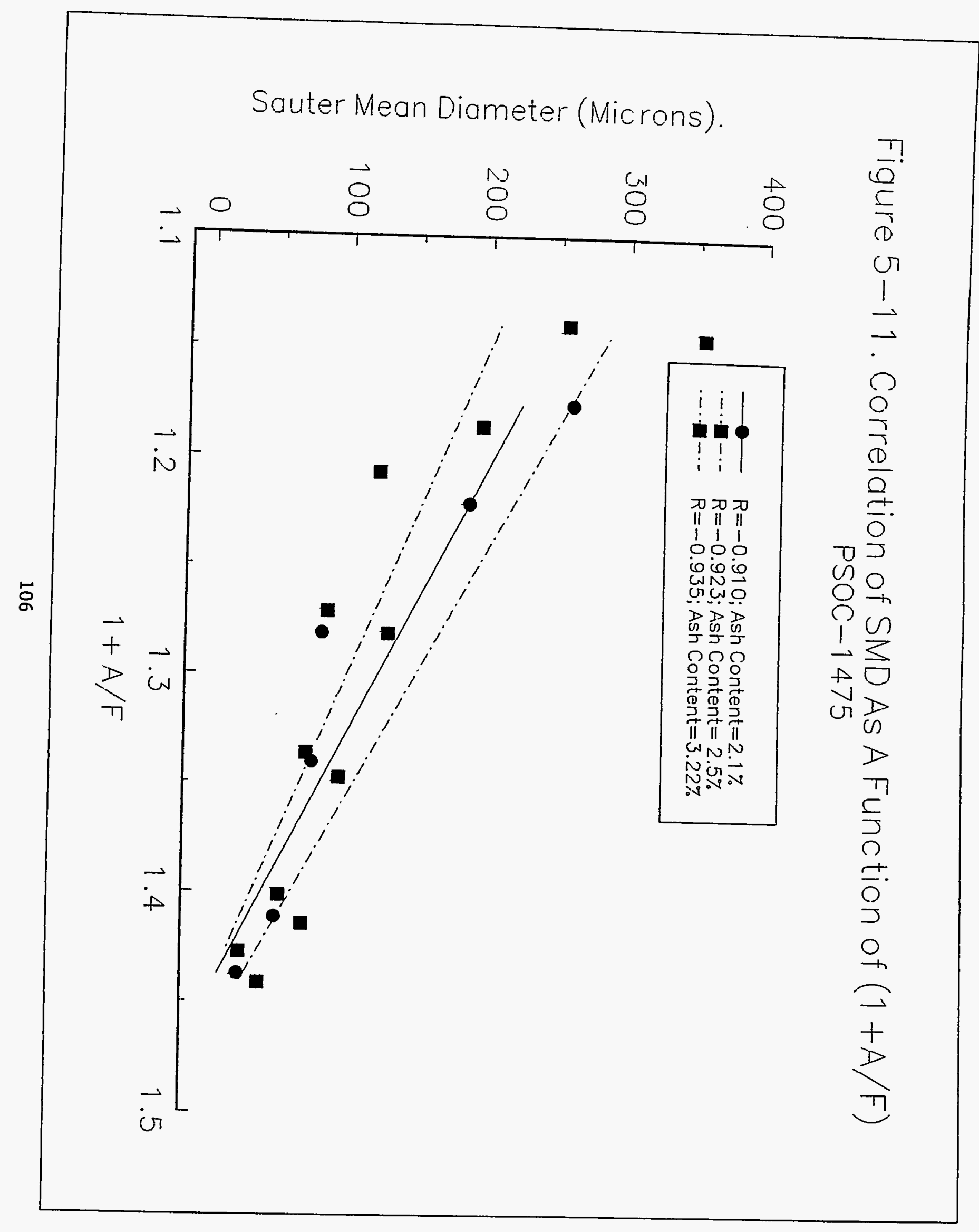


Figure 5-12. Correlation of (1+Air/Fuel).

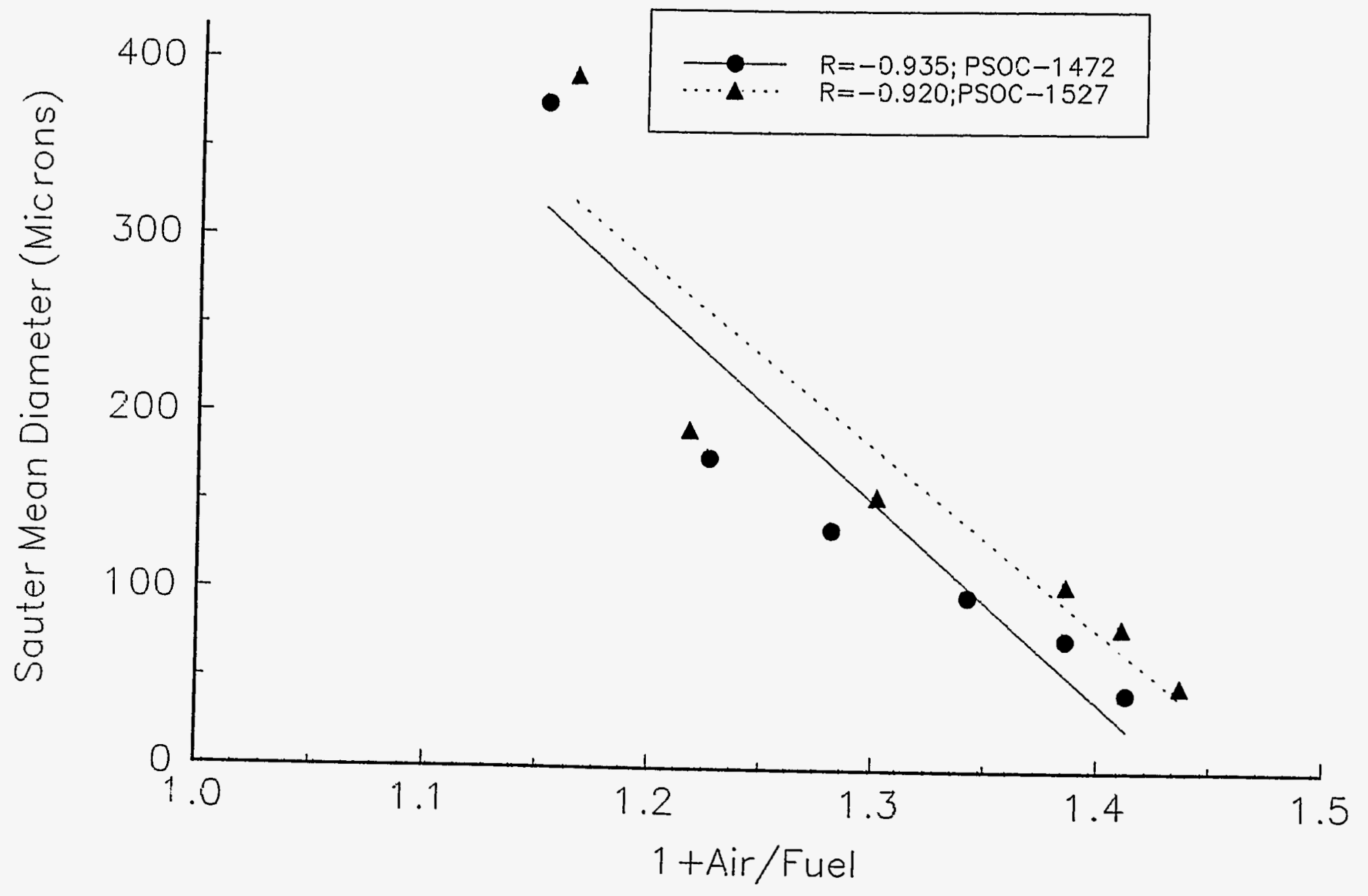


$\Delta E=\Delta E_{\sigma}\left(1+\frac{\Delta E_{\mathfrak{u}}}{\Delta E_{\sigma}}\right)$

Expressing $\frac{\Delta E_{\mu}}{\Delta E_{\sigma}}$ as $k \frac{R e^{-1}}{W e^{-1}}$ and substituting in Equation 5-2, yields:

$\Delta E=\Delta E_{\sigma}\left(1+k \frac{R e^{-1}}{W e^{-1}}\right)=\frac{\Delta E_{\sigma}}{W e^{-1}}\left(W e^{-1}+k R e^{-1}\right)$

where the Reynolds number, $R e=\rho_{F} \frac{V D_{F}}{\mu}$ is the ratio of the inertial to viscous forces in the fuel flowing through a passage with diameter, $D_{F}$, with viscosity, $\mu$, and velocity, $\mathrm{V}$, and the Weber number, $W e=\frac{\rho_{A} \nu_{A}^{2}}{\sigma}$, represents the ration of inertial forces due to air velocity, $V_{A}$, and the surface forces, $L$ is the characteristic length, and $k$ is a constant.

It follows that:

$\frac{W e^{-1}}{\left(W e^{-}+k R e^{-1}\right)} \Delta E=\frac{3 a M_{F}}{\rho p S M}$

This can be expressed as:

$\frac{\sigma}{\rho_{A} V_{A} L} \frac{M_{A} M_{F}}{\left(M_{A}+M M_{F}\right)} \frac{V_{A}^{2}}{\left(W e^{-1}+k R e^{-1}\right)}=\frac{3 \sigma}{P F} \frac{M_{F}}{S M}$

which results in

$\frac{S M D}{L}=\frac{1}{3} \frac{\rho_{A}}{\rho_{p}}\left(W e^{-1}+k R e^{-1}\right)\left(1+\frac{M_{p}}{M_{A}}\right)$

The above equation was finally expressed in the form:

$\frac{S M D}{L}=\frac{1}{3} \frac{\rho_{A}}{\rho_{p}} W e^{-1}\left(1+\frac{M_{F}}{M_{A}}\right)^{m}+\frac{1}{3} \frac{\rho_{A}}{\rho F} C k \gamma^{n}\left(1+\frac{M_{F}}{M_{A}}\right)^{b}$

The above equation shows that there are two possible mechanisms responsible for the fluid breakup. The first term is due to competition between surface tension forces and aerodynamic shearing force, and the second term is due to the competition between viscosity forces and surface tension forces.

The modified model equation, (equation 5-7), was applied to the glycerol-xantham gum data in order to determine the exponents in equation 5-7. A fit of the glycerol-xantham gum solution atomization data to equation 5-7, suggests that the model equation can best be represented by:

$\frac{S M D}{L}=\frac{1}{3} \frac{\rho_{A}}{\rho_{p}} W e^{-1}\left(1+\frac{M_{F}}{M_{A}}\right)^{0.5}+\frac{1}{3} \frac{\rho_{A}}{\rho_{p}} C k \gamma^{n}\left(1+\frac{M_{F}}{M_{A}}\right)^{-0.25}$ 
A comparison of the calculated SMD data and the measured data for the glycerol-xantham gum solutions are as shown in Figure 5-13. The SMD values were calculated using viscosity data at a shear rate of both 100/s and 100,000/s. There is a better correlation between the calculated and the measured values when viscosity data at $100,000 / \mathrm{s}$ is used compared to using the viscosity data at $100 / \mathrm{s}$.

\section{5-4 Coal-Water Spray Data}

Several CWS samples were sprayed using the Malvern Instruments particle size analyzer. The drop size data are presented in Figures 5-4 through 5-8. Figures 5-4 through 5-8 show the effect of AFR on SMD. An increase in the AFR decreases the SMD values. The values also suggest that low SMD values can be obtained using the Delavan solid cone nozzle, depending on the formulation of the CWS. The data indicate that in the high AFR regime, the SMD values obtained for the CWS are higher than those obtained for the Newtonian and non-Newtonian fluids. This is an indication that the presence of the solids tend to influence the size of the spray droplets.

Figures 5-6 through 5-8 show plots of SMD data as a function of AFR for PSOC-1475 CWS. These samples have different ash contents which vary from $3.22 \%$ to $2.1 \%$. The data indicate that the CWS with the least amount of ash content, atomized well and that the SMD values obtained at all AFR, were smaller compared to the CWS with the higher ash content. The viscoelastic behavior and the high shear flow behavior of these samples are shown in Figures 3-20 and 3-31. The high shear flow behavior of these samples are almost identical (Figure 3-31) and in the shear rate regime of $100,000 / \mathrm{s}$, they have almost identical shear viscosity. Figure 3-20 however, indicate the CWS with the highest ash content, had the highest storage modulus 


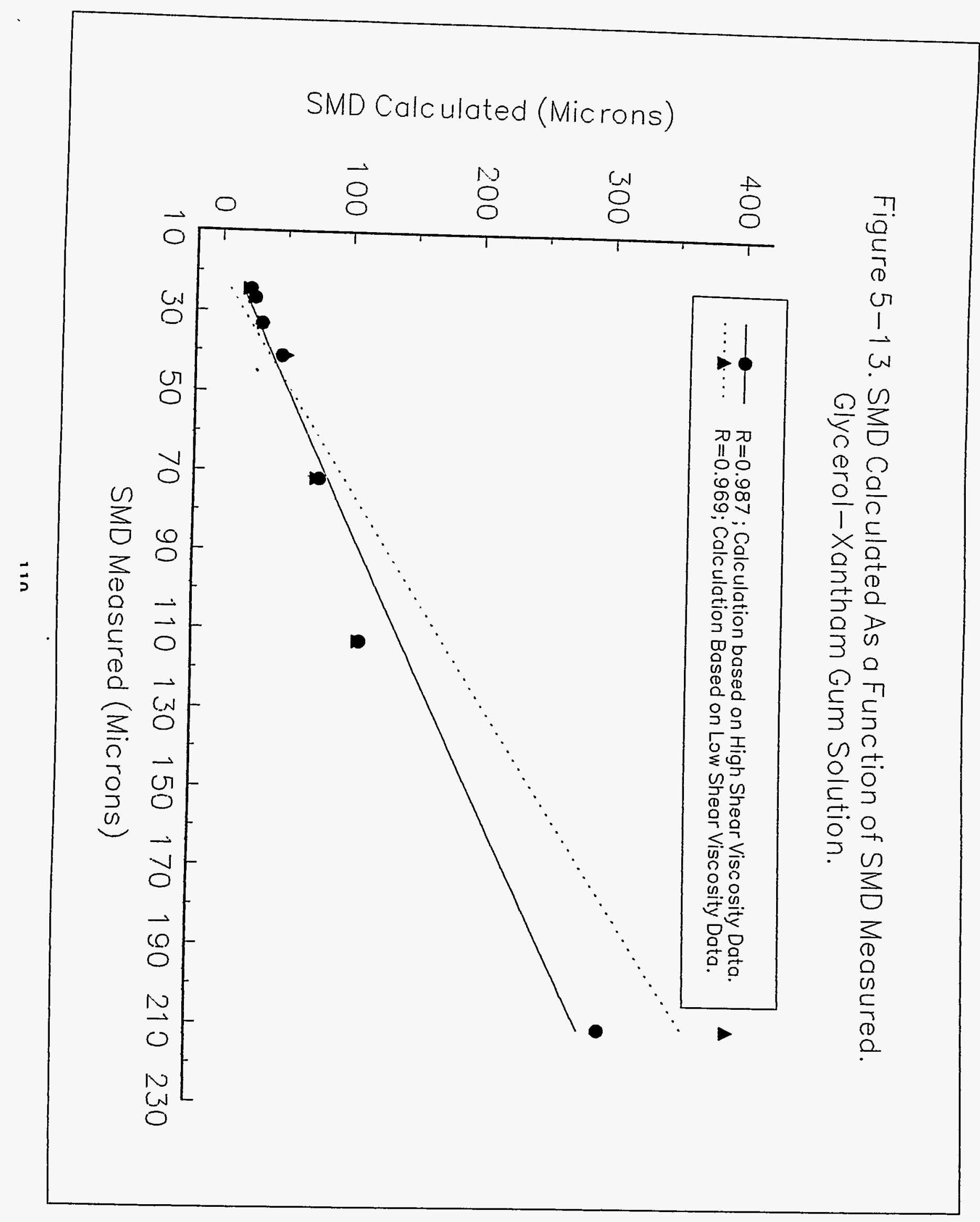


SMD Calculated (Microns)
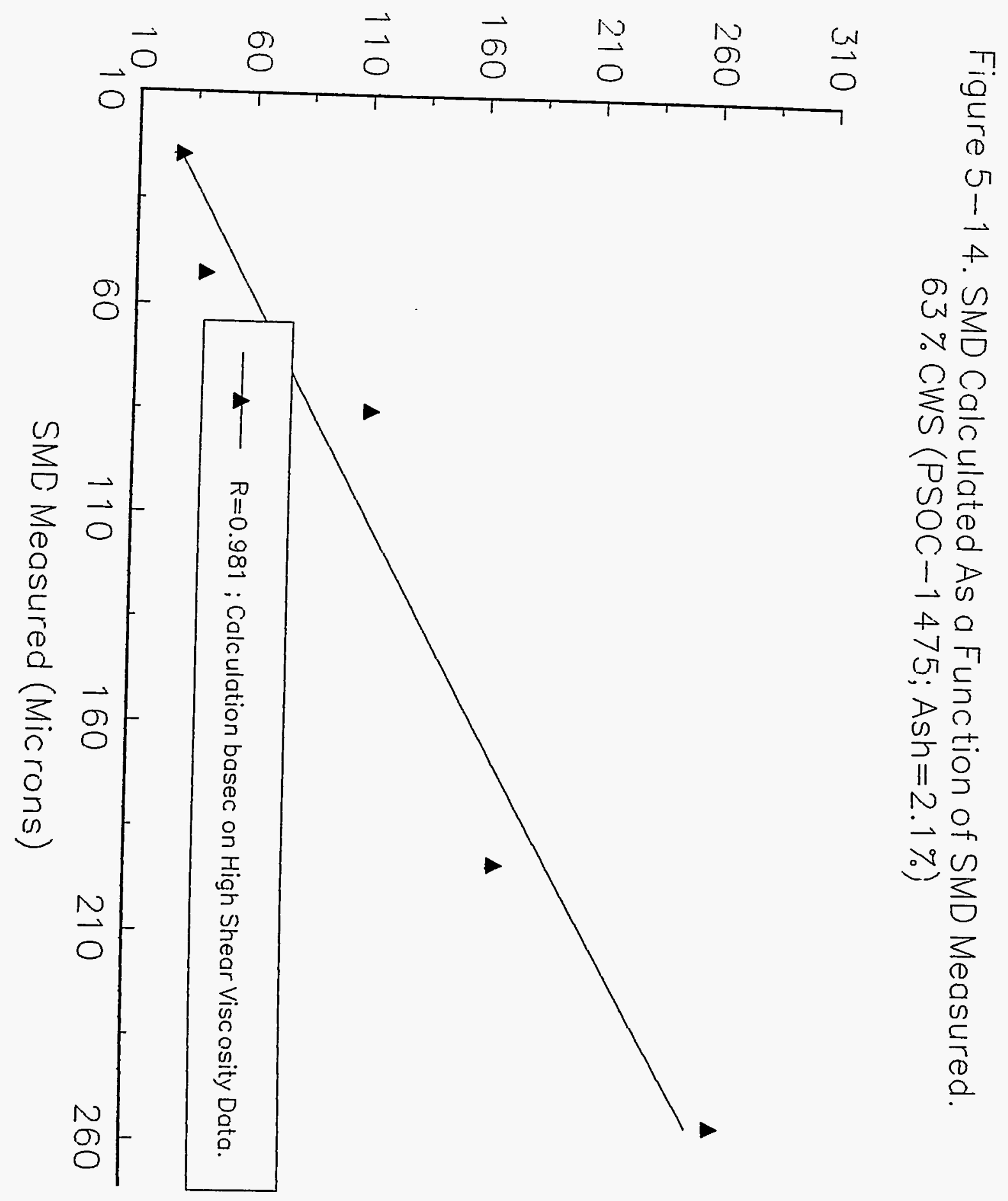
SMD Calculated (Microns)

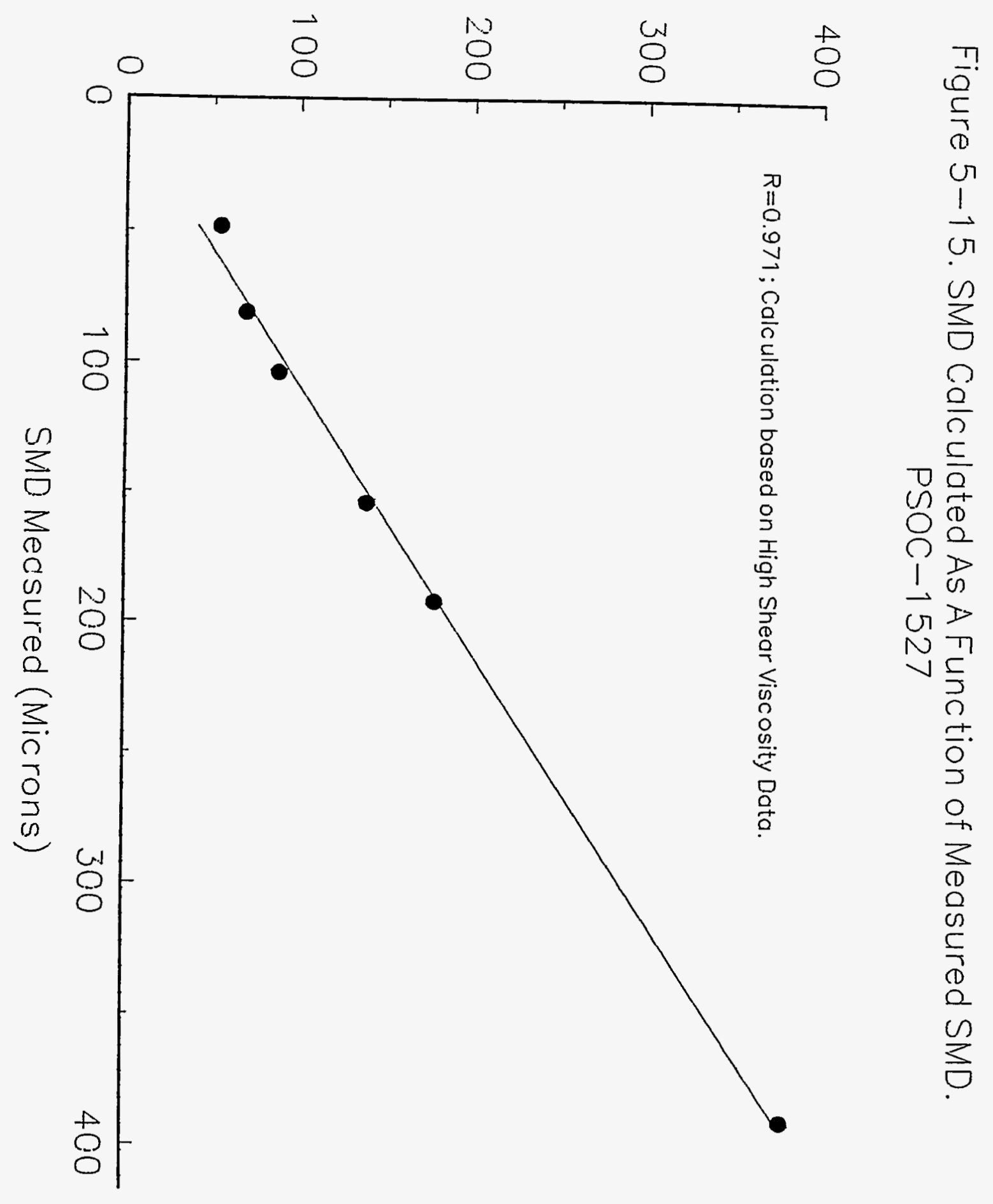


SMD Calculated (Microns)

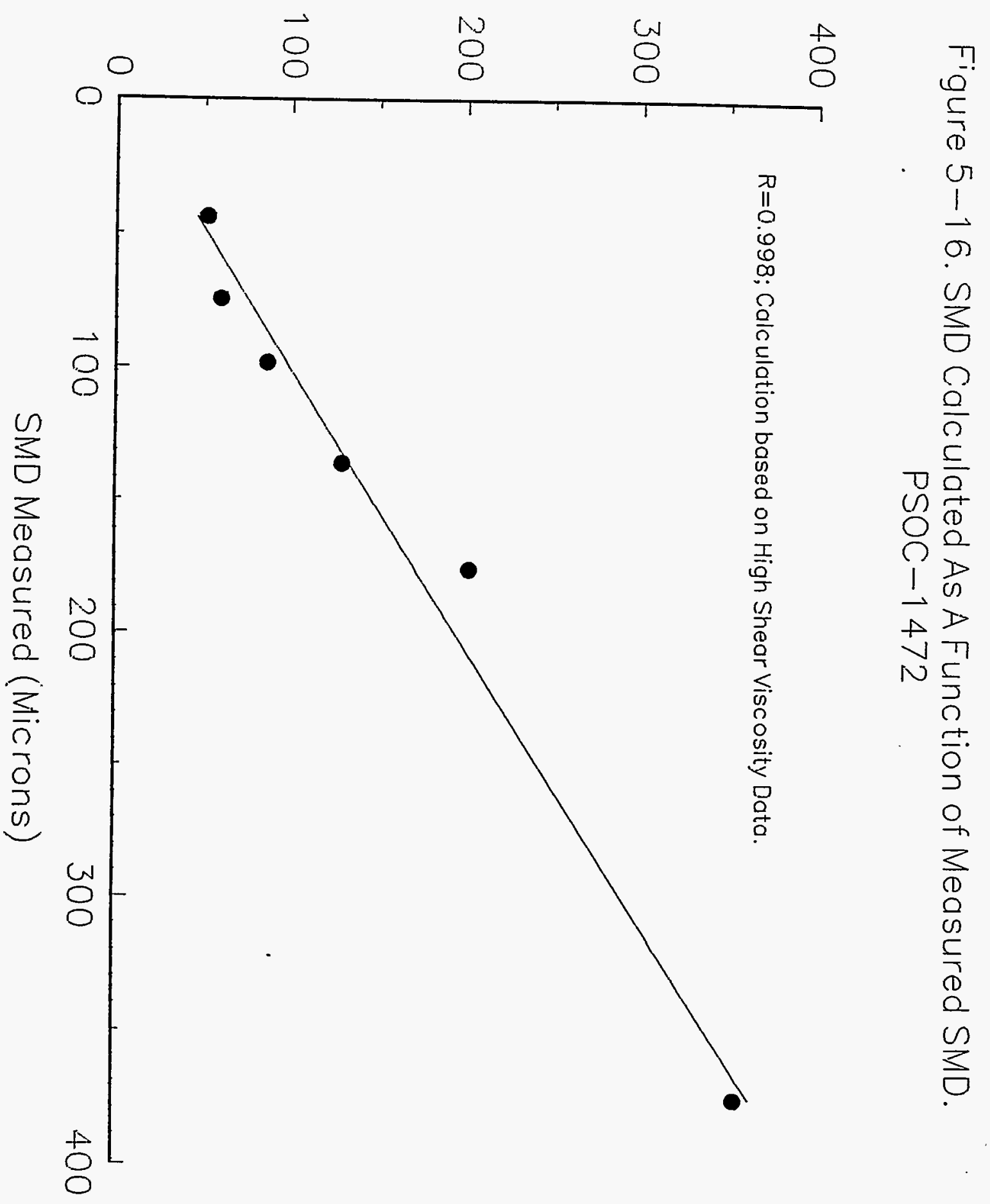




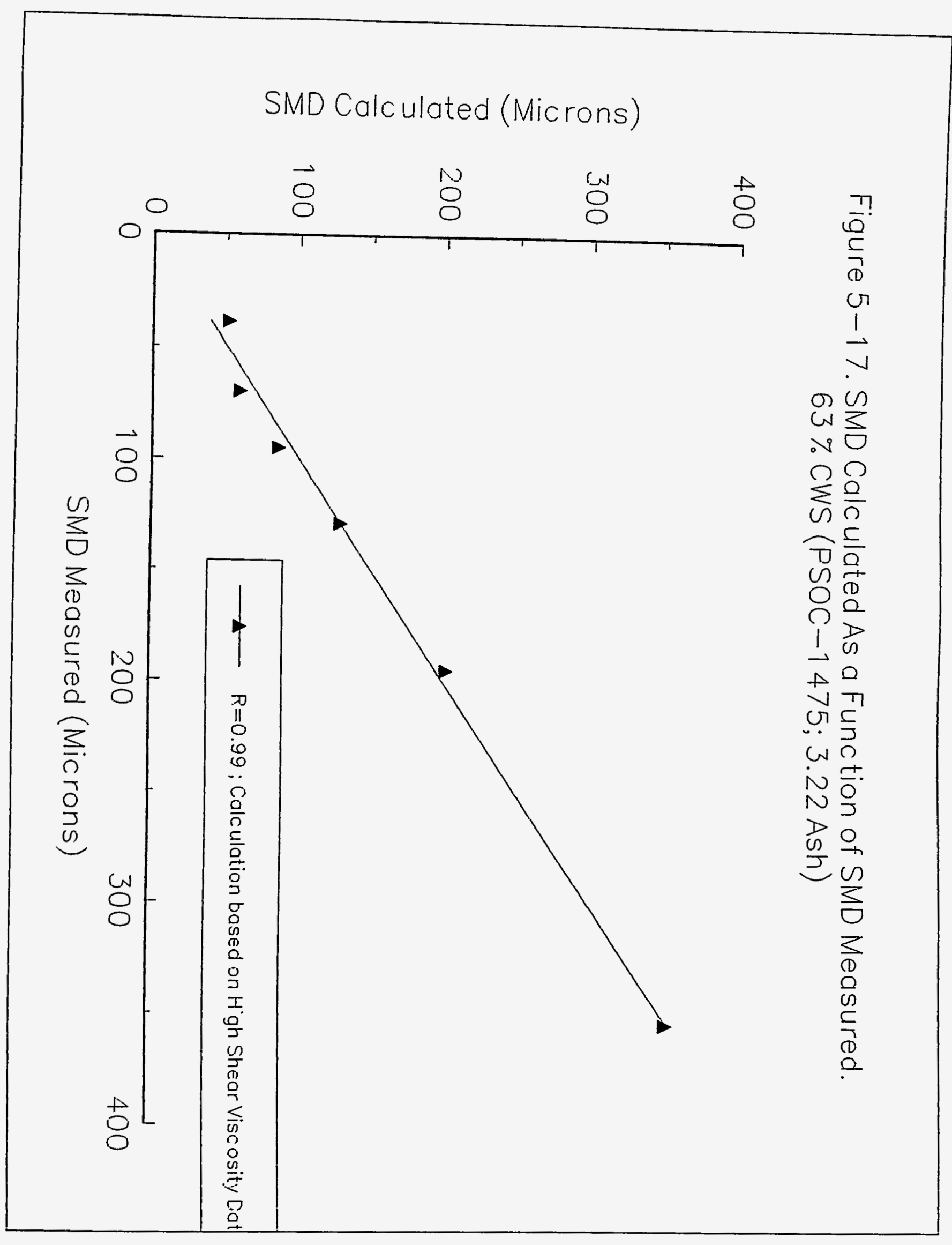


compared to the other two CWS with the lesser ash content. This observation was true for all values of AFR. Oliver and Young-Hoon [41] have previously observed that fluids of increasing pseudoplasticity have lessened interaction between the phases and that viscoelasticity damps waves that occur in air-Newtonian fluid flow. Thus, the variation in the SMD as a function of the viscoelastic property of the CWS is due to the fact that the restoring force must be overcome before a drop can break up since more energy would be required to overcome the forces associated with viscoelasticity. This property is still dominant even at high AFR for fluids that have high storage modulus. The energy associated with the large mass of air is not completely able to dominate and overcome the fluid viscoelastic properties. As a result, the SMD values at high AFR showed significant differences for the CWS atomized. This observation also, accounts for the increase drop sizes of the glycerol-xantham gum solutions when compared to the glycerol-water solutions as well as, the CWS prepared from the different coal samples. PSOC-1527 had the highest ash content and it also had the highest storage modulus compared to PSOC-1472 and 1475. Comparison of the data listed in Tables 5-5 through 5-7, indicate that the CWS prepared from the PSOC-1527, had the highest SMD values at all AFR. This is an indication that it is difficult to atomize the CWS prepared from this coal and that the viscoelastic property plays a significant role in determining the quality of atomization of the CWS.

Equation 5-8 was applied to the CWS atomization data. Figures 5-13 through 5-17 show plots of the calculated SMD as a function of the measured SMD values. The plots show good agreement between the measured values and the calculated values. 


\section{CHAPTER 6}

\section{CONCLUSIONS AND RECOMMENDATION FOR FUTURE WORK.}

This work was proposed in order to better understand the effects of rheological properties responsible for the results reported in this work. An expression for SMD was developed using two-phase flows, momentum and energy conservations. The flow within the nozzle was determined to be concentric plug flow, and that the drop size is a function of the relative velocity between the liquid and the atomizing air at low AFR.

The model developed in chapter 4 was applied to the data generated in the course of this work. Incorporation of viscosity data at a shear rate of $10^{5} \mathrm{sec}^{-1}$ indicate the ability to use this model to predict SMD values. This model relates SMD to the liquid surface tension and density, the initial air and fluid velocities, and the AFR.

The atomization studies began with the spraying of glycerol-water mixture with viscosities ranging from $900 \mathrm{mPas}$ to $300 \mathrm{mPas}$. This was followed by a non-Newtonian fluid, glycerol-xantham gum solution, and CWS. The flow behavior indices for the non-Newtonian fluid ranged from 0.95 to 1.23 and that of the CWS ranged from 0.6 to 1.3 .

The results presented in chapter 5 clearly indicate that the Delavan solid cone nozzle successfully atomized the CWS. Several qualitative features can be inferred from the experimental data. The AFR was found to have a great impact on atomization quality. The SMD decreases significantly as the AFR increases. For Newtonian fluids, there is a threshold limit of the AFR beyond which the AFR has no effect on the SMD. This trend is based on the fact that, to effectively transfer the energy of the air to the fluid, both the air and the fluid must establish good contact. At low AFR, the atomizing air is surrounded with the fluid that shields it from losses to the ambient so that a large portion of the atomizing air energy goes into increasing the fluid 
surface energy, causing a break of the fluid into ligaments. As AFR increases however, the air shielding the fluid becomes thinner resulting in the production of fine droplets. Energy losses are minimized and the effect of AFR is leveled off.

Fluid viscosity as characterized by low shear theological data showed very little variation with the SMD at a given high AFR. The calculated SMD values for the non-Newtonian fluid based on low shear viscosity data correlated well with the measured values ( $R$-square $=0.938)$, a better agreement was however, obtained when viscosity data at a shear rate of $100,000 / \mathrm{s}$ was used. This observation is due to the fact that the change in the flow behavior index for the non-Newtonian fluid showed no consistent correlation with changes in the SMD at a given AFR and thus, the viscosity at a shear rate of $100 / \mathrm{s}$ which was used to calculate the SMD, does not actually represent the prevalent viscosity when the fluid flows through the nozzle.

Figure comparison of Figure 3-20 and the data in Tables 5-7 through 5-9, indicate that the SMD increase with increase in the storage modulus of the CWS. This shows that, there is energy loss associated with overcoming the stored energy present in the slurries. This energy loss affects the spray formation process. This suggests a decrease in energy transfer in fluids that have high storage modulus.

\section{Recommendations For Future Work}

This study reveals that viscoelastic behavior of the CWS plays a significant role in producing fine droplet sizes. Thus, the technique of producing CWS with the same consistency must be improved particularly, the optimum amount of polymer to be added to the CWS in order to stabilize it, must be established. Such an improvement will minimize the influence of the added 
polymer and allow the drop sizes to be predicted from the viscoelastic and high shear behavior with certainty.

This study also reveals that, the high ash content increase the storage modulus. This is due to the fact that the presence of the multi-charged cations in the ash, contribute to the crosslinking of the polymer added to stabilize the slurry which increases the storage modulus of the CWS, and therefore make it difficult to atomize the slurries. Thus, a systemic study of the correlation of the viscoelastic behavior of CWS, with the variation of the amount of multi-charged cations present in the CWS containing polymers additives, and their effect on the spray droplet sizes should be made. 


\section{REFERENCES}

1. Glenn, R.D., and A.W. Rhodes, "Coal-Water Slurry Systems for Oil Design Power Plants," Final Report FP-1 164, EPRI, Combustion Processes, Inc., September, 1979.

2. Marnel, P., "Overview," DOE Coal-Water Fuel Technology Workshop, Brookhaven National Laboratory, March 19, 1981.

3. Atlantic Research Corporation, "Development and Evaluation of Coal-Water Mixture Combustion Technology, Phase I," Project Status Report, DE-AC22-80PC30185, November 25, 1980.

4. Tsai S.C., and Vu T., "Atomization of Coal Water Slurry Using Twin-fluid Jet Atomizer," Fuel, 65, 566-571, 1986.

5. LaFlesh, R.C., Y.V. Lachowicz and J.G. McGowan, "Combustion Characteristics of Coal-Water Fuels", Proc. Eighth Int. Symp. on Coal Slurry Prep. and Util., U.S. Dept. of Energy, P.E.T.C., Pittsburgh, PA, pp.438-452, (1986).

6. Winters, P.J., R. T. Bailey adn K. R. Olen, "The Effect of Fuel Formulation on the Atomization Characteristics of Coal-Water Mixtures", Proc. Seventh Int. Symp. on Coal Slurry Fuels Prep. and Util., U.S. Dept. of Energy, P.E.T.C., Pittsburgh, PA, pp. 430-439, 1985.

7. Yu, T.U., S.H. Rah, S.W. Kang, J.M. Beer, "Measurement of Viscosity of Coal-Water Fuels at High Shear Rate", Proc. Eighth Int., Symp., on Coal Slurry Fuels Prep. and Util., U.S. Dept. of Energy, P.E.T.C., Pittsburgh, PA, pp 85-94, 1986.

8. Yu, T.U., S.W. Kang, M.A. Toqan, P.M. Walsh, J.D. Teare, J.M. Beer and A.F. Sarofim, "Disruptive Atomization and Combustion of CWF, ibid., pp. 162-175, 1986. 
9. Pohl, J.H., J. Sepulveda and L.B. Rothfeld, "Correlation of the Spray Characteristics of Coal-Water-Fuels", Proc., Seventh Int. Symp. on Coal Slurry Fuels Prep. and Util., U.S. Dept. of Energy, P.E.T.C., Pittsburgh, PA, pp.357-376, (1985).

10. Miesse, C.C., "Recent Advances in Spray Technology", Appl. Mech. Reviews, vol. 9, no. 8, pp. 321-322, (1956).

11. Elkotb, M. M., " Fuel Atomization for Spray Modelling". Progress in Energy and Combustion Science, 8, pp 61-91, 1982

12. Wigg L. D., "Drop Size Prediction for Twin-Fluid Atomizers" Journal of Insitute of Fuel, 37, pp 500-505, 1964.

13. Stover, N.S.H., and K.V. Thambimuthu, "Correlation of Coal Water Fuel (CWF) Spray Droplet Size with Atomizer and CWF Data," Twelfth International Conference on Slurry Technology, March 1987.

14. Wildman, D.J., Ekmann, J.M., and Dooher, J. "A Comparison of Rheological Data for Coal-Water Mixtures and Liquid Mixtures with Implications for Atomization," Proceedings of the Thirteenth International Conference on Slurry Technology, April 1989.

15. Gupta, R. L. and Sridhar, T., "A Simple Extensional Viscometer, " Rheology Acta, 24, no. 2. 1985 .

16. Rakitsky, W. G., Knell, E. W., and Murphy, T. J., "Rheological Properties Significant for the Atomization of Coal-Water Slurries, "Proceedings of the Eleventh International Conference on Slurry Technology, March 1986. 
17. Botsaris, G. D. and K. N. Astill, "Effect of Interaction Between Particles On The Viscosity Of Coal Water Slurries". Proc. 6th Intl. Symp. on Coal Slurry Combustion and Technology, Orlando, Fl., 304, 1984.

18. Casassa, E. Z., G. D. Parfitt, A. S. Rao and E. W. Toor, "The Effects of Surface Active Agents On Coal-Water Slurry Stability". Proc. 6th Intl. Symp. on Coal Slurry Combustion and Technology, Orlando, Fl., 1984.

19. Dinger, D. R., Funk, J. E., Jr., and Funk, J. E., Sr., " Rheology of High Solids CoalWater Mixture." Proc. 4th Intl. Symp. on Coal Slurry Combustion, Orlando, Fl., 1982.

20. E. L. Fuller, Jr., and N. R. Smyrl, "Diffuse Reflectance Infrared Spectroscopy studies of the Air oxidation of Coal Surfaces, Proc. Div. Fuel Chem. ACS 33, 691 (1988).

21. Mooney, M., "Viscosity of a Concentrated Suspension of Spherical Particles", J. Coll. Sci., 6, 162, 1951.

22. .Kikkawa, H., Okiura, K., Arikawa, Y., Hitachi, K., and Kure, K., "Development of Highly Loaded CWM Preparation System". Proc. Sixth Int'l. Symp. on Coal Slurry Fuels Preparation and Utilization, 1984, 949.

23. LaFlesh, R.C., Y.V. Lachowicz and J.G. McGowan, "Combustion Characteristics of Coal-Water Fuels", Proc. Eighth Int. Symp. on Coal Slurry Prep. and Util., U.S. Dept. of Energy, P.E.T.C., Pittsburgh, PA, pp.438-452, 1986.

24. Turian, R.M. et.. al., "Characterization, Stability, and Rheology of Coal-Water Mixtures". Proceedings, Eighth International Symposium on Coal-slurry Fuels Preparation and Utilization, Orlando, FL., May, 1986. 
25. Winters, P.J., R. T. Bailey adn K. R. Olen, "The Effect of Fuel Formulation on the Atomization Characteristics of Coal-Water Mixtures", Proc. Seventh Int. Symp. on Coal Slurry Fuels Prep. and Util., U.S. Dept. of Energy, P.E.T.C., Pittsburgh, PA, pp. 430-439, 1985.

26. Dooher, J.P., Cote, D., Malicki, N., and Wright, D., "Handling Properties of coalWater Slurries". Proceedings, Seventh International Symposium on Coal-slurry Fuels Preparation and Utilization, New Orleans, May 21-24, pp 1057-1069., 1985.

27. Ohene, F. Final Report DOE/DE-FG22-88PC925

28. Philippoff, W. "Vibrational Measurements with Large Amplitudes, Trans. Soc. Rheol., 10, 317-334, 1966.

29. HVA-6 Capillary Viscometer Handbook, Parr Instruments, Vienna Austria.

30. Bagley, E. B., J. Appl. Physics, 28, 624, 1957.

31. Lupton J. M. and J. W. Regester, Polymer Eng. and Sci., 5, 235, 1965 .

32. Antonini, G., Francois, O., Gislais, P., and A. Touret, "A Direct Rheological Characterization Of Highly Loaded Coal- Water Slurries Flowing Through Pipes". Proc. 6th Intl. Symp. on Coal Slurry Combustion and Technology, 899, 1984.

33. Adelphi Center for Energy Studies. "Coal-Water Slurry pumping and Flow Tests," Report CS-3722, Electric Power research Institute, October 1984.

34. Murphy, T.J., Flanigan, E.P., McCormick, R.J., and Goulet, A.B., "Laminar Flow Transport Properties of OXCE Fuel Company's Coal-Water Fuel". Proceedings, Sixth International Symposium on Coal-Slurry Combustion and technology, June 25-27, Orlando, Fl. pp. 993, 1984. 
35. Chen, R. C., and Kadambi, J.R., "LDV Measurements of Solid-liquid Slurry Flow Using Refractive Index Matching Technique", Particulate Science and Technology, 8, No. 2, 1990.

36. Crowder, R. S., Daily, J.W., and J. A. C. Humphrey, "Numerical Calculation of Particle Dispersion in a Turbulent Mixing layer Flow" Energy Sources Technology Conference, ASME, 1984.

37. Schurz, J., "The Network Solution: Theoretical Concepts and Experimental Tests with Dissolved Polymers" Proceedingd, Seventh International Conference on Rheology, Gothenburg, 1976.

38. Ohene, F., Levingston, L., and Y. Rhonda, "The Study of Pressure Drop in a capillary viscometer for a Two-Phase Flow. Proceedings of the Eighth International Concference on Freight and Pipeline Transportation, Pittsburgh, PA., 1995.

39. Ruiz, F., and N. A. Chigier, "Design and Uncertainty Analysis of a Series of Atomization Experiments in Seven Variables". J. Fluid Eng., vol. 97, 96,1990

40. Lefebvre, A. H., Wang X.F., and C.A. Martin, "Spray Characteristics of AeratedLiquid Pressure Atomizers", AIAA Journal Propulsion and Power, 4, 293, 1986.

41. Oliver, R.D., and A. Young-Hoon, "Two phase non-Newtonian Flow: Pressure Drop and Hol-up." Transactions Institute Chemival Engineers, 46 T106-T115, 1968. 
Appendix

Atomization Data Sheet

High Shear Rheological Data (Glycerol)

High Shear Rheological Data (Xantham Gum Solution)

High Shear Rheological Data (63\% CWS (1475)

128

High Shear Rheological Data (63\% CWS (1475) + Xantham Gum Solution)

129 
SAHPLE: Air: $2.0 \mathrm{scth}$ Lens: 300 an 22.4 un

CWS.

5n from nozzle

000000000000785

$\begin{array}{llll}\text { Air guage: } & 40 & \text { psig } & \text { Hixing Energy: } h p-h r / 1000 / \text { liq. } \\ \text { Liquid guage: } & & \text { psig } & \text { Solids } \text {.0\% }\end{array}$

Additive:

viscosity: cp Density, $g / n l$ dỵnes/car 2

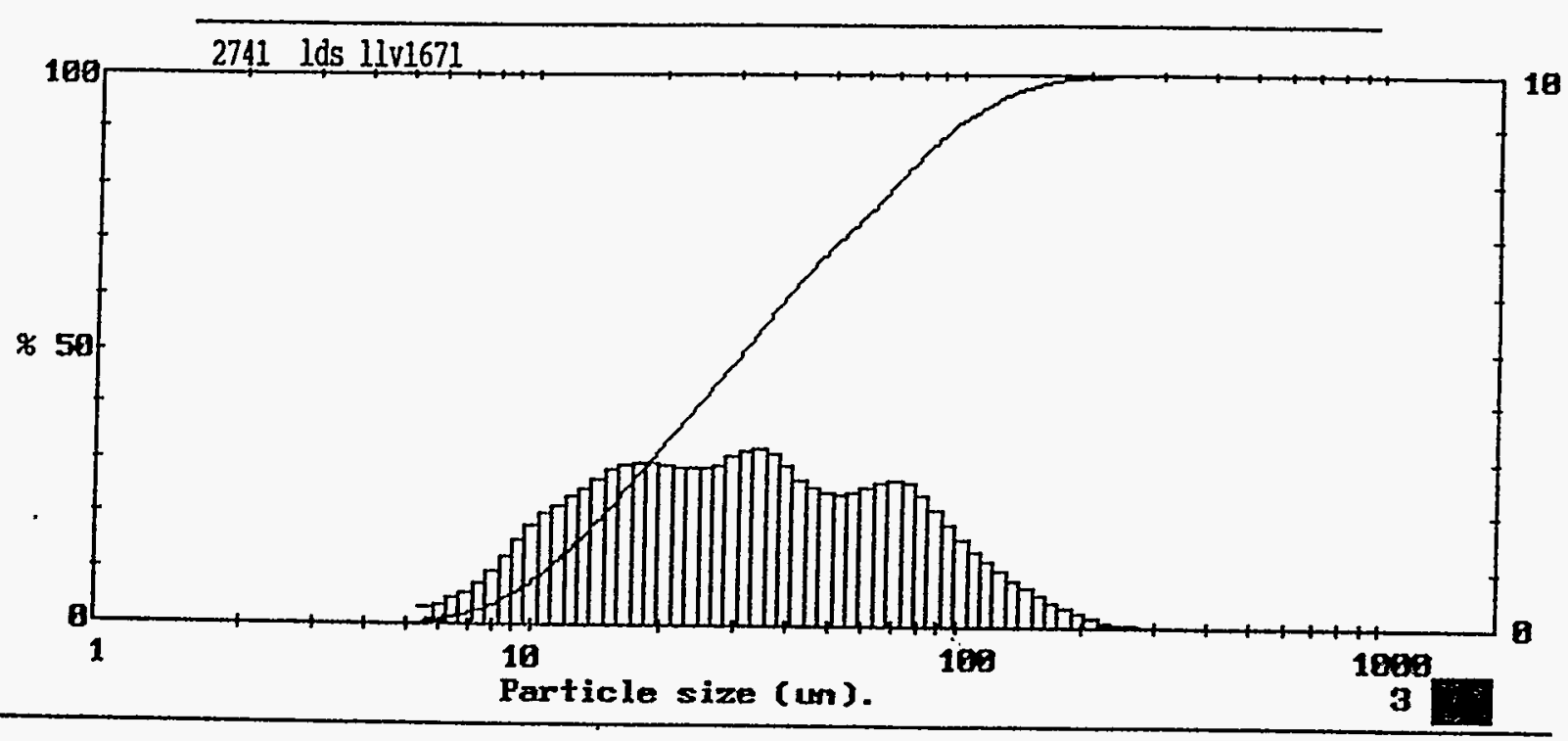

\begin{tabular}{|c|c|c|c|c|c|c|c|c|c|}
\hline \multicolumn{3}{|l|}{ Upper } & per & in Lo & & Opper & in 1 & & \multirow{2}{*}{$\frac{\text { Span }}{2.66}$} \\
\hline \multirow{4}{*}{$\begin{array}{l}564 \\
487 \\
420 \\
362 \\
313 \\
270 \\
233 \\
201\end{array}$} & \multirow{4}{*}{$\begin{array}{ll}0.0 & 187 \\
0.0 & 420 \\
0.0 & 362 \\
0.0 & 313 \\
0.0 & 270 \\
0.1 & 233 \\
0.3 & 201 \\
0.6 & 173 \\
\end{array}$} & \multirow{4}{*}{$\begin{array}{l}100 \\
100 \\
100 \\
100 \\
100 \\
99.9 \\
99.6 \\
99.0\end{array}$} & \multirow{4}{*}{$\begin{array}{l}173 \\
150 \\
129 \\
111 \\
96.0 \\
82.5 \\
71.5 \\
61.5 \\
53.0 \\
45.8 \\
39.5 \\
34.1\end{array}$} & \multirow{4}{*}{\multicolumn{2}{|c|}{$\begin{array}{lll}1.1 & 150 & 97.9 \\
1.6 & 129 & 96.2 \\
2.4 & 111 & 93.8 \\
3.2 & 96.0 & 90.7 \\
4.4 & 82.5 & 86.3 \\
5.1 & 71.5 & 81.2 \\
5.4 & 61.5 & 75.8 \\
5.0 & 53.0 & 70.8 \\
4.8 & 45.8 & 66.0 \\
5.5 & 39.5 & 60.5 \\
6.4 & 34.1 & 54.1 \\
6.4 & 29.5 & 47.7 \\
\end{array}$}} & \multirow{4}{*}{$\begin{array}{l}29.5 \\
25.4 \\
21.9 \\
18.9 \\
16.3 \\
14.1 \\
12.1 \\
10.4 \\
9.05 \\
7.80 \\
6.70 \\
5.80\end{array}$} & \multirow{4}{*}{$\begin{array}{ll}5.9 & 25.4 \\
5.9 & 21.9 \\
6.0 & 18.9 \\
6.1 & 16.3 \\
5.7 & 14.1 \\
4.9 & 12.1 \\
4.4 & 10.4 \\
3.4 & 9.05 \\
2.3 & 7.80 \\
1.4 & 6.70 \\
0.8 & 5.80 \\
0.8 & 1.50\end{array}$} & \multirow{4}{*}{$\begin{array}{r}41.7 \\
35.9 \\
29.9 \\
23.8 \\
18.1 \\
13.3 \\
8.9 \\
5.5 \\
3.1 \\
1.7 \\
0.8 \\
0.0\end{array}$} & \\
\hline & & & & & & & & & $\begin{array}{r}D[3,2 \\
22.4 \\
\end{array}$ \\
\hline & & & & & & & & & $\mathrm{D}$ \\
\hline & & & & & & & & & $D[v, 0.1]$ \\
\hline \multirow{2}{*}{\multicolumn{3}{|c|}{$\begin{array}{l}\text { Source }=\quad \text { :Sample } \\
\text { Pocal length }=300 \mathrm{~m} \\
\text { Presentation }=1 \mathrm{ds}\end{array}$}} & \multirow{2}{*}{\multicolumn{3}{|c|}{$\begin{array}{l}\text { Bean length }=22.4 \mathrm{~m} \\
\text { Log. Diff. }=2.580 \\
\text { Obscuration }=0.1101 \\
\text { Volune distribution }\end{array}$}} & \multirow{2}{*}{\multicolumn{3}{|c|}{$\begin{array}{l}\text { Hodel indp } \\
\text { Volune Conc. }=0.00398 \\
\text { Sp.S.A } 0.2672 \mathbf{1}^{2} / \text { cc. }\end{array}$}} & $\begin{array}{l}D[y, 0.5] \\
31.09, j]\end{array}$ \\
\hline & & & & & & & & & \\
\hline
\end{tabular}

Malvern Instruments 
R E S U L, T S from

$\begin{array}{ll}\text { Operator } & : 1000 \\ \text { Sample } & : 02 / 03 / 1993 \\ \text { Solvent } & : \text { Glycerol } \\ \text { Density }(\mathrm{kg} / \mathrm{m3}): & 1260 \\ \text { Capillary-length } & (\mathrm{mm}): 100.00\end{array}$

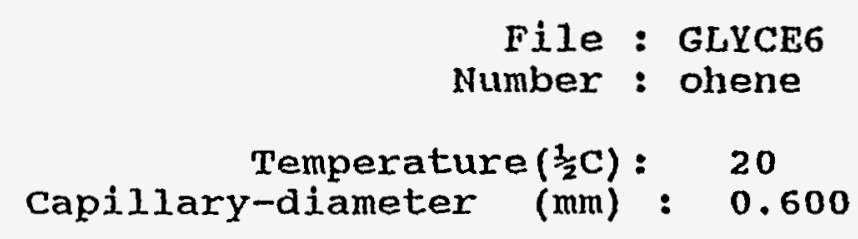

1

IIVA 6 - Evaluation

No. Pressure(bar) Time(s) Volume(mI)

Flowrate (ml/s) Pressure $\mathrm{min} / \max$ (bar)

$\begin{array}{lllllll}1 & 42.1 & 8.77 & 2.011 & 0.22930 & 42.1 & 42.1 \\ 2 & 50.6 & 6.63 & 2.011 & 0.30331 & 50.5 & 50.6 \\ 3 & 60.7 & 5.49 & 2.011 & 0.36630 & 60.7 & 60.7 \\ 4 & 71.9 & 4.38 & 2.011 & 0.45913 & 71.8 & 71.9 \\ 5 & 82.1 & 3.87 & 2.011 & 0.51963 & 82.1 & 82.2 \\ 6 & 94.8 & 3.21 & 2.011 & 0.62647 & 94.8 & 94.8\end{array}$

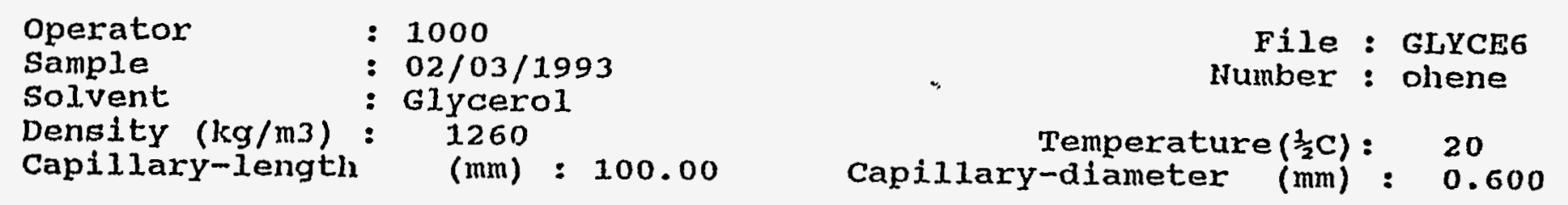
1

IVA 6 - Table lin (measured)

No. TAU(Pa) TNU corr(Pa) D(1/s) ETA(Pa.s) Reynolds tv(s)

$\begin{array}{lllllll}1 & 6.315 E+03 & 6.314 E+03 & 1.081 E+04 & 0.5839 & 1 & 0.1233 \\ 2 & 7.590 E+03 & 7.588 E+03 & 1.430 E+04 & 0.5305 & 2 & 0.0932 \\ 3 & 9.105 E+03 & 9.101 E+03 & 1.727 E+04 & 0.5269 & 2 & 0.0772 \\ 1 & 1.078 E+04 & 1.078 E+04 & 2.165 E+04 & 0.4979 & 2 & 0.0616 \\ 5 & 1.231 E+04 & 1.231 E+04 & 2.450 E+04 & 0.5023 & 3 & 0.0544 \\ 6 & 1.422 E+04 & 1.421 E+04 & 2.954 E+04 & 0.4810 & 3 & 0.0451\end{array}$


R E S U L T S from 26/01/1993

$\begin{array}{ll}\text { Operator } & \text { : ohene } \\ \text { Sample } & \text { : xantham Gum } \\ \text { Solvent } & : 1000 \\ \text { Density (kg/m3) : } & 992 \\ \text { Capillary-lengtll } & \text { (mm) : } 100.00\end{array}$

File : XANTHAM2 Number : 1 .

Temperature $\left(\frac{1}{2} \mathrm{C}\right): \quad 20$ Capillary-diameter $(\mathrm{mm}): 0.800$

IIVA 6 - Evaluation

No. Pressure(bar) Time(s) Volume(ml) Flowrate(ml/s) Pressure $\min / \max (\mathrm{bar})$

$\begin{array}{rllllll}1 & 0.8 & 0.32 & 0.785 & 2.45312 & 0.8 & 0.8 \\ 2 & 1.3 & 0.21 & 0.785 & 3.73809 & 1.3 & 1.3 \\ 3 & 1.9 & 0.16 & 0.785 & 4.90625 & 1.9 & 1.9 \\ 4 & 2.4 & 0.14 & 0.785 & 5.60714 & 2.4 & 2.4 \\ 5 & 2.9 & 0.12 & 0.785 & 6.54166 & 2.9 & 2.9 \\ 6 & 3.5 & 0.10 & 0.785 & 7.85000 & 3.5 & 3.5 \\ 7 & 4.1 & 0.09 & 0.785 & 8.72222 & 4.9 & 4.9 \\ 8 & 4.9 & 0.08 & 0.785 & 9.81250 & 5.6 & 5.6 \\ 9 & 5.6 & 0.08 & 0.785 & 9.81250 & 6.4 & 6.4 \\ 10 & 6.4 & 0.38 & 0.785 & 2.06578 & 6.4 & 6.4 \\ 11 & 6.4 & 0.49 & 0.785 & 1.60204 & \end{array}$

IIVA 6 - Table Iin (measured)

$\begin{array}{rcccrrr}\text { HO. } & \text { TAU(Pa) } & \text { TAU corr(Pa) } & \mathrm{D}(1 / \mathrm{s}) & \text { ETA(Pa.s) } & \text { Reynolds } & \text { tV(s) } \\ 1 & 1.600 \mathrm{E}+02 & 1.071 \mathrm{E}+02 & 4.880 \mathrm{E}+04 & 0.0022 & 1765 & 0.0205 \\ 2 & 2.600 \mathrm{E}+02 & 1.371 \mathrm{E}+02 & 7.437 \mathrm{E}+04 & 0.0018 & 3201 & 0.0134 \\ 3 & 3.800 \mathrm{E}+02 & 1.683 \mathrm{E}+02 & 9.761 \mathrm{E}+04 & 0.0017 & 4492 & 0.0102 \\ 4 & 4.800 \mathrm{E}+02 & 2.035 \mathrm{E}+02 & 1.116 \mathrm{E}+05 & 0.0018 & 4853 & 0.0090 \\ 5 & 5.800 \mathrm{E}+02 & 2.036 \mathrm{E}+02 & 1.301 \mathrm{E}+05 & 0.0016 & 6600 & 0.0077 \\ 6 & 7.000 \mathrm{E}+02 & 1.580 \mathrm{E}+02 & 1.562 \mathrm{E}+05 & 0.0010 & 10000 & 0.0064 \\ 7 & 8.200 \mathrm{E}+02 & 1.509 \mathrm{E}+02 & 1.735 \mathrm{E}+05 & 0.0009 & 10000 & 0.0058 \\ 8 & 9.800 \mathrm{E}+02 & 1.332 \mathrm{E}+02 & 1.952 \mathrm{E}+05 & 0.0007 & 10000 & 0.0051 \\ 9 & 1.120 \mathrm{E}+03 & 2.732 \mathrm{E}+02 & 1.952 \mathrm{E}+05 & 0.0014 & 10000 & 0.0051 \\ 10 & 1.280 \mathrm{E}+03 & 1.242 \mathrm{E}+03 & 4.110 \mathrm{E}+04 & 0.0302 & 108 & 0.0243 \\ 11 & 1.280 \mathrm{E}+03 & 1.257 \mathrm{E}+03 & 3.187 \mathrm{E}+04 & 0.0395 & 64 & 0.0314\end{array}$


RES U L T S from 20/05/1995

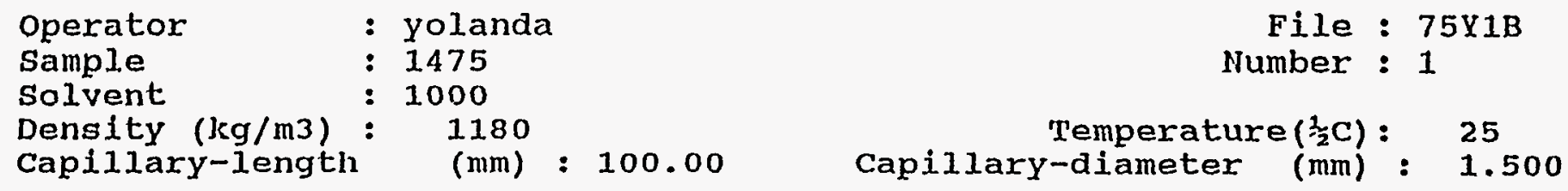

IVA 6 - Evaluation

No. Pressure(bar) Time(s) Volume(ml) Flowrate(ml/s) Pressure min/max(bax)

$\begin{array}{rrrrrrr}1 & 4.7 & 2.19 & 2.011 & 0.91826 & 4.7 & 4.7 \\ 2 & 8.8 & 1.21 & 2.011 & 1.66198 & 8.8 & 8.8 \\ 3 & 9.0 & 1.07 & 2.011 & 1.87943 & 9.0 & 9.0 \\ 4 & 14.3 & 0.63 & 2.011 & 3.19206 & 14.3 & 14.3 \\ 5 & 18.4 & 0.48 & 2.011 & 4.18958 & 18.4 & 18.4 \\ 6 & 24.4 & 0.33 & 2.011 & 6.09393 & 24.4 & 24.4 \\ 7 & 28.5 & 0.28 & 2.011 & 7.18214 & 28.5 & 28.5\end{array}$

RE S U L T S from $20 / 05 / 1995$

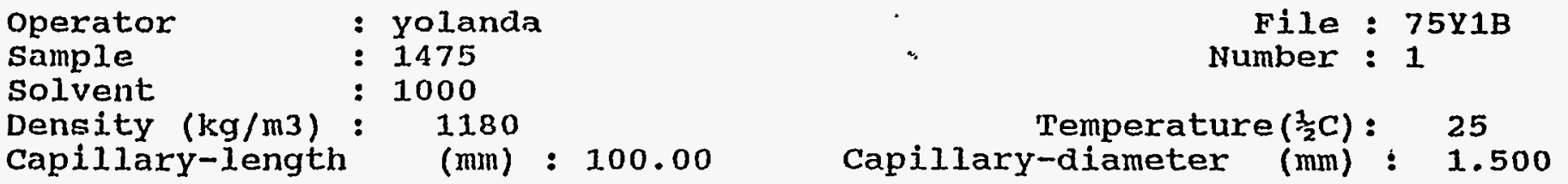

IIVI 6 - Table lin (measured)

$\begin{array}{cccccrr}\text { No. } & \text { LAU(Pa) } & \text { TAU corr(Pa) } & D(1 / s) & \text { ETA(Pa.s) } & \text { Reynolds } & \text { tV(s) } \\ 1 & 1.762 \mathrm{E}+03 & 1.761 \mathrm{E}+03 & 2.771 \mathrm{E}+03 & 0.6355 & 1 & 0.1924 \\ 2 & 3.300 \mathrm{E}+03 & 3.296 \mathrm{E}+03 & 5.016 \mathrm{E}+03 & 0.6570 & 3 & 0.1063 \\ 3 & 3.375 \mathrm{E}+03 & 3.369 \mathrm{E}+03 & 5.672 \mathrm{E}+03 & 0.5940 & 3 & 0.0940 \\ 4 & 5.363 \mathrm{E}+03 & 5.346 \mathrm{E}+03 & 9.634 \mathrm{E}+03 & 0.5550 & 6 & 0.0554 \\ 5 & 6.900 \mathrm{E}+03 & 6.872 \mathrm{E}+03 & 1.264 \mathrm{E}+04 & 0.5435 & 8 & 0.0422 \\ 6 & 9.150 \mathrm{E}+03 & 9.091 \mathrm{E}+03 & 1.839 \mathrm{E}+04 & 0.4943 & 12 & 0.0290 \\ 7 & 1.069 \mathrm{E}+04 & 1.061 \mathrm{E}+04 & 2.168 \mathrm{E}+04 & 0.4893 & 15 & 0.0246\end{array}$


operator

Sample

Solvent

Density $(\mathrm{kg} / \mathrm{m} 3)$ :

Capillary-length ohene

$.1475+$ xantham gum

1180

$(\mathrm{mm}): 100.00$
File:

Number :

Temperature $\left(\frac{1}{2} C\right): \quad 20$ capillary-diameter $(\mathrm{mm}): 0.800$

This .

$0.2 \%$

IIVA 6 - Evaluation

No. Pressure(bar) Time(s) Volume(ml) Flowrate (ml/s) Pressure min/max(bar)

$\begin{array}{lllllll}1 & 16.4 & 0.24 & 0.785 & 3.27083 & 16.4 & 16.4 \\ 2 & 20.2 & 0.22 & 0.785 & 3.56818 & 20.2 & 20.2 \\ 3 & 26.0 & 0.17 & 0.785 & 4.61764 & 26.0 & 26.0 \\ 4 & 34.6 & 0.11 & 0.785 & 7.13636 & 34.6 & 34.6 \\ 5 & 42.3 & 0.25 & 2.011 & 8.04400 & 42.3 & 42.3 \\ 6 & 50.1 & 0.73 & 6.158 & 8.43561 & 50.0 & 50.3\end{array}$

Operator

Sample

Solvent

Density $(\mathrm{kg} / \mathrm{m} 3)$ :

Capillary-1ength olsene
$: 1475+$ Xantham Gum

1180

$(\mathrm{mm}): 100.00$

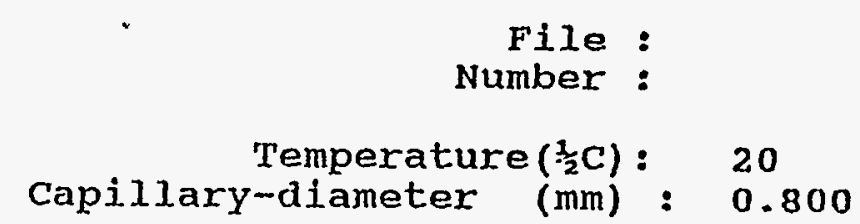

File :

Temperature $\left(\frac{1}{2} \mathrm{C}\right): \quad 20$

Ihis

$0.2 \%$

IIVI 6 - Table Iin (measured)

$\begin{array}{cccccrc}\text { No. } & \text { TAU(Pa) } & \text { TAU } \operatorname{corr}(\mathrm{Pa}) & \mathrm{D}(1 / \mathrm{s}) & \text { ETA(Pa.s) } & \text { Reynolds } & \text { tv(s) } \\ & & & & & & \\ 1 & 3.280 \mathrm{E}+03 & 3.168 \mathrm{E}+03 & 6.507 \mathrm{E}+04 & 0.0487 & 126 & 0.0154 \\ 2 & 4.040 \mathrm{E}+03 & 3.907 \mathrm{E}+03 & 7.099 \mathrm{E}+04 & 0.0550 & 122 & 0.0141 \\ 3 & 5.200 \mathrm{E}+03 & 4.977 \mathrm{E}+03 & 9.187 \mathrm{E}+04 & 0.0542 & 160 & 0.0109 \\ 4 & 6.920 \mathrm{E}+03 & 6.387 \mathrm{E}+03 & 1.420 \mathrm{E}+05 & 0.0450 & 298 & 0.0070 \\ 5 & 8.460 \mathrm{E}+03 & 7.783 \mathrm{E}+03 & 1.600 \mathrm{E}+05 & 0.0486 & 311 & 0.0062 \\ 6 & 1.002 \mathrm{E}+04 & 9.276 \mathrm{E}+03 & 1.678 \mathrm{E}+05 & 0.0553 & 287 & 0.0060\end{array}$

